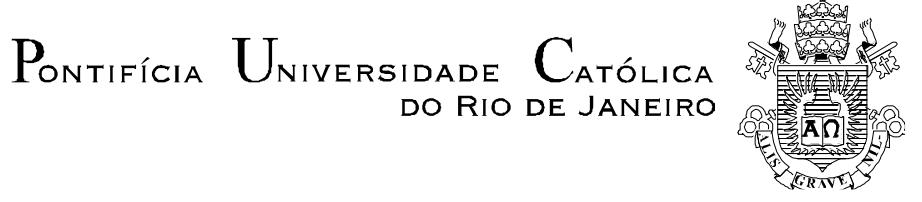

Suzana Gonzaga da Veiga

Proposição de modelo de referência para projeto de Centros de Material e Esterilização (CME)

Dissertação de Mestrado

Dissertação apresentada como requisito parcial para obtenção do grau de Mestre pelo Programa de PósGraduação em Engenharia de Produção do Departamento de Engenharia Industrial da PUC-Rio.

Orientador: Prof. Fernando Luiz Cyrino Oliveira Co-orientadora: Prof. Thaís Spiegel

Rio de Janeiro

Agosto de 2017 
Suzana Gonzaga da Veiga

\section{Proposição de modelo de referência para projeto de Centros de Material e Esterilização (CME)}

Dissertação apresentada como requisito parcial para obtenção do grau de Mestre pelo Programa de Pós-Graduação em Engenharia de Produção da PUC-Rio. Aprovada pela Comissão Examinadora abaixo assinada.

Prof. Fernando Luiz Cyrino Oliveira Orientador Departamento de Engenharia Industrial - PUC-Rio

Prof. Thaís Spiegel Co-orientadora Universidade do Estado do Rio de Janeiro - UERJ

Prof. Luiz Felipe Roris Rodriguez Scavarda do Carmo Departamento de Engenharia Industrial - PUC-Rio

Prof. Renato Flórido Cameira Universidade Federal do Rio de Janeiro - UFRJ

Prof. Márcio da Silveira Carvalho

Coordenador Setorial do Centro

Técnico Científico - PUC-Rio

Rio de Janeiro, 22 de agosto de 2017 
Todos os direitos reservados. É proibida a reprodução total ou parcial do trabalho sem autorização da universidade, da autora e do orientador.

\section{Suzana Gonzaga da Veiga}

Graduou-se em Engenharia de Produção pela Universidade do Estado do Rio de Janeiro (UERJ) em 2015. Aluna de mestrado da PUC-Rio desde agosto de 2015.

Ficha Catalográfica

Veiga, Suzana Gonzaga da

Proposição de modelo de referência para projeto de Centros de Material e Esterilização (CME) / Suzana Gonzaga da Veiga ; orientador: Fernando Luiz Cyrino Oliveira ; co-orientadora: Thaís Spiegel. -2017.

126 f. : il. ; $30 \mathrm{~cm}$

Dissertação (mestrado)-Pontifícia Universidade Católica do Rio de Janeiro, Departamento de Engenharia Industrial, 2017. Inclui bibliografia

1. Engenharia Industrial - Teses. 2. Centros de Material e Esterilização (CME). 3. Modelos de referência. 4. Planejamento e gestão de operações em saúde. I. Oliveira, Fernando Luiz Cyrino. II. Spiegel, Thaís. III. Pontifícia Universidade Católica do Rio de Janeiro. Departamento de Engenharia Industrial. IV. Título.

CDD: 658.5 


\section{Agracedimentos}

Aos meus amados pais Geneval e Noeme, por me ensinarem a ter a fé necessária para superar todos os obstáculos e a sonhar, não importando as circunstâncias. Vocês me passaram a inspiração e a força para chegar até aqui. Amo vocês!

Ao meu irmão Isaac, por todo amor e o sorriso fortalecedor de todas as manhãs. Você ajudou os momentos difíceis a serem leves. Te amo demais!

À minha professora, orientadora, mestre e amiga Thaís Spiegel, você fez diferença na minha trajetória acadêmica e pessoal, me deu oportunidades de crescimento com as quais somente posso agradecer. Obrigada por me acompanhar desde a graduação e estar comigo na concretização de mais um sonho, cresci muito com você, como pessoa e profissional.

Ao meu orientador Fernando Cyrino por ter aceitado de braços abertos este projeto, por responder prontamente na orientação e contorno de todas as demandas exigidas por esta pesquisa. Obrigada por todo o apoio!

Ao Hospital Universitário Pedro Ernesto (HUPE) por abrir as portas para a realização desta pesquisa. Aos diretores Dércio e Thaís, pelas discussões excepcionais durante a construção do modelo. Em especial ao Dércio, pelas contribuições de conteúdo e pelas palavras de apoio. Muito obrigada!

Aos coordenadores de enfermagem Fátima, Ana Maria e Rogério, pela oportunidade rica de conhecer a vivência de um CME, obrigada pela disponibilidade de tempo para as entrevistas, pelas contribuições, validações, e confiança transmitida para realização desta pesquisa.

Aos técnicos de enfermagem, pela recepção calorosa e pela paciência para responder as diversas dúvidas acerca das operações do CME.

Aos meus colegas de pesquisa em CME, Gabriel, Jéssica Ricão, Jéssica Costa, Bianca e Rogério, por me ajudarem na coleta dos dados dos CMEs. A contribuição de vocês foi importantíssima para atingir os objetivos desta pesquisa. 
Aos professores Luiz Felipe Scavarda e Renato Cameira por terem aceitado o convite de participarem da banca, contribuindo ricamente com seus conhecimentos.

Ao prof. Silvio Hamacher pela confiança e conhecimentos transmitidos durante o mestrado.

Ao prof. Renato Cameira, pelas palavras de apoio e o conselho de respirar sempre, admiro seu trabalho e agradeço os conselhos e conhecimentos transmitidos na trajetória GPI/UFRJ.

Ao meu querido amigo e "avô", Daniel Bouzon. Seu apoio, conhecimentos, e principalmente, sua amizade, foram fundamentais para chegar aqui. Agradeço os conselhos, ombro amigo e conversas cabeças, obrigada por tudo!

Ao meu colega de UERJ/CME e amigo do peito, Gabriel Marassi, meu muito obrigada pelas discussões sobre CME e sobre a vida. Caminhar essa trajetória com você culminou em excelentes contribuições para esta pesquisa. Obrigada pelo apoio, amigo.

Ao meu amigo mais que irmão André, pelas palavras de conforto nos momentos difíceis e por acreditar e viver comigo este sonho. Ter você na minha caminhada a faz mais divertida e leve.

Ao meu querido professor Hélcio Rocha, por todo suporte e boas energias transmitidas através dos "bons dias" diários. Sou grata por tê-lo na minha caminhada, obrigada por toda força e ânimo!

Aos meus colegas da PUC-Rio, pelas discussões e aprendizado. Foram de suma importância para a minha formação.

À UERJ, por me formar de forma excelente e ter me dado o título de engenheira de produção. Essa instituição tem importância sem igual!

Ao prof. Heitor e prof. Thaís pela oportunidade de trajetória no GPI/UFRJ, os conhecimentos apreendidos neste grupo de pesquisa incrementaram sem medida minhas habilidades para realizar a presente pesquisa.

À PUC-Rio pela oportunidade de vivência com colegas, estrutura e professores excelentes, que tornaram viável a realização desta pesquisa.

Ao CNPq e à PUC-Rio pelos auxílios fornecidos, sem os quais este trabalho não seria concretizado. 


\section{Resumo}

Veiga, Suzana Gonzaga; Oliveira, Fernando Luiz Cyrino (Orientador); Spiegel, Thaís (Co-Orientador). Proposição de modelo de referência para projeto de Centros de Material e Esterilização (CME). Rio de Janeiro, 2017. 126p. Dissertação de Mestrado - Departamento de Engenharia Industrial, Pontifícia Universidade Católica do Rio de Janeiro.

O reprocessamento de materiais médicos é um processo essencial para manter a funcionalidade do hospital. O Centro de Material e Esterilização (CME) é a unidade de apoio técnico hospitalar orientado por normas e regulações específicas destinada a reprocessar os materiais, tendo como principal objetivo a prevenção de infecções e entrega de artigos médicos seguros. Contudo, é uma área de pouca visibilidade e com altas variabilidades no processo de esterilização e não são contemplandos com um modelo de tomada de decisão que contemple tanto os requisitos dos modelos assistenciais estabelecidos pelas legislações quanto os aspectos de projeto da gestão e gerência das operações. Dessa forma, a presente pesquisa visa elaborar um modelo de referência construído a partir das categorias de projetos de operações a fim de auxiliar o gestor a projetar um CME. O objetivo da pesquisa é atingido através do cumprimento dos seguintes objetivos específicos: a) levantamento do referencial teórico; b) levantamento e identificação dos instrumentos normativos e regulatórios; c) condução de uma pesquisa de campo em um CME representativo dos níveis de complexidade; d) análise e síntese da lógica de funcionamento à luz das categorias de operações; e) definição da estrutura do modelo de referência; f) validação do modelo com especialistas; g) refinamento do modelo; e h) aplicação do modelo. A proposição do modelo de referência de requisitos, com base na legislação e aspectos gerenciais da produção, é a principal contribuição da pesquisa.

\section{Palavras-chaves}

Centros de Material e Esterilização (CME); modelos de referência; planejamento e gestão de operações em saúde. 


\section{Abstract}

Veiga, Suzana Gonzaga; Oliveira, Fernando Luiz Cyrino (Advisor); Spiegel, Thaís (Co-Advisor). Reference model proposition for Central Sterile Supply Department (CSSD) project. Rio de Janeiro, 2017. 126p. Dissertação de Mestrado - Departamento de Engenharia Industrial, Pontifícia Universidade Católica do Rio de Janeiro.

Reprocessing of medical supplies is an essential process to maintain the hospital's functionality. The Central Sterile Supply Department (CSSD) is the hospital technical support unit oriented by specific norms and regulations aimed at reprocessing the materials, having as main objective the prevention of infections and delivery of safe medical articles. However, it is an area of low visibility and with high variability in the sterilization process and there is not a model of decision making that has both the requirements of the assistance models established by the legislations and the design aspects of the management and operations management. In this way, the present research aims to elaborate a reference model based on the project operation categories in order to help the manager to design a CSSD. The research objective is achieved through the following specific objectives: a) survey of the reference theory; b) survey and identification of regulatory instruments; c) field research in a complexity levels representative CSSD; d) analysis and synthesis of the operating logic in the light of the categories of operations; e) definition of the structure of the reference model; f) validation of the model with specialists; g) model refinement; and h) model application. The proposal of the reference model of requirements, based on legislation and production management, is the main contribution of the research.

\section{Keywords}

Central Sterile Supply Department (CSSD); reference models; healthcare planning and management operations. 


\section{Sumário}

1 Introdução 14

$\begin{array}{ll}1.1 \text { Objetivos da Pesquisa } & 17\end{array}$

$\begin{array}{ll}1.2 \text { Justificativa da Pesquisa } & 18\end{array}$

$\begin{array}{ll}1.3 \text { Procedimentos Metodológicos } & 19\end{array}$

$\begin{array}{ll}1.4 \text { Estrutura do documento } & 20\end{array}$

2 Referencial Teórico $\quad 21$

$\begin{array}{ll}2.1 \text { Modelos de Referência } & 21\end{array}$

2.2 Gestão de Operações em Saúde 23

$\begin{array}{ll}2.3 \mathrm{CME} & 25\end{array}$

3 Método da Pesquisa $\quad 27$

3.1 Abordagem metodológica: classificação da pesquisa 28

$\begin{array}{ll}3.2 \text { Revisão da literatura } & 29\end{array}$

3.3 Identificação dos instrumentos normativos 31

3.4 Pesquisa de campo em CMEs representativas 33

4 Construção do modelo de referência $\quad 37$

4.1 Lógica de construção do modelo 38

$\begin{array}{ll}4.2 \text { Validação do modelo } & 49\end{array}$

4.3 Estrutura e refinamento do modelo de referência 49

5 Verificação prática: demonstração da aplicação do modelo 94

5.1 Método de aplicação do modelo de referência proposto 94

5.2 Resultados e enquadramento dos CMEs no modelo 96

$\begin{array}{ll}5.3 \text { Discussões } & 109\end{array}$

6 Conclusão 111

6.1 Síntese da Pesquisa 111

6.2 Contribuições e Limitações 113

$\begin{array}{ll}\text { 6.3 Propostas de trabalhos futuros } & 114\end{array}$ 
APÊNDICES 


\section{Lista de Figuras}

Figura 1 - Macroprocessos do CME com a representação de processos utilizando a ferramenta Aris. Elaboração própria.

Figura 2 - Objetivos específicos. Elaboração própria.

Figura 4 - Procedimentos do método da pesquisa. Elaboração própria.

Figura 5 - Etapas de construção do modelo de referência. Elaboração própria.

Figura 6 - Framework do modelo de referência de tomada de decisão de projeto de operação de CMEs. Elaboração própria.

Figura 7 - Estrutura do modelo de referência referente à decisão um. Elaboração própria.

Figura 8 - Estrutura do modelo de referência referente à decisão dois. Elaboração própria.

Figura 9 - Estrutura do modelo de referência referente à decisão três. Elaboração própria.

Figura 10 - Framework dos possíveis roteiros de processamento para os produtos críticos. Elaboração própria.

Figura 11 - Framework dos possíveis roteiros de processamento para os produtos semi críticos. Elaboração própria.

Figura 12 - Framework dos possíveis roteiros de processamento para os produtos não críticos. Elaboração própria.

Figura 13 - Estrutura do modelo de referência referente à decisão quatro. Elaboração própria.

Figura 14 - Estrutura do modelo de referência referente à decisão cinco. Elaboração própria.

Figura 15 - Estrutura do modelo de referência referente à decisão seis. Elaboração própria.

Figura 16 - Estrutura do modelo de referência referente à decisão sete. Elaboração própria.

Figura 17 - Estrutura do modelo de referência referente à decisão oito. Elaboração própria.

Figura 18 - Estrutura do modelo de referência referente à decisão nove. Elaboração própria.

Figura 19 - Estrutura do modelo de referência referente à decisão dez. Elaboração própria.

Figura 20 - Estrutura do modelo de referência referente à decisão onze. Elaboração própria.

Figura 21 - Estrutura do modelo de referência referente à decisão doze. Elaboração própria.

Figura 22 - Estrutura do modelo de referência referente à decisão treze. Elaboração própria.

Figura 23 - Estrutura do modelo de referência referente à decisão quatorze. Elaboração própria.

Figura 24 - Estrutura do modelo de referência referente à decisão quinze. Elaboração própria.

Figura 25 - Estrutura do modelo de referência referente à decisão dezesseis. Elaboração própria. 
Figura 26 - Estrutura do modelo de referência referente à decisão dezessete. Elaboração própria.

Figura 27 - Estrutura do modelo de referência referente à decisão dezoito. Elaboração própria.

Figura 28 - Estrutura do modelo de referência referente à decisão dezenove. Elaboração própria.

Figura 29 - Estrutura do modelo de referência referente à decisão vinte. Elaboração própria.

Figura 30 - Estrutura do modelo de referência referente à decisão vinte e um. Elaboração própria.

Figura 31 - Estrutura do modelo de referência referente à decisão vinte e dois. Elaboração própria.

Figura 32 - Estrutura do modelo de referência referente à decisão vinte e três. Elaboração própria.

Figura 33 - Estrutura do modelo de referência referente à decisão vinte e quatro. Elaboração própria.

Figura 34 - Estrutura do modelo de referência referente à decisão vinte e cinco. Elaboração própria.

Figura 35 - Estrutura do modelo de referência referente à decisão vinte e seis. Elaboração própria.

Figura 36 - Estrutura do modelo de referência referente à decisão vinte e sete. Elaboração própria.

Figura 37 - Estrutura do modelo de referência referente à decisão vinte e oito. Elaboração própria.

Figura 38 - Estrutura do modelo de referência referente à decisão vinte e nove. Elaboração própria.

Figura 39 - Estrutura do modelo de referência referente à decisão trinta. Elaboração própria.

Figura 40 - Estrutura do modelo de referência referente à decisão trinta e um. Elaboração própria.

Figura 41 - Decisões do modelo de referência tomadas pelos CMEs do complexo UERJ. Elaboração própria. 


\section{Lista de Tabelas}

Tabela 1 - Lista descritiva dos instrumentos normativos. Elaboração própria.

Tabela 2 - Descrição dos aspectos da operação do CME/HUPE e $\mathrm{CME} / \mathrm{PPC}$

Tabela 3 - Descrição das categorias de operação com adequações ao contexto de saúde. Fonte: Elaboração própria.

Tabela 4 - Fontes utilizadas na construção das decisões nas categorias de operação. Elaboração própria.

Tabela 5 - Fontes adotadas na construção das decisões da categoria de operação Organização com detalhamento das decisões. Elaoração própria.

Tabela 6 - Fontes e conteúdos utilizados para articulação das decisões do modelo proposto. Elaboração própria.

Tabela 7 - Qualificação profissional dos especialistas avaliadores. Elaboração própria.

Tabela 8 - Regras de projeto para executar o modelo de tomada de decisão referente à decisão um. Elaboração própria.

Tabela 9- Regras de projeto para executar o modelo de tomada de decisão referente à decisão dois. Elaboração própria.

Tabela 10- Regras de projeto para executar o modelo de tomada de decisão referente à decisão três. Elaboração própria.

Tabela 11 - Regras de projeto para executar o modelo de tomada de decisão referente à decisão quatro. Elaboração própria.

Tabela 12 - Regras de projeto para executar o modelo de tomada de decisão referente à decisão cinco. Elaboração própria.

Tabela 13 - Regras de projeto para executar o modelo de tomada de decisão referente à decisão seis. Elaboração própria.

Tabela 14 - Regras de projeto para executar o modelo de tomada de decisão referente à decisão sete. Elaboração própria.

Tabela 15 - Regras de projeto para executar o modelo de tomada de decisão referente à decisão oito. Elaboração própria.

Tabela 16 - Regras de projeto para executar o modelo de tomada de decisão referente à decisão nove. Elaboração própria.

Tabela 17 - Regras de projeto para executar o modelo de tomada de decisão referente à decisão dez. Elaboração própria.

Tabela 18 - Regras de projeto para executar o modelo de tomada de decisão referente à decisão onze. Elaboração própria.

Tabela 19 - Regras de projeto para executar o modelo de tomada de decisão referente à decisão doze. Elaboração própria.

Tabela 20 - Regras de projeto para executar o modelo de tomada de decisão referente à decisão treze. Elaboração própria.

Tabela 21 - Regras de projeto para executar o modelo de tomada de decisão referente à decisão quatorze. Elaboração própria.

Tabela 22 - Regras de projeto para executar o modelo de tomada de decisão referente à decisão quinze. Elaboração própria. 
Tabela 23 - Regras de projeto para executar o modelo de tomada de decisão referente à decisão dezesseis. Elaboração própria.

Tabela 24 - Regras de projeto para executar o modelo de tomada de decisão referente à decisão dezessete. Elaboração própria.

Tabela 25 - Regras de projeto para executar o modelo de tomada de decisão referente à decisão dezoito. Elaboração própria.

Tabela 26 - Regras de projeto para executar o modelo de tomada de decisão referente à decisão dezenove. Elaboração própria.

Tabela 27 - Regras de projeto para executar o modelo de tomada de decisão referente à decisão vinte. Elaboração própria.

Tabela 28 - Regras de projeto para executar o modelo de tomada de decisão referente à decisão vinte e um. Elaboração própria.

Tabela 29 - Regras de projeto para executar o modelo de tomada de decisão referente à decisão vinte e dois. Elaboração própria.

Tabela 30 - Regras de projeto para executar o modelo de tomada de decisão referente à decisão vinte e três. Elaboração própria.

Tabela 31 - Regras de projeto para executar o modelo de tomada de decisão referente à decisão vinte e quatro. Elaboração própria.

Tabela 32 - Regras de projeto para executar o modelo de tomada de decisão referente à decisão vinte e cinco. Elaboração própria.

Tabela 33 - Regras de projeto para executar o modelo de tomada de decisão referente à decisão vinte e seis. Elaboração própria.

Tabela 34 - Regras de projeto para executar o modelo de tomada de decisão referente à decisão vinte e sete. Elaboração própria.

Tabela 35 - Regras de projeto para executar o modelo de tomada de decisão referente à decisão vinte e oito. Elaboração própria.

Tabela 36 - Regras de projeto para executar o modelo de tomada de decisão referente à decisão vinte e nove. Elaboração própria.

Tabela 37 - Regras de projeto para executar o modelo de tomada de decisão referente à decisão trinta. Elaboração própria.

Tabela 38 - Regras de projeto para executar o modelo de tomada de decisão referente à decisão trinta e um. Elaboração própria.

Tabela 39 - Aplicação do modelo de referência proposto aos CMEs pertencentes ao complexo UERJ. Elaboração própria.

Tabela 40 - Informações sobre validação da estrutura do modelo de referência proposto. Elaboração própria.

Tabela 41 - Resultados da revisão da literatura na base Scielo 


\section{Introdução}

A relevância dos modelos de referência surgiu, inicialmente, nas áreas de engenharia de negócios, desenvolvimento de sistemas de informação e da customização dos sistemas do Enterprise Resource Planning (ERP). As ideias iniciais sobre modelos de referência surgiram por volta de 1930, mas as pesquisas na área tiveram início na Alemanha, na década de 90 (Fettke \& Loos, 2006).

Cardoso (2008) apresenta os conceitos de dois tipos de modelos de referência: os modelos de referência de orientação e os modelos de referência de requisitos, classificação baseada na forma de descrição do conteúdo do modelo. Os primeiros são aqueles que apresentam informações para auxiliar as organizações, podendo ser incorporados ou não pelas organizações. Já os segundos, são modelos construídos com regras que precisam ser atendidas pelas organizações.

Para o desenvolvimento dos sistemas de informações, tornou-se vital a construção do modelo conceitual e do modelo de processo da organização. Como desenvolver modelo do processo da organização demanda altos consumos de recursos e tempo e resulta em elevados níveis de defeitos e retrabalhos, o conceito de modelo de referência passou a ser introduzido no desenvolvimento de sistemas de informação (Fettke \& Loos, 2006).

O modelo de referência para tomada de decisão de projeto configura um modelo genérico e padronizado utilizado para orientar o projeto das operações e dos processos (Spiegel \& Caulliraux, 2012). O modelo genérico também estipula os requerimentos que devem ser cumpridos a fim de apoiar a decisão dos gestores através de uma lógica explicitamente definida (Bernardo, 2016).

Conceitualmente, modelos de referências representam uma classe de domínios. Consistem em um quadro conceitual que pode ser usado como exemplo para o desenvolvimento de sistemas. Modelos de referência também são chamados de modelos universais, modelos genéricos ou modelos padrão. Uma 
característica na aplicação do modelo de referência é a adaptação do modelo genérico às requisições específicas da organização (Fettke \& Loos, 2006).

Exemplos de modelos de referência são os pacotes de desenvolvimento de ERP e os desenvolvedores de linguagens e ferramentas para mapeamento de processos, como o ARIS Toolset, utilizado na presente pesquisa para mapear processos. Esses exemplos demonstram a relevância em aplicação dos modelos de referências nos sistemas produtivos.

Os modelos de referência, inicialmente desenvolvidos para facilitar o desenvolvimento de sistemas de informações, também passaram a ser utilizados para auxílio na tomada de decisão nos setores produtivos. Um exemplo de modelo de referência para tomada de decisão é o Supply Chain Operations Reference (SCOR), utilizado para definir, mensurar e melhorar a cadeia de suprimento (Bolstorff \& Rosenbaum, 2007).

$\mathrm{Na}$ área da saúde, os modelos de referência são observados em diversos formatos, quais sejam: a legislação, os manuais, os protocolos assistenciais e as normas de acreditação hospitalar. Em geral, norteiam os procedimentos a serem adotados nos cuidados assistenciais. Contudo, não abrangem os aspectos de gestão e gerência dos sistemas hospitalares.

Os sistemas hospitalares geralmente enfrentam desafios relacionados com a insuficiência de limpeza e manutenção de instrumentais cirúrgicos, que impactam a segurança do paciente (Scheinberg et al., 2017). No contexto brasileiro, o reprocessamento de materiais tem sido um grande desafio para a equipe de enfermagem, devido à diversidade de tipos, composições e formas de materiais reprocessados, dificultando a realização do processo de desinfecção e esterilização de artigos hospitalares (Hoyashi et al., 2016). O setor responsável pelo reprocessamento dos instrumentais cirúrgicos, dentre outros materiais reprocessáveis, é o Centro de Material e Esterilização (CME). O CME consiste em uma unidade de apoio técnico dentro do estabelecimento de saúde destinada a receber material considerado sujo e contaminado e esterilizá-los para futuras utilizações (Leite, 2008). Dessa forma, o principal objetivo do CME é prevenir infecções associadas à utilização de materiais reprocessados, entregando artigos médicos seguros e garantindo uma contribuição positiva para o controle de infecções hospitalares (Veiga-Malta, 2016). 
O reprocessamento de materiais médicos é um processo essencial para manter a funcionalidade do hospital (Rüther et al. 2013). Visto a importância da operação da CME para o contexto hospitalar, projetar as operações desse setor em conformidade com a legislação vigente é essecial para o controle de infecções hospitalares e para a garantia da qualidade dos materiais esterilizados (Di Mascolo et al., 2006).

Por se tratar de uma unidade de manufatura, tendo em vista que possui atividades separadas por etapas bem definidas (Figura 1), para transformar os materiais sujos em materiais limpos e esterilizados para reuso pelas unidades consumidoras do hospital, a natureza de operação do CME se assemelha a de uma unidade fabril, sendo, portanto, um espaço rico para aplicação e desenvolvimento de conhecimentos em Engenharia de Produção. Pode-se, dessa forma, aplicar os métodos clássicos oriundos da Engenharia de Produção, como mapeamento de processos, simulação, dimensionamento de recursos humanos (RH), mapofluxogramas, dentre outras ferramentas, nas categorias de operação existentes em um CME, como RH, tecnologia e equipamentos, instalações, capacidade, dentre outras.

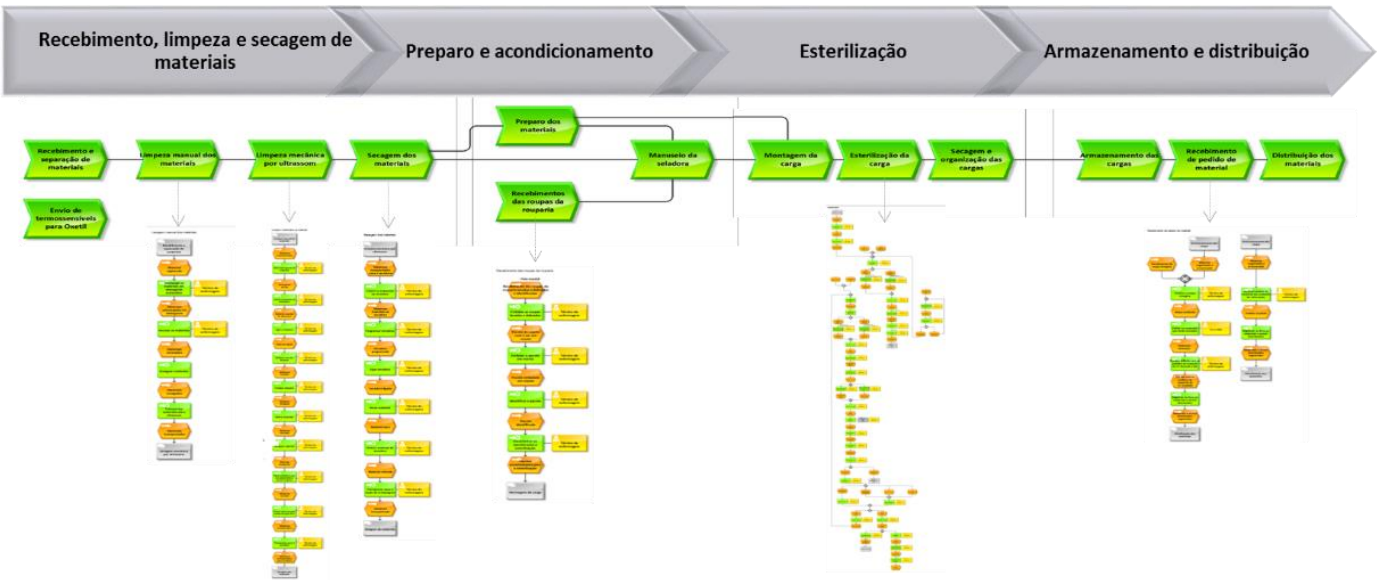

Figura 1 - Macroprocessos do CME com a representação de processos utilizando a ferramenta Aris. Elaboração própria.

Atualmente, os CMEs executam suas operações orientadas por normas e regulações específicas. Contudo, as mesmas não têm um modelo de tomada de decisão que contemplem tanto os modelos assistenciais estabelecidos pelas legislações, protocolos assistenciais e normas de acreditação quanto os aspectos de projeto da gestão e gerência das operações. Tendo em vista o CME ser orientado por legislação, a mesma constitu-se como requisitos a serem seguidos 
para o CME ter uma operação conforme. Do ponto de vista de operações, há requisitos oriundos das categorias de operações a fim de operacionalizar a produção. Dessa forma, a presente pesquisa visa elaborar um modelo de referência que contemple tanto os requisitos providos pelos instrumentos normativos quanto os requisitos oriundos da teoria clássica de gestão de operações para projetar o CME. O modelo de referência é construído com base no conceito de modelos de referência de requisitos, isto é, modelo de tomada de decisão construído a partir de uma seleção de instrumentos normativos e referencial teórico da literatura com aplicação a CMEs reais. O modelo de referência de requisito proposto auxilia o gestor do CME na produção de artigos esterilizados conformes e seguros para o paciente, diminuindo e antecipando falhas de decisões de projeto.

\section{1}

\section{Objetivos da Pesquisa}

O objetivo principal da pesquisa é a proposição de um modelo de referência de requisito para auxiliar na tomada de decisão quanto ao projeto de CMEs. O modelo de referência proposto visa melhorar o desempenho do CME, com atendimento dos parâmetros de qualidade, de infecção hospitalar e dos instrumentos normativos. A melhoria do desempenho do CME contribui para o aumento da produtividade do setor, pois utiliza melhor os recursos disponíveis para produzir produtos conformes, assegurando a segurança do paciente.

O modelo de referência proposto nesta pesquisa é resultado da construção de um quadro conceitual genérico, construído a partir da seleção de instrumentos normativos e referencial teórica da literatura, validado por especialistas e aplicado a CMEs reais, para auxiliar na tomada de decisão quanto ao projeto e operação de um Centro de Material e Esterilização (CME). Portanto, não consiste em um modelo de referência voltado para o desenvolvimento de tecnologia de informação.

Para atender ao objetivo principal da pesquisa, foi necessário focar o estudo a fim de trabalhar com uma pesquisa de relevância teórica e prática. Nesse sentido, foram elaboradas as seguintes perguntas de pesquisa que este documento pretende responder:

a) Como projetar um CME de forma a obter alto desempenho com atendimento dos parâmetros de qualidade, de infecção hospitalar e dos instrumentos normativos? 
b) Qual seria o modelo de referência voltado para o auxílio da tomada de decisão para projetar o sistema de operação de um CME?

O objetivo principal será atendido através do cumprimento dos seguintes objetivos específicos, apresentados na Figura 2: a) levantamento do referencial focado em modelos de referência em saúde e CME através da revisão da literatura; b) levantamento e identificação dos instrumentos normativos e regulatórios; c) condução de uma pesquisa de campo em um CME representativo dos níveis de complexidade; d) análise e síntese da lógica de funcionamento à luz das categorias de operações; e) definição da estrutura do modelo de referência; f) validação do modelo com especialistas; g) refinamento do modelo; e h) aplicação do modelo.

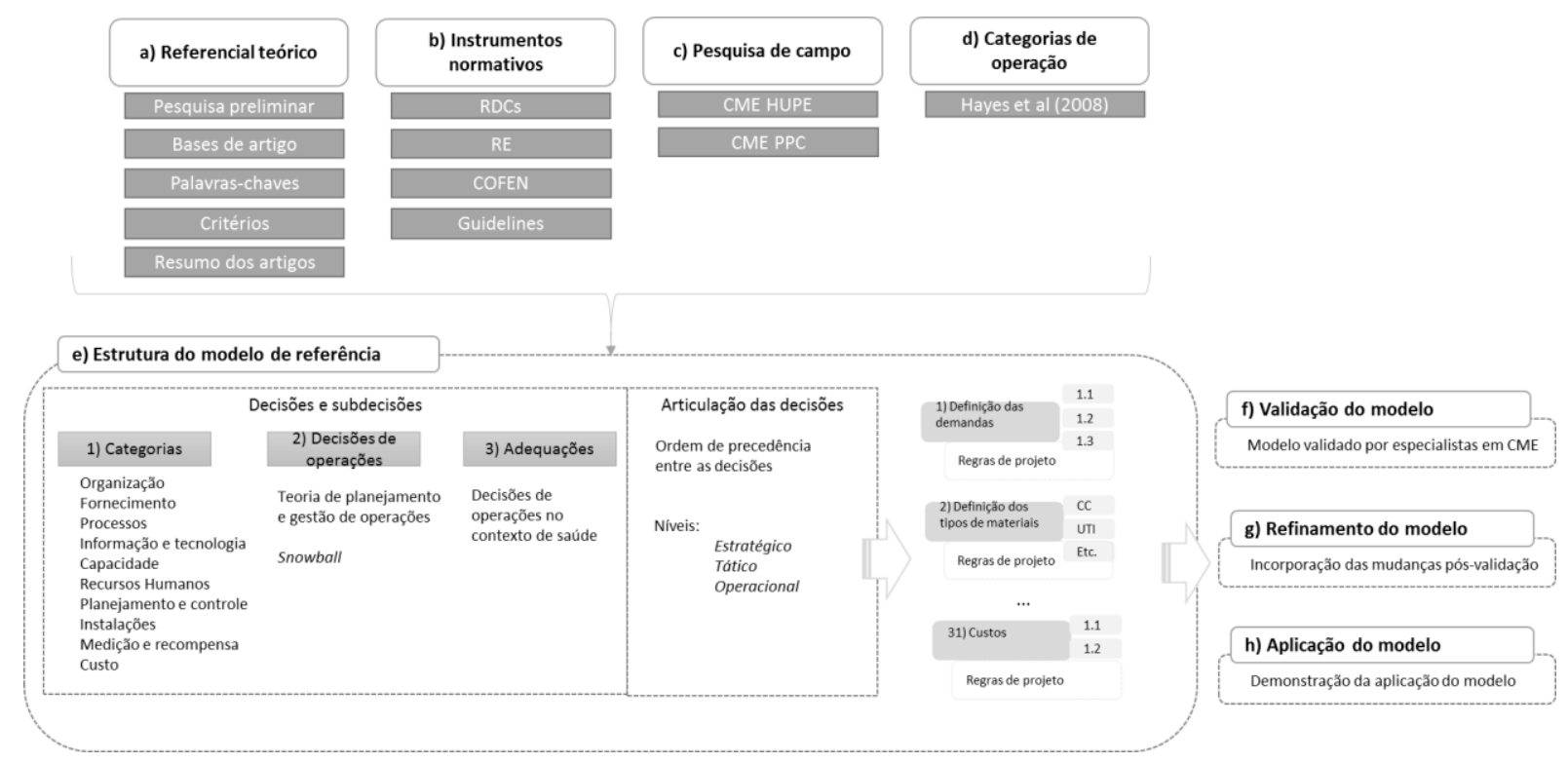

Figura 2 - Objetivos específicos. Elaboração própria.

\section{2}

\section{Justificativa da Pesquisa}

A escolha específica por esta área do hospital é motivada pela participação da pesquisadora em projetos relacionados aos CMEs. Nesses projetos percebeu-se a importância do CME no hospital, visto que é um departamento que fornece materiais esterilizados para enfermaria, salas de operação, unidades de transplante e ambulatórios (Basu et al., 2015).

Do ponto de vista de cadeia de suprimentos interna, o CME é um dos elos que fornece materiais para os demais componentes do hospital. Dessa forma, se o CME tem atrasos de entrega dos materiais, ou tem baixa velocidade de entrega, ou 
entrega materiais não conformes que precisam ser reprocessados, a mesma impacta diretamente no desempenho do hospital.

Sob a lente de operações, a atividade de esterilização realizada no CME é essencial para o funcionamento adequado da assistência médica e realização de exames. Contudo, na perspectiva de custos, torna-se uma atividade cara, visto que, esterilizar $0,5 \mathrm{~m}^{3}$ de dispositivos médicos pode custar mais do que 250 euros (Di Mascolo \& Gouin, 2013). Reymondon, Pellet \& Marcona (2008) relacionam alta qualidade no serviço hospitalar às condições higiênicas, que estão diretamente relacionadas aos instrumentos cirúrgicos e hospitalares utilizados. Di Mascolo et al. (2006) ressaltam que o serviço de esterilização é essencial para a luta contra as infecções.

Nesse sentido, estudar o CME é relevante, pois se trata de uma área de suma importância para os hospitais, pois o seu desempenho operacional contribui de forma significativa para atingir o aumento da qualidade do serviço oferecido e a redução dos custos (Reymondon, Pellet \& Marcona, 2008).

A possibilidade de pesquisa no Hospital Universitário Pedro Ernesto (HUPE), detalhado na subseção 3.4, viabilizou o acesso a um caso real caracterizado por seu sistema de alta complexidade composto por diversas especialidades clínicas e cirúrgicas a serem atendidas (ortopedia, vascular, torácica, geral, dentre outras). O HUPE, por sua vez, comporta um CME também complexo, que processa diversos tipos de instrumentais, insumos e materiais clínicos e cirúrgicos. Dessa forma, começar a construir o modelo de referência de projeto de CME tendo como cunho prático uma organização, que inclui as diversidades e complexidades associadas ao objeto, motiva e incentiva a realização desta pesquisa.

\section{3}

\section{Procedimentos Metodológicos}

A proposta da presente pesquisa é a formulação de um modelo de referência para auxílio na tomada de decisão quanto ao projeto de Centros de Material e Esterilização. O objeto escolhido sobre o qual é construído o modelo de referência de projeto é o Centro de Material e Esterilização, mais conhecido na área da saúde pela sigla CME ou CSSD (Central Sterilized Service Department ou Central Sterilized Supply Department). 
Os pilares do modelo de referência proposto consistem nas categorias de operação apresentadas por Hayes et al. (2008). As decisões pertinentes às categorias de operação e as respectivas articulações são construídas com base nos instrumentais normativos específicos, no conteúdo advindo da revisão focada da literatura e na teoria clássica de gestão de operações, tendo a aplicação a CMEs reais pertencentes ao complexo UERJ.

\section{4}

\section{Estrutura do documento}

O capítulo 1 apresenta a síntese dos objetivos da pesquisa, justificativa do trabalho e os procedimentos metodológicos utilizados para a construção do modelo. O referencial teórico pesquisado na literatura e instrumentais normativos utilizados são descritos no capitulo 2 . O capítulo 3 explica o método de pesquisa utilizado para a construção do modelo. As etapas de construção do modelo são apresentadas no capítulo 4. A demonstração da aplicação do modelo é realizada no capítulo 5. Por fim a conclusão da pesquisa (capítulo 6) e apêndices são apresentados. 


\section{2 \\ Referencial Teórico}

O objetivo da seção de referencial teórico é a apresentação do contexto no qual a proposta da presente pesquisa (modelo de referência para tomada de decisão de projeto de CMEs) se enquadra. A seção 2.1 conforma a proposta do modelo através da definição dos modelos de referência e justifica teoricamente a construção do modelo no arquétipo de modelo de referência. A seção 2.2 apresenta o contexto de gestão de operações, no qual a construção do modelo de referência proposto se encontra. São apresentados os aspectos de gestão de operação utilizados na construção do modelo de referência proposto. A seção 2.3 define a estrutura de operação de um CME, objeto de estudo central sobre o qual o modelo de referência proposto é construído.

\section{1 \\ Modelos de Referência}

Dentre diversas definições existentes na literatura, Cardoso (2008) define modelos de referência como modelos padronizados e genéricos, que são referência para os agentes tomadores de decisão sobre práticas a serem empregadas nas operações e processos organizacionais.

O modelo de referência para tomada de decisão de projeto configura um modelo genérico e padronizado utilizado para orientar o projeto das operações e dos processos (Spiegel \& Caulliraux, 2012). O modelo genérico também estipula os requerimentos que devem ser cumpridos a fim de apoiar a decisão dos gestores através de uma lógica explicitamente definida (Bernardo, 2016).

Fettke \& Loos (2006) apresentam duas vertentes de modelos de referência: os descritivos e os prescritivos. Os primeiros são construídos com base em processos, o que justifica ter uma amotra de organizações para se estudar os processos, de onde emerge a construção do modelo de referência. Já os modelos prescritivos são "blueprints para construção de novos sistemas". Nesse sentido, a presente pesquisa segue a vertente dos modelos de referência prescritivos, visto 
que se utiliza das regras propostas pelos instrumentais normativos e da literatura para a construção de um modelo de projeto de CMEs de referência.

Cardoso (2008) menciona dois tipos de modelos de referência: os modelos de referência de orientação e os modelos de referência de requisitos, classificação baseada na forma de descrição do conteúdo do modelo. Os primeiros são aqueles que apresentam informações para auxiliar as organizações, podendo ser incorporados ou não pelas organizações. Já os segundos, são modelos construídos com regras que precisam ser atendidas pelas organizações. Nesse contexto, a presente pesquisa visa à proposição de um modelo de referência de requisitos, pois os elementos que formam o modelo de tomada de decisão proposto baseiamse em regras estabelecidas pelos instrumentos normativos e pela literatura.

A construção dos modelos de referência de tomada de decisão parte de uma abordagem estruturada e racional para a resolução de problemas e incluem as seguintes etapas: identificação e enquadramento do problema, geração ou determinação de possíveis cursos de ação e avaliação das alternativas, escolha ou implementação da melhoria de solução ou alternativa e reavaliação dos passos anteriores (Mclaughlin \& Hays, 2008).

Devido ao crescimento da demanda por serviços médicos e ao aumento dos custos de operação hospitalar, as organizações da área de saúde estão tentando reorganizar os processos de forma eficiente e eficaz (Hans et al., 2011). A racionalização da alocação de recursos e a política de redução de custos e aumento de eficiência nos estabelecimentos hospitalares têm guiado as decisões estratégicas nos hospitais e assume papel relevante na economia em recessão (Merola, Padoano \& Zuliani, 2016). Dessa forma, há o aumento de interesse da Gestão de Operações e Pesquisa Operacional na pesquisa e aplicação na área da saúde (Hans et al., 2011).

Conforme as definições mencionadas anteriormente, um modelo de referência configura um modelo genérico que orienta o projeto de operações (Spiegel \& Caulliraux, 2012). Dessa forma, o modelo proposto na pesquisa conforma um modelo de referência, visto se tratar de um modelo genérico para orientar o projeto de CMEs, aplicável e adequável a qualquer CME.

A justificativa para a construção de um modelo genérico e de requisitos, e não específico para determinado CME, deve-se ao fato do estudo ter como fontes de informações os instrumentais normativos nacionais pertinentes aos CMEs, 
conteúdos de boas práticas adotados internacionalmente e evidentes em artigos e teses nacionais e internacionais, e objetos de estudo e aplicação caracterizados por CMEs de alta complexidade.

Além de englobar as decisões assistenciais advindas dos instrumentais normativos, o modelo de referência proposto contempla as decisões provenientes do contexto de planejamento e gestão de operações em saúde, objeto este descrito na subseção 2.2. Devido à natureza normativa das fontes para embasar as decisões assistenciais do modelo e à incorporação das decisões gerenciais, as decisões que formam o modelo podem ser generalizadas e enquadradas no modelo de referência.

Um facilitador no enquadramento do modelo proposto na pesquisa como modelo de referência é a padronização de operação existente nos CMEs, que funcionam como fábricas, visto que tem etapas estritamente definidas para cada roteiro de produção definido pelo tipo de produto processado, roteiros estes também propostos na presente pesquisa no capítulo 4.

\section{2}

\section{Gestão de Operações em Saúde}

Bozarth \& Handfield (2008) definem gestão de operações como planejamento, sequenciamento e controle dos processos que transformam inputs em produtos acabados e serviços. A estratégia de operações contempla um plano de longo prazo para as funções de operações que especificam o projeto e o uso dos recursos para apoiar a estratégia de negócios (Reid \& Sanders, 2011). A importância da gestão de operações advém da ideia de ligar a eficiência operacional à estratégia de operações, isto é, produzir de maneira eficiente eficiência operacional, o produto certo que irá atender a demanda - estratégia operacional (Reid \& Sanders, 2011).

Brandeu et al. (2004) ressaltam o uso inadequado dos recursos públicos para atender as demandas tanto nas nações ricas como nas pobres, elevando a responsabilidade dos projetistas e gestores dos sistemas de saúde a proverem cuidado em saúde efetivo para os cidadãos tendo em vista os recursos disponíveis.

Dessa forma, o papel da gestão de operações em saúde é garantir que os recursos adequados estão sendo utilizados de forma a prover serviços de saúde aceitáveis (Visser \& Beech, 2005). As atividades tratadas na gestão de operações em saúde incluem problemas de planejamento estratégico, como projeto do 
serviço oferecido, projeto da cadeia de suprimento, projeto de instalações e rede, previsão de demanda, avaliação e seleção de equipamentos, planejamentos de escalas e dimensionamento de profissionais, sistemas de estoques, medida e gestão do sistema de desempenho e qualidade, avaliação do desempenho dos equipamentos, sendo que os sistemas de suporte às decisões devem ser projetados e implementados para orientar todas as atividades de gestão de operações (Brandeu et al., 2004).

A gestão de operações em saúde está focada no fornecedor individual que produz o serviço de saúde e nas habilidades envolvidas na produção desse serviço (Visser \& Beech, 2005). Na presente pesquisa, a gestão de operações em saúde estará focada no CME, caracterizado como o fornecedor dos serviços de esterilização para as unidades consumidoras do hospital.

Rowbotham, Galloway \& Azhashemi (2007) e Reid \& Sanders (2011) agrupam as decisões operacionais em dois blocos: decisões estruturais, relacionadas ao projeto de processos de produção, e as decisões de infraestrutura, referentes ao planejamento e controle de sistemas de operação. As decisões pertencentes ao primeiro bloco são as de estratégia de instalações, tecnologia, integração e organização. As pertencentes ao segundo bloco são as de capacidade, suprimento, estoque, recursos humanos, planejamento e controle e medição e sistemas de recompensa.

Visser \& Beech (2005) mencionam que a gestão de operações em saúde é complementada e relacionada com outras áreas de gestão que focam nos processos centrais da organização.

Hayes et al. (2008) agrupam as decisões pertinentes ao projeto e gestão de operações nas seguintes categorias: Fornecimento e integração vertical, Informação e tecnologia de processo, Medição e sistemas de recompensa, Sistemas de recursos humanos, Sistemas de qualidade, Planejamento do trabalho e sistemas de controle, Sistemas de desenvolvimento de processos, Capacidade, Instalações, Organização e Custos. Essas categorias de decisões embasarão a construção das decisões do modelo de referência proposto para orientar os gestores de CMEs no projeto de operações dessas unidades. As definições das categorias de operação sofreram adequações ao contexto de saúde e são apresentadas na Tabela 3, localizada no capítulo 4 . 
Maclaughlin \& Hays (2008) reforçam a importância do entendimento dos sistemas que influenciam a entrega do cuidado para efetuar a melhoria das operações em saúde. Para o entendimento do sistema CME, foram estudados dois CMEs, sendo seus processos mapeados e apresentados na seção 3.4.

A seção 2.3 apresenta a descrição detalhada sobre o funcionamento de um CME e a importância do mesmo para o contexto operacional hospitalar.

\section{3 \\ CME}

O Centro de Materiais de Esterilização (CME) é uma área de suma importância para o hospital, pois o seu desempenho operacional contribui de forma significativa para atingir dois principais objetivos de um hospital: aumento da qualidade do serviço oferecido e redução dos custos (Reymondon, Pellet \& Marcona, 2006). Os principais objetivos do CME é a prevenção das infecções hospitalares através da entrega de artigos hospitalares seguros e garantia de contribuição positiva para controlar as infecções (Veiga-Malta, 2016).

Nesse sentido, a atividade de esterilização realizada no CME é essencial para o funcionamento adequado da assistência médica e realização de exames, mas é uma atividade cara, visto que, por exemplo, esterilizar $0,5 \mathrm{~m} 3 \mathrm{de}$ dispositivos médicos pode custar mais do que 250 euros (Di Mascolo \& Gouin, 2012). Por isso, o maior desafio enfrentado pelos hospitais é fornecer serviços médicos de forma eficiente e oferecer um serviço com nível de qualidade satisfatório. Reymondon, Pellet \& Marcona (2007) relacionam alta qualidade no serviço hospitalar às condições higiênicas, tendo o objetivo de reduzir as taxas de infecção.

Debabrata et al (2015) caracterizam um CME como um departamento do hospital que fornece materiais esterilizados para enfermaria, salas de operação, unidades de transplante e ambulatórios.

Esterilização consiste na eliminação dos microrganismos transportados nos dispositivos médicos contaminados, sendo tais dispositivos caracterizados como qualquer instrumento, aparelho ou outro artigo utilizado para propósito médico nos pacientes no diagnóstico, terapia ou cirurgia (Di Mascolo \& Gouin, 2012).

Segundo Ozturk, Begen e Zaric (2014), dois tipos de materiais podem ser esterilizados: os de utilidade única e os reutilizáveis, que por sua vez, são 
esterilizados para posterior reutilização. Dentre os materiais esterilizados estão inclusos: roupas, instrumentos cirúrgicos, lençóis, endoscópios, dentre outros equipamentos (Debabrata et al, 2015).

As áreas de operação do CME consistem no expurgo (recepção, descontaminação, lavagem e separação de materiais), preparo e acondicionamento (verificação das condições de funcionalidade e integridade dos materiais, inspeção da limpeza e empacotamento), esterilização, armazenagem e distribuição dos materiais esterilizados (Costa, 2009).

Ozturk, Begen e Zaric (2014) mencionam que um serviço de esterilização é composto pelas etapas de pré-desinfecção (na qual os materiais são submergidos em materiais químicos), lavagem, empacotamento e esterilização e destacam a etapa de lavagem como sendo o gargalo da operação do CME.

As operações do CME são críticas, visto que os instrumentais não esterilizados conformemente podem causar perigosas infecções no paciente e implicar em altos gastos para o hospital. Dessa forma, tomar decisões nas operações do CME evitando incidentes, contribui diretamente para a qualidade no cuidado à saúde hospitalar (Rüther et al., 2013). 


\section{3 \\ Método da Pesquisa}

Nesta seção serão descritos a classificação da presente pesquisa, a abordagem do problema de pesquisa, a natureza exploratória do estudo e os procedimentos técnicos utilizados para atingir o objetivo proposto na presente dissertação.

O estudo é classificado como pesquisa aplicada, pois propõe um novo modelo a partir das operações reais de dois CMEs. A pesquisa aborda o problema de forma qualitativa, descrevendo as decisões e articulações necessárias para projetar um CME. A natureza dos objetivos da pesquisa é exploratória, conforme explicado na seção 3.1.

Os procedimentos técnicos utilizados para construção do modelo proposto foram a revisão focada na literatura, para entendimento dos modelos de referência existentes e conhecimento sobre o contexto de operação de CMEs; identificação dos instrumentos normativos, para embasar os parâmetros mínimos exigidos para operar um CME; e a condução da pesquisa de campo em dois CMEs, para justificar a natureza exploratória da pesquisa e englobrar aspectos oriundos da realidade de operação das unidades de esterilização.

\section{Procedimentos técnicos do método de pesquisa}

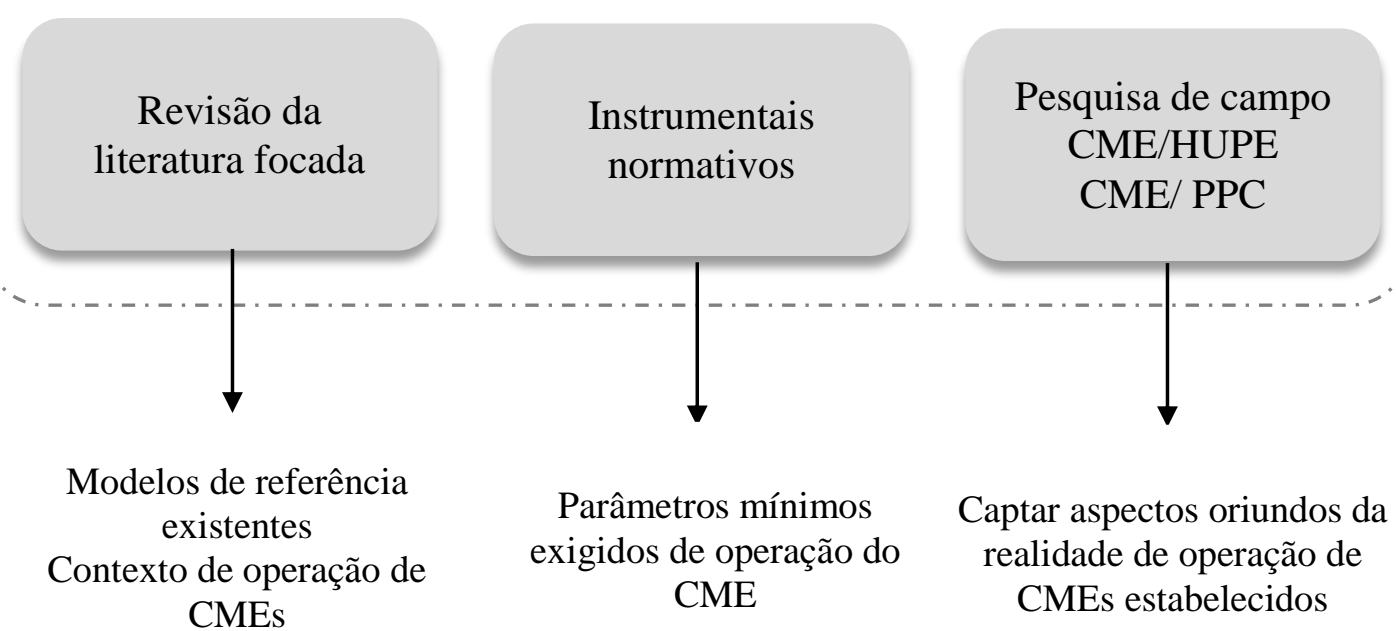

Figura 3 - Procedimentos do método da pesquisa. Elaboração própria. 
O método utilizado para realizar a revisão focada da literatura é apresentado na seção 3.2. A lista das legislações nacionais utilizada para a construção do modelo é apresentada na seção 3.3. A apresentação dos CMEs nos quais foi realizada a pesquisa de campo é descrita na seção 3.4 .

\section{1}

\section{Abordagem metodológica: classificação da pesquisa}

Há três tipos de classificações de pesquisa: básica, pura ou aplicada. A pesquisa é básica quando se propõe novos conhecimentos (Silva \& Menezes, 2001; Spiegel, 2011). Quando o conhecimento desenvolvido tem aplicação prática visando interesses acadêmicos para a comunidade de pesquisadores é dita pesquisa pura. Por outro lado, quando a pesquisa relaciona-se a operações reais com o objetivo de solucionar problemas de consequências práticas, trata-se de pesquisa aplicada (Booth et al., 2008; Spiegel, 2011).

Dentre as classificações apresentadas, a pesquisa proposta enquadra-se nas características da pesquisa aplicada ou empírica, por ter o cunho de desenvolver conhecimentos a partir das operações reais, obtendo informações com tomadores de decisões das operações, além da oportunidade de testar e validar o conhecimento desenvolvido (Gallien et al., 2015).

A pesquisa proposta utiliza a investigação empírica por se tratar de um estudo que visa compreender as principais decisões da área de projeto de CMEs a fim de elaborar um modelo de referência genérico de tomada de decisão voltado para o projeto deste setor do hospital a partir do conhecimento da operação real de dois CMEs.

Quanto à abordagem do problema da pesquisa, esta pode ser quantitativa ou qualitativa. A abordagem quantitativa tem como natureza quantificar informações, que, por sua vez, são trabalhadas por meio de técnicas estatísticas a fim de serem classificadas, agrupadas e analisadas (Silva \& Menezes, 2001; Spiegel, 2011). Por outro lado, a abordagem qualitativa visa à qualidade das propriedades dos objetos, fenômenos, situações, pessoas, significados e eventos, sendo, portanto, uma abordagem geralmente utilizada para estudar pessoas, grupos, organizações e sociedades (Van Aken et al., 2007).

Nesse sentido, a presente pesquisa enquadra-se como uma pesquisa qualitativa, por evidenciar as qualidades e características da operação de CMEs de 
uma organização, e descrever as decisões e articulações do modelo de referência proposto.

Segundo a natureza dos objetivos da pesquisa, a mesma pode ser classificada como exploratória, descritiva e explicativa (Silva \& Menezes, 2001; Spiegel, 2011). A pesquisa exploratória visa tornar o problema explícito ou construir hipóteses (Gil, 2007; Spiegel, 2011). A forma descritiva da pesquisa descreve as características de determinada população ou fenômeno, utilizando formas padronizadas de aquisição de dados. A pesquisa é explicativa quando busca identificar o "porquê" de determinados fenômenos, utilizando técnicas experimentais e observacionais (Silva \& Menezes, 2001; Spiegel, 2011).

Nesse contexto, a presente pesquisa tem natureza exploratória, visto que a pesquisa visa obter o entendimento prático das melhores práticas de projeto de CME para formular um modelo de referência que oriente a tomada de decisão dos gestores desse setor do hospital.

Os procedimentos técnicos empíricos adotados na pesquisa prática podem ser pesquisas de tipo survey, estudos de casos simples ou múltiplos, pesquisaação, análises de bases de dados, pesquisa experimental, ou revisões sistemáticas da literatura.

Nesta pesquisa, os procedimentos técnicos utilizados são a revisão focada da literatura, a identificação dos instrumentais normativos específicos e a condução de pesquisa de campo em CMEs de níveis de complexidade representativos. Os detalhamentos dos procedimentos técnicos são apresentados nas seções 3.2, 3.3 e 3.4 .

\section{2}

\section{Revisão da literatura}

A técnica de revisão da literatura que atende ao objetivo desta pesquisa é a focada, pois é restrita a teorias e estudos empíricos diretamente relacionados ao objetivo central do trabalho de pesquisa.

A teoria pesquisada é focada em modelos de referência na área da saúde e conteúdos focados em CMEs.

As bases de artigos e teses eletrônicos utilizadas na pesquisa de revisão da literatura foram Scielo (para pesquisa de artigos nacionais), Scopus e Isi Web of Science. 
Em uma pesquisa preliminar, para entendimento do tema e objeto de estudo, foram encontrados livros e guias que ajudaram na formulação das palavraschaves. Os livros e guias utilizados foram: Guideline for Disinfection and Sterilization in Healthcare Facilities (2008); Supply chain excellence - A Handbook for Dramatic Improvement Using the SCOR Model (2007); Reference Modeling for Business Systems Analysis (2007); Health Operations Management (2005).

As palavras-chaves selecionadas para busca de artigos foram: CME, Central de material esterilizado, esterilização, sterilization, center/centre sterilized supply department, center/centre/cent* sterilized service department, reference model*, decision mak*, decision, healthcare, hospital, medical devices, hospital sterilization services, OR (Operational Research) in health services. As combinações de palavras-chaves são: "OR (Operational Research) in health services" AND "sterilization", "reference modeling” AND “decision", "reference model*" AND "decision mak*", "reference model*" AND "healthcare", "central sterile service department" AND "decision", "central sterile service department" AND "reference model*", "reference model*" AND "decision mak*".

O critério para seleção e exclusão de artigos foi a área de pesquisa. Dessa forma, os artigos incluídos são aqueles pertencentes às seguintes áreas: medicine, nursing, enginnering, computer science, health care sciences services, decision sciences.

Após a utilização do critério de inclusão e exclusão dos artigos, foi feita a revisão manual dos resumos dos artigos, resultando no conjunto final utilizado nesta pesquisa.

Os resultados detalhados da busca de artigos e teses são apresentados na Tabela 41, Tabela 42 e Tabela 43, localizadas no apêndice deste documento.

O detalhamento do conteúdo dos artigos e teses utilizados na pesquisa é apresentado nos capítulos 2 e 4 .

A pesquisa realizada na base Scielo se justifica pela necessidade de obtenção de artigos nacionais para a compreensão da realidade dos CMEs no contexto brasileiro, visto que o modelo de referência formulado será aplicado em CMEs no Brasil. A Tabela 41 apresenta os resultados da revisão da literatura realizada na base Scielo a partir das palavras-chaves selecionadas. 
Houve retorno à literatura para pesquisar conteúdos específicos exigidos para embasar as decisões pertencentes ao modelo de referência proposto. O retorno à literatura foi feito através do método snowball, descrito por Van Aken et al. (2007). Esse método de pesquisa tem como base o traço de referências extraídas das principais fontes de artigos (Van Aken et al., 2007). Na presente pesquisa, as especificações das decisões foram descritas através de referências assinaladas pelos artigos da revisão da literatura original.

\section{3}

\section{Identificação dos instrumentos normativos}

Os instrumentos normativos, no contexto de esterilização, têm como objetivo a padronização dos processamentos de materiais clínicos e cirúrgicos. Leite (2008) ressalta a importância da padronização de normas e rotinas técnicas para validação dos processamentos de materiais e controle de infecções.

Os pacotes normativos de CME brasileiros são compostos por nota técnica da ANVISA, portaria e resoluções (RDC e RE). Ressaltam-se as práticas recomendadas oriundas do COFEN. Cabe ressaltar os manuais de normas e rotinas técnicas para $\mathrm{CME}$, consistindo em regimento interno da central distrital, elaboradas com base nos pacotes normativos apresentados.

Há os pacotes internacionais de certificação de CME, que fornecem certificação internacional, como a IAHCSMM (International Association of Healthcare Central Services and Material Management) e a CBSPD (Certification Board for Sterile Processing and Distribution). Também há a acreditação de CME oferecida pela Joint Comission on Accreditation of Healthcare Organizations. A Tabela 1 apresenta os instrumentos normativos e de acreditação utilizados nesta pesquisa.

Tabela 1 - Lista descritiva dos instrumentos normativos. Elaboração própria.

\begin{tabular}{|c|c|l|l|}
\hline $\mathbf{x x}$ & $\begin{array}{c}\text { Título do } \\
\text { normativo }\end{array}$ & \multicolumn{1}{c|}{ Descrição } & \multicolumn{1}{c|}{ Fonte } \\
\hline 1 & RDC 08/2009 & $\begin{array}{l}\text { Dispõe sobre as medidas para } \\
\text { redução da ocorrência de infecções } \\
\text { por Microbactérias de Crescimento } \\
\text { Rápido - MCR em serviços de } \\
\text { saúde. }\end{array}$ & $\begin{array}{l}\text { http://www.abebras } \\
\text { il.org.br/imagem/p } \\
\text { df/RDC_08.pdf }\end{array}$ \\
\hline 2 & RDC 15/2012 & $\begin{array}{l}\text { Dispõe sobre requisitos de boas } \\
\text { práticas para o processamento de } \\
\text { produtos para saúde e dá outras } \\
\text { providências. }\end{array}$ & $\begin{array}{l}\text { http://www.abebras } \\
\text { il.org.br/imagem/p } \\
\text { df/RDC_15.pdf }\end{array}$ \\
\hline 3 & RDC 50/2002 & Dispõe sobre o Regulamento & http://www.abebras \\
\hline
\end{tabular}




\begin{tabular}{|c|c|c|c|}
\hline & & $\begin{array}{l}\text { Técnico para planejamento, } \\
\text { programação, elaboração e } \\
\text { avaliação de projetos físicos de } \\
\text { estabelecimentos assistenciais de } \\
\text { saúde. }\end{array}$ & $\begin{array}{l}\text { il.org.br/imagem/p } \\
\text { df/RDC\%2050.pdf }\end{array}$ \\
\hline 4 & RDC 55/2012 & $\begin{array}{l}\text { Dispõe sobre os detergentes } \\
\text { enzimáticos de uso restrito em } \\
\text { estabelecimentos de assistência à } \\
\text { saúde com indicação para limpeza } \\
\text { de dispositivos médicos e dá outras } \\
\text { providências. }\end{array}$ & $\begin{array}{l}\text { http://www.abebras } \\
\text { il.org.br/imagem/p } \\
\text { df/RDC55\%20Dete } \\
\text { rgentes\%20Enzima } \\
\text { ticos.pdf }\end{array}$ \\
\hline 5 & RDC 91/ 2008 & $\begin{array}{l}\text { Proíbe o uso isolado de produtos } \\
\text { que contenham paraformaldeído ou } \\
\text { formaldeído, para desinfecção e } \\
\text { esterilização, regulamenta o uso de } \\
\text { produtos que contenham tais } \\
\text { substâncias em equipamentos de } \\
\text { esterilização e dá outras } \\
\text { providências. }\end{array}$ & $\begin{array}{l}\text { http://bvsms.saude. } \\
\text { gov.br/bvs/saudele } \\
\text { gis/anvisa/2008/res } \\
\text { 0091_28_11_2008. } \\
\text { html }\end{array}$ \\
\hline 6 & $\begin{array}{l}\text { RDC } \\
306 / 2004\end{array}$ & $\begin{array}{l}\text { Dispõe sobre o Regulamento } \\
\text { Técnico para o gerenciamento de } \\
\text { resíduos de serviços de saúde }\end{array}$ & $\begin{array}{l}\text { http://www.abebras } \\
\text { il.org.br/imagem/p } \\
\text { df/RDC\%20306.pd } \\
\text { f }\end{array}$ \\
\hline 7 & $\begin{array}{l}\text { RDC } \\
307 / 2002\end{array}$ & $\begin{array}{l}\text { Altera a Resolução - RDC no } 50 \text { de } \\
21 \text { de fevereiro de } 2002 \text { que dispõe } \\
\text { sobre o Regulamento Técnico para } \\
\text { planejamento, programação, } \\
\text { elaboração e avaliação de projetos } \\
\text { físicos de estabelecimentos } \\
\text { assistenciais de saúde }\end{array}$ & $\begin{array}{l}\text { http://portal.anvisa. } \\
\text { gov.br/legislacao }\end{array}$ \\
\hline 8 & RE 2605/2006 & $\begin{array}{l}\text { Estabelece a lista de produtos } \\
\text { médicos enquadrados como de uso } \\
\text { único proibidos de ser } \\
\text { "reprocessados". }\end{array}$ & $\begin{array}{l}\text { http://www.abebras } \\
\text { il.org.br/imagem/p } \\
\text { df/RE\%20N\%C2\% } \\
\text { B02.606.pdf }\end{array}$ \\
\hline 9 & RE2606/2006 & $\begin{array}{l}\text { Dispõe sobre as diretrizes para } \\
\text { elaboração, validação e } \\
\text { implantação de produtos de } \\
\text { "reprocessamento" de produtos } \\
\text { médicos e dá outras providências. }\end{array}$ & $\begin{array}{l}\text { http://www.abebras } \\
\text { il.org.br/imagem/p } \\
\text { df/RE\%20N\%C2\% } \\
\text { B02.606.pdf }\end{array}$ \\
\hline 10 & $\begin{array}{l}\text { RESOLUÇÃO } \\
\text { COFEN N } \\
293 / 04\end{array}$ & $\begin{array}{l}\text { Fixa e estabelece parâmetros para o } \\
\text { Dimensionamento do Quadro de } \\
\text { Profissionais de enfermagem nas } \\
\text { unidades assistenciais das } \\
\text { instituições de saúde e } \\
\text { assemelhados. }\end{array}$ & $\begin{array}{l}\text { http://www.cofen.g } \\
\text { ov.br/resoluo- } \\
\text { cofen- } \\
\text { 2932004_4329.htm } \\
\text { 1 }\end{array}$ \\
\hline
\end{tabular}

\begin{tabular}{|c|c|c|c|}
\hline 11 & $\begin{array}{l}\text { RESOLUÇAO } \\
\text { COFEN N }^{\circ} \\
424 / 2012\end{array}$ & $\begin{array}{l}\text { Normatiza as atribuições dos } \\
\text { profissionais de enfermagem em } \\
\text { Centro de Material e Esterilização }\end{array}$ & $\begin{array}{l}\text { ov.br/resoluo- } \\
\text { cofen-n- }\end{array}$ \\
\hline
\end{tabular}




\begin{tabular}{|c|c|c|c|}
\hline & & $\begin{array}{l}\text { (CME) e em empresas } \\
\text { processadoras de produtos para } \\
\text { saúde. }\end{array}$ & $\begin{array}{l}\text { 4242012_8990.htm } \\
1\end{array}$ \\
\hline 12 & $\begin{array}{l}\text { RESOLUÇÃO } \\
\text { COFEN N }^{\circ} \\
527 / 2016\end{array}$ & $\begin{array}{l}\text { Atualiza e estabelece parâmetros } \\
\text { para o Dimensionamento do } \\
\text { Quadro de Profissionais de } \\
\text { Enfermagem nos serviços/locais em } \\
\text { que são realizadas atividades de } \\
\text { enfermagem. }\end{array}$ & $\begin{array}{l}\text { http://www.cofen.g } \\
\text { ov.br/resolucao- } \\
\text { cofen-no- } \\
\text { 05272016_46348.h } \\
\text { tml }\end{array}$ \\
\hline 13 & $\begin{array}{l}\text { Portaria } \\
\text { No}^{\circ} 482 / 1999\end{array}$ & $\begin{array}{l}\text { Considera o gás óxido de etileno } \\
\text { altamente tóxico, facilmente } \\
\text { inflamável e explosivo, além de ser } \\
\text { carcinogênico, mutagênico, } \\
\text { teratogênico e neurotóxico. }\end{array}$ & $\begin{array}{l}\text { http://www.abebras } \\
\text { il.org.br/imagem/p } \\
\text { df/PORTARIA_IN } \\
\text { TERMINISTERIA } \\
\text { L_N_482.pdf }\end{array}$ \\
\hline 14 & NR 32 & $\begin{array}{l}\text { Estabelece as diretrizes básicas para } \\
\text { a implementação de medidas de } \\
\text { proteção à segurança e à saúde dos } \\
\text { trabalhadores dos serviços de } \\
\text { saúde, bem como daqueles que } \\
\text { exercem atividades de promoção e } \\
\text { assistência à saúde em geral. }\end{array}$ & $\begin{array}{l}\text { http://www.abebras } \\
\text { il.org.br/imagem/p } \\
\text { df/NR_32.pdf }\end{array}$ \\
\hline 15 & $\begin{array}{l}\text { Consulta } \\
\text { pública No } \\
34 / 2009\end{array}$ & $\begin{array}{l}\text { Propõe, dentre os novos parâmetros } \\
\text { de funcionamento para o CME, a } \\
\text { realização de testes periódicos para } \\
\text { monitoramento da limpeza. }\end{array}$ & $\begin{array}{l}\text { http://www4.anvisa } \\
\text {.gov.br/base/visado } \\
\text { c/CP/CP\%5B26720 } \\
\text {-1-0\%5D.PDF }\end{array}$ \\
\hline 16 & AAMI & $\begin{array}{l}\text { Association for the Advancement } \\
\text { of Medical Instrumentation. }\end{array}$ & $\begin{array}{l}\text { http://www.aami.or } \\
\mathrm{g} /\end{array}$ \\
\hline 17 & AORN & $\begin{array}{l}\text { Association of periOperative } \\
\text { Registered Nurses. }\end{array}$ & $\begin{array}{l}\text { http://www.aorn.or } \\
\mathrm{g} /\end{array}$ \\
\hline 18 & CBSPD & $\begin{array}{l}\text { Certificação internacional dos } \\
\text { processos de esterilização e } \\
\text { distribuição. }\end{array}$ & $\begin{array}{l}\text { http://www.sterilep } \\
\text { rocessing.org/cbsp } \\
\text { d.htm }\end{array}$ \\
\hline 19 & $\begin{array}{l}\text { Joint } \\
\text { Comission on } \\
\text { Accreditation } \\
\text { of Healthcare } \\
\text { Organizations }\end{array}$ & $\begin{array}{l}\text { Acreditação internacional de } \\
\text { unidades de saúde }\end{array}$ & $\begin{array}{l}\text { https://www.jointc } \\
\text { ommission.org/ }\end{array}$ \\
\hline
\end{tabular}

\section{4}

\section{Pesquisa de campo em CMEs representativas}

Parte dos insumos necessários para a construção do modelo de referência proposto advém da condução da pesquisa de campo nos CMEs pertencentes ao complexo de saúde da UERJ, compostos pelo CME do Hospital Universitário Pedro Ernesto (HUPE) e pelo CME da Policlínica Américo Piquet Carneiro (PPC). 
O HUPE trabalha com 41 especialidades médicas, dentre elas, a cardíaca, torácica, vascular, pediátrica e geral (acesso em: www.hupe.uerj.br), o que caracteriza um sistema complexo composto por diferentes tipos de artigos reprocessados advindos de diversas especialidades. O HUPE é constituído de centro cirúrgico para atendimento das especialidades, unidades de internação, UTI, ambulatórios, além de comportar o Centro Obstetrico, Núcleo Perinatal, Núcleo de Estudo da Saúde do Adolescente (NESA).

Além de ser um hospital prestador de atendimento médico geral, o HUPE engloba o papel de ensino através do perfil de hospital universitário, tratando questões acadêmicas como estudos de raridades clínicas e doenças em estado final de evolução. O HUPE abrange as questões de ensino pertinentes às áreas de medicina, enfermagem, serviços sociais, psicologia, dentre outras (acesso em: www.hupe.uerj.br).

Nesse contexto, os CMEs do complexo da UERJ reprocessam artigos de diversas especialidades, oriundos de diferentes tipos de unidades consumidoras (centro cirúrgico, ambulatórios, unidades de internação, UTI). Dessa forma, o alto volume e variedade de artigos processados e a gama de unidades consumidoras atendida pelos CMEs do complexo de saúde da UERJ, justificam o embasamento e generalização para a construção de um modelo de referência nacional para o projeto de um CME.

A contribuição da pesquisa de campo feita nos CMEs do complexo da UERJ é a possibilidade de aplicação do modelo de referência proposto e validação do modelo junto aos chefes de enfermagem dos CMEs estudados.

Os CMEs do complexo UERJ são compostos pelo CME do HUPE, que reprocessa os artigos advindos das unidades de internação, centro cirúrgico, UTI e ambulatórios pertencentes ao HUPE, e pelo CME da PPC, que atende as demandas dos ambulatórios, odontologia e centro cirúrgico da PPC. O detalhamento das operações de cada CME é apresentado na Tabela 2.

A pesquisa de campo dá-se através da condução de entrevistas aos funcionários e gestores das unidades, que são compostos pelos chefes de enfermagens dos CMEs do HUPE e da PPC (detalhamento na seção 4.2) e mapeamento dos processos para compreensão descritiva e sequencial das atividades que formam os processos do CME. A pesquisa de campo é um meio 
real de validação e aplicação do modelo de referência construído com base nos requisitos extraídos da literatura e dos instrumentais normativos.

Tabela 2 - Descrição dos aspectos da operação do CME/HUPE e CME/PPC

\begin{tabular}{|c|c|c|}
\hline Aspectos da operação & CME/HUPE & CME/PPC \\
\hline Artigos processados & $\begin{array}{l}\text { Instrumentais cirúrgicos, } \\
\text { roupas, próteses, material } \\
\text { clínico. }\end{array}$ & $\begin{array}{l}\text { "Insumos do } \\
\text { almoxarifado" que } \\
\text { consistem em } \\
\text { compressas, cotonetes, } \\
\text { para citar alguns, além } \\
\text { do processamento de } \\
\text { instrumentais avulsos, e } \\
\text { itens avulsos da } \\
\text { odontologia, roupas, } \\
\text { próteses, material } \\
\text { clínico. }\end{array}$ \\
\hline $\begin{array}{l}\text { Artigos processados } \\
\text { externamente }\end{array}$ & $\begin{array}{l}\text { Macro e micro } \\
\text { respiradores, circuitos de } \\
\text { ventilação mecânica, } \\
\text { dentre outros aparelhos, } \\
\text { são reprocessados através } \\
\text { da desinfecção. } \\
\end{array}$ & $\begin{array}{l}\text { Macro e micro } \\
\text { respiradores, circuitos de } \\
\text { ventilação mecânica, } \\
\text { dentre outros aparelhos, } \\
\text { são reprocessados } \\
\text { através da desinfecção. }\end{array}$ \\
\hline Macroprocessos & $\begin{array}{l}\text { Recebimento, limpeza e } \\
\text { secagem de materiais; } \\
\text { preparo e } \\
\text { acondicionamento; } \\
\text { esterilização e } \\
\text { armazenagem e } \\
\text { distribuição. }\end{array}$ & $\begin{array}{l}\text { Recebimento, limpeza e } \\
\text { secagem de materiais; } \\
\text { preparo e } \\
\text { acondicionamento; } \\
\text { esterilização e } \\
\text { armazenagem e } \\
\text { distribuição. }\end{array}$ \\
\hline Demandas atendidas & $\begin{array}{l}\text { centro cirúrgico (cirurgia } \\
\text { cardíaca, geral, } \\
\text { pediátrica, plástica, } \\
\text { torácica e vascular, } \\
\text { ambulatórios e UTI } \\
\text { (materiais clínicos e } \\
\text { bandejas de pequenas } \\
\text { cirurgias). }\end{array}$ & $\begin{array}{l}\text { Centro cirúrgico, onde } \\
\text { são realizadas cirurgias } \\
\text { sem internação, além de } \\
\text { atender ambulatórios e } \\
\text { odontologia. }\end{array}$ \\
\hline Atividades terceirizadas & $\begin{array}{l}\text { Operação de desinfecção } \\
\text { e lavagem das roupas. }\end{array}$ & $\begin{array}{l}\text { Operação de desinfecção } \\
\text { e lavagem das roupas. }\end{array}$ \\
\hline
\end{tabular}

Nota-se através das entrevistas realizadas e do mapeamento dos processos, a carência de orientação quanto às decisões pertinentes aos aspectos gerenciais, como parâmetros de capacidade, indicadores de desempenho e produtividade, previsão de demandas e fornecimento, programação e sequenciamento da produção, priorização do produto a ser esterilizado, tecnologias de rastreamento dos produtos e custos associados. Por outro lado, parâmetros de qualidade do 
processo, procedimentos operacionais padrão, layout das instalações, segurança do paciente, por sua vez, são aspectos fortemente orientados por legislações e protocolos assistenciais.

A pesquisa de campo, portanto, alarma a necessidade de articular decisões de natureza gerencial na gestão de operações de CMEs junto às decisões de natureza assistencial, já considerados na gestão tradicional das unidades de esterilização. A construção do modelo de referência proposto considera ambas naturezas de decisões, visto que as operações precisam ser eficientes, com processamento conforme atendendo aos prazos estabelecidos pelas demandas (aspectos gerenciais), com atenção aos parâmetros mínimos de qualidade e controle estabelecidos pelas legislações e protocolos assistenciais. 


\section{Construção do modelo de referência}

Nessa seção serão apresentadas a lógica de construção utilizada para a construção do modelo de referência de tomada de decisão para projetar as operações de CMEs (subseção 4.1), a validação do modelo de referência por especialistas da área (subseção 4.2), a estrutura articulada das decisões do modelo de referência e o refinamento do modelo a partir das propostas de mudanças evidenciadas na etapa de validação (subseção 4.3).

A lógica utilizada para construção do modelo de referência é baseada na abordagem das categorias de operação (Hayes et al., 2008), nas quais as decisões de projeto de operação são agrupadas. Segundo estudo de Spiegel (2013), dentre as categorias de operações propostas pelos autores da América do Norte, as categorias formuladas por Hayes et al. (2008) se destacam pela completude, fator que justifica a adoção das mesmas na construção do modelo a ser proposto nesta pesquisa.

As decisões incipientes emergem das categorias de operações clássicas da produção e são adequadas ao contexto de operação de CME e articuladas através das pesquisas de campo, dos instrumentos normativos e da literatura (guias de boas práticas, guias internacionais, artigos nacionais e internacionais, teses e dissertações).

A estrutura articulada do modelo de referência é acompanhada da descrição e do detalhamento das decisões e subdecisões. O detalhamento contempla as regras de projeto, no qual são mostradas alternativas para executar as decisões, norteando os gestores de CMEs na aplicação do modelo.

A validação do modelo foi realizada por especialistas da área de gestão de CME, pertencentes às chefias de CMEs do complexo HUPE. Propostas de mudanças e aprovações foram assinaladas e registradas.

A proposta final da estrutura do modelo de referência emerge da incorporação das mudanças assinaladas na etapa de validação com especialistas, resultando no refinamento do modelo. 


\section{1}

\section{Lógica de construção do modelo}

O modelo de referência proposto nesta pesquisa é gerado a partir da identificação das principais decisões a serem tomadas para projetar as operações de um CME. Em se tratando de projetos de operações, foram adotadas as categorias de operações apresentadas por Hayes et al. (2008) como base para a construção das principais decisões de projeto de operações de CMEs a serem articuladas no modelo de referência proposto.

Para identificação, proposta e articulação das principais decisões, foram executadas as seguintes etapas: 1) identificação das categorias de operações como ponto de partida para formulação das decisões; 2) identificação das decisões de operações genéricas (aplicáveis a qualquer organização) nas categorias de operação citadas pelos autores clássicos de planejamento e gestão de operações; 3) adequação das decisões genéricas ao contexto de saúde, através da extração de parâmetros mínimos estabelecidos pelos instrumentais normativos nacionais e das recomendações advindas de guias de boas práticas, além das decisões identificadas na pesquisa de campo através do mapeamento de processos, sendo tais decisões embasadas por artigos, teses e dissertações; 4) articulação das decisões identificadas e listadas, estabelecendo a precedência de tomada de decisão.

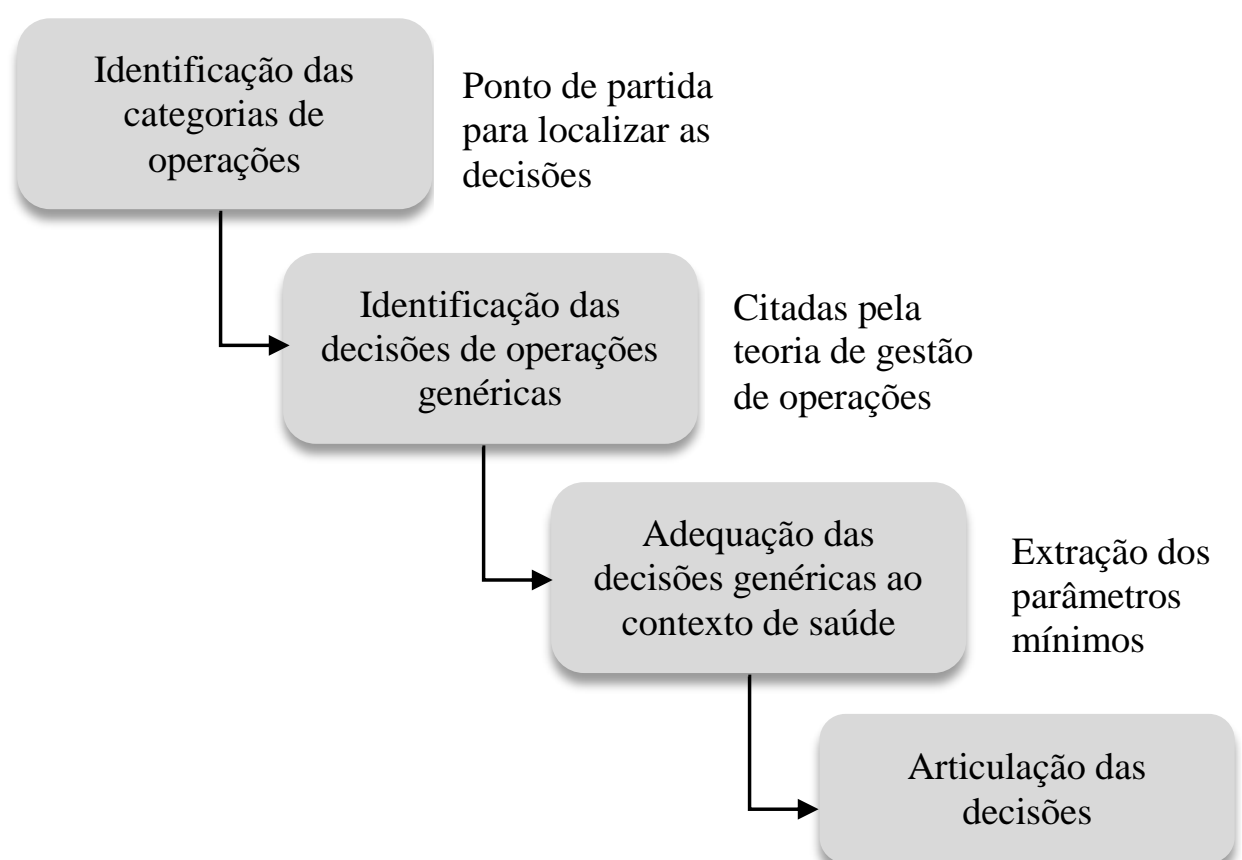

Precedência na tomada de decisão

Figura 4 - Etapas de construção do modelo de referência. Elaboração própria. 
Segue o detalhamento de cada etapa de construção do modelo de tomada de decisão proposto.

1) Identificação das categorias de operações como ponto de partida para formulação das decisões: as categorias das principais decisões de projeto de CMEs adotadas são advindas da teoria de gestão de operações proposta por Hayes et al. (2008), que identificam onze categorias necessárias para projetar e gerir operações, sendo estas compostas por: organização, fornecimento e integração vertical, sistemas de desenvolvimento de processos, informação e tecnologia de processo, capacidade, sistemas de qualidade, sistemas de recursos humanos, planejamento do trabalho e sistemas de controle, instalações, medição e sistemas de recompensa e custos. As categorias de operação utilizadas na construção do modelo foram extraídas da teoria clássica de operações tendo em vista que o objeto de estudo (CME) comporta processos de manufatura. Ressalta-se que os autores Hayes et al (2008) foram utilizados pela completude das categorias em comparação aos demais autores da América do Norte (Spiegel, 2013).

2) Identificação das decisões de operações genéricas (aplicáveis a qualquer organização) nas categorias de operação citadas pelos autores clássicos de planejamento e gestão de operações: Dessas categorias irão emergir as decisões iniciais que formarão o modelo de tomada de decisão para projetar as operações de um CME. Contudo, as decisões apresentadas por cada categoria remontam à manufatura tradicional. Portanto, adequações ao contexto de saúde foram necessárias para se conformarem à proposta de formulação das principais decisões para projetar e gerir operações da CME. A Tabela 3 apresenta as categorias de operações com as respectivas descrições utilizadas na construção do modelo. A partir das definições das categorias de operações, identificam-se decisões iniciais a serem inseridas no modelo de tomada de decisão proposto. Ressalta-se que o conteúdo descritivo das decisões nas categorias de operação apresentado na Tabela 3 sofreu adequações ao contexto de saúde, adequações decorrentes da execução da etapa 3 , a ser detalhada a seguir. 
Tabela 3 - Descrição das categorias de operação com adequações ao contexto de saúde. Fonte: Elaboração própria.

\begin{tabular}{|c|c|}
\hline $\begin{array}{l}\text { Categorias de } \\
\text { operação a partir de } \\
\text { Hayes et al (2008) }\end{array}$ & Descrição \\
\hline Organização & $\begin{array}{l}\text { Centralizada versus descentralizada, decisões a serem } \\
\text { delegadas; papel dos grupos de apoio. Hierarquia, } \\
\text { demandas, relações hieráquicas. }\end{array}$ \\
\hline $\begin{array}{l}\text { Fornecimento e } \\
\text { integração vertical }\end{array}$ & $\begin{array}{l}\text { Quantidade de trabalho total necessário para criar e } \\
\text { entregar seus produtos feitos internamente e } \\
\text { quantidade a ser comprada de organizações externas. } \\
\text { Compras por comodato, licitação. Tipos de } \\
\text { embalagem, utilidades dos insumos, detergentes } \\
\text { enzimáticos, etc. }\end{array}$ \\
\hline $\begin{array}{l}\text { Sistemas de } \\
\text { desenvolvimento de } \\
\text { processos }\end{array}$ & $\begin{array}{l}\text { Definição de projeto de processos conformes, } \\
\text { atendendo aos objetivos de desempenho e aos } \\
\text { instrumentos normativos. }\end{array}$ \\
\hline $\begin{array}{l}\text { Informação e } \\
\text { tecnologia de processo }\end{array}$ & $\begin{array}{l}\text { Grau de automação, variedade de padrões de processo } \\
\text { que resultam em uma ampla escala de produtos e } \\
\text { serviços. Sistema de informação que vincula os } \\
\text { indicadores de processamento de esterilização ao } \\
\text { prontuário do paciente, equipamentos, forma de } \\
\text { chegada do mapa cirúrgico ao CME. }\end{array}$ \\
\hline Capacidade & $\begin{array}{l}\text { Quantidade de capacidade fornecida por um conjunto } \\
\text { de espaço físico e equipamentos. }\end{array}$ \\
\hline Sistemas de qualidade & $\begin{array}{l}\text { Prevenção, monitoramento, intervenção e eliminação } \\
\text { de defeitos. Práticas e testes de controle que atestem } \\
\text { qualidade. }\end{array}$ \\
\hline $\begin{array}{l}\text { Sistemas de recursos } \\
\text { humanos }\end{array}$ & $\begin{array}{l}\text { Seleção, habilidades, compensação, segurança do } \\
\text { empregado. Escalas, perfil profissional, regras de não } \\
\text { cruzamento, definição das escalas, dimensionamento, } \\
\text { formação prévia. }\end{array}$ \\
\hline $\begin{array}{l}\text { Planejamento do } \\
\text { trabalho e sistemas de } \\
\text { controle }\end{array}$ & $\begin{array}{l}\text { Plano agregado, planejamento, controle ou estoques } \\
\text { e/ou reservas de tempo de espera. Rotina de trabalho/ } \\
\text { processos, transporte, sequenciamento, escala de RH, } \\
\text { metas de ocupação e atravessamento. }\end{array}$ \\
\hline Instalações & $\begin{array}{l}\text { Tamanho, localização, especialização. Determinação } \\
\text { dos fluxos a fim de não ter cruzamento de área limpa } \\
\text { com área suja. }\end{array}$ \\
\hline $\begin{array}{l}\text { Medição e sistemas de } \\
\text { recompensa }\end{array}$ & $\begin{array}{l}\text { Medições, bônus, política de promoções. Mensuração } \\
\text { de produtividade, indicadores de operação, } \\
\text { reconhecimento profissional. }\end{array}$ \\
\hline Custo & $\begin{array}{l}\text { Envolve o objetivo de obter a combinação certa de } \\
\text { recursos e instalações para fornecer produtos e } \\
\text { serviços de bom valor a baixo custo. }\end{array}$ \\
\hline
\end{tabular}

3) Adequação das decisões genéricas ao contexto de saúde, através da extração de parâmetros mínimos estabelecidos pelos instrumentos normativos nacionais e das recomendações advindas de guias de boas práticas, além das 
decisões identificadas na pesquisa de campo através do mapeamento de processos, sendo tais decisões embasadas por artigos, teses e dissertações: As definiçõos das categorias de operações são insumos de decisões iniciais para formar o modelo de tomada de decisão. Contudo, não contêm todas as decisões necessárias para projetar uma CME. As decisões referentes especificamente às operações da CME precisaram ser extraídas de outras fontes. As fontes de extração utilizadas para formular as decisões de projeto de operação de CMEs são os instrumentos normativos, que estabelecem os parâmetros mínimos de projeto a serem cumpridos, guia internacional e normas de acreditação, que oferecem parâmetros de boas práticas de operações de esterilização, decisões emergentes da pesquisa de campo através do mapeamento de processos, detalhado na subseção 3.4, decisões estas embasadas por artigos nacionais e internacionais, teses e dissertações.

Devido às diversas fontes de extração das decisões para projeto de CME, foi construída a Tabela 4 para rastrear as decisões de cada categoria de operações nas fontes.

Dos instrumentais normativos emergiram decisões referentes às instalações, como por exemplo, direcionamento do fluxo de materiais e pessoas da área suja para área limpa; decisões de qualidade, como por exemplo, estabelecimento de testes químicos para validação da esterilização, dentre outras decisões por categoria de operação, conforme apresentado na Tabela 3.

A pesquisa de campo com o respectivo mapeamente dos processos, trouxe, por sua vez, a necessidade de inserir decisões de gestão, como por exemplo, decisões sobre estabelecimento de horários de atendimento e mapeamento dos roteiros de produção, fator que justificou a busca focada em artigos, guias de boas práticas, teses e dissertações para embasamento de tais decisões.

A Tabela 4 apresenta o rastreamento das fontes por categoria de operação, sendo que cada categoria possui um conjunto de decisões. A Tabela 5 mostra como exemplo, a categoria de operação Organização com suas respectivas decisões e o rastreamento das fontes utilizadas para embasar cada decisão.

A apresentação das decisões pertencentes a cada categoria de operação é apresentada na seção 4.3.

4) Articulação das decisões identificadas e listadas, estabelecendo a precedência de tomada de decisão: uma vez listada as principais decisões de projeto de operação de CMEs, passa-se para a articulação dessas decisões, que 
consiste no estabelecimento da ordem de precedência para a tomada de decisão e a divisão das decisões entre os níveis estratégico, tático e operacional. O estabelecimento da ordem de precedência das decisões é embasado nos autores clássicos de planejamento e gestão de operações. O conteúdo e os autores utilizados para construir a precedência das decisões é apresentado na Tabela 6. A ideia de articular as decisões através dos níveis estratégico, tático e operacional é inspirado pelo modelo do Langevin \& Riopel (2005). As decisões tomadas no longo prazo são enquadradas no nível estratégico, as de médio prazo são pertencentes ao nível tático e as de curto prazo são as de nível operacional.

As etapas são iterativas, isto é, o conteúdo utilizado para articular as decisões (etapa 4) também oferece insumos para a construção das decisões (etapa $3)$. 
Tabela 4 - Fontes utilizadas na construção das decisões nas categorias de operação. Elaboração própria.

$$
\text { Legislação nacional }
$$

Guia internacional e artigos nacionais e internacionais (respectivamente)

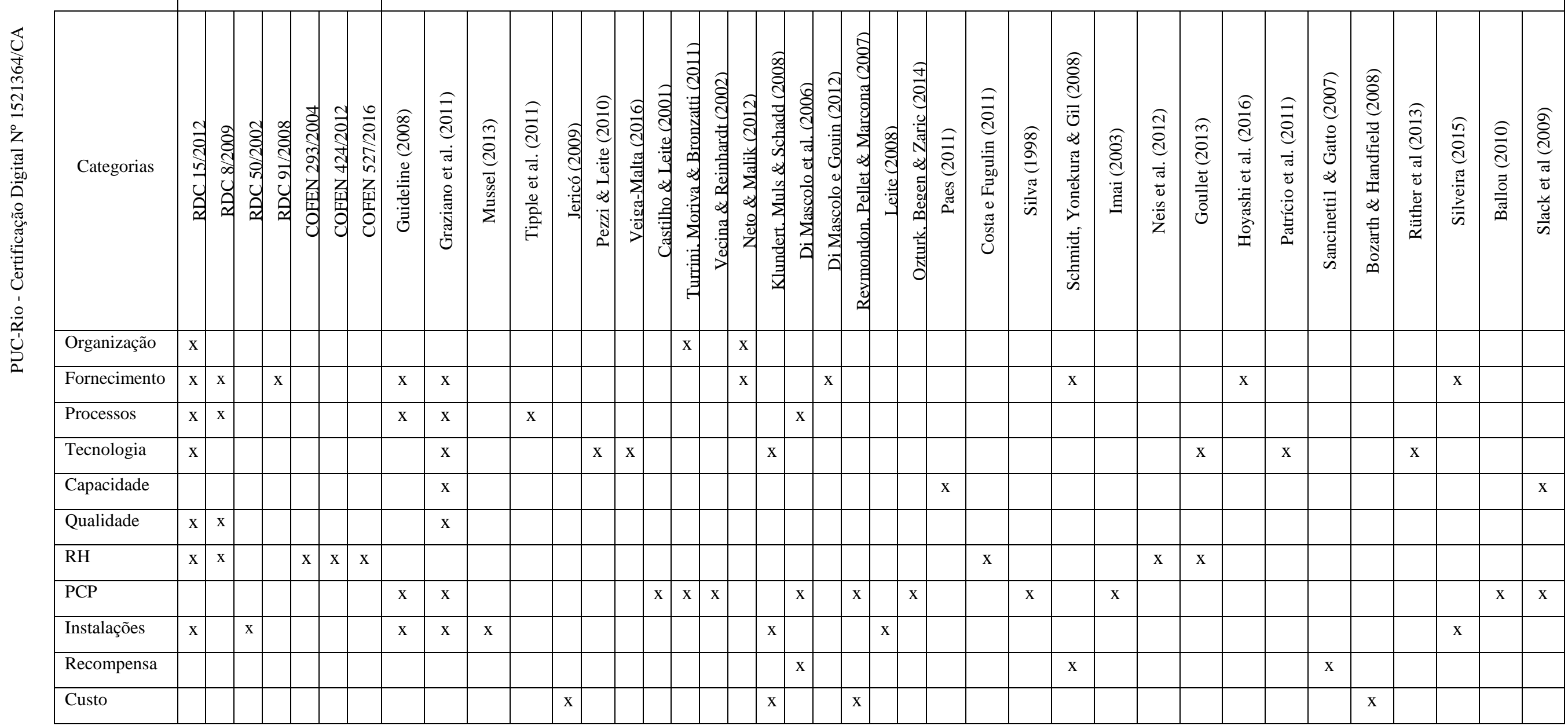


Tabela 5 - Fontes adotadas na construção das decisões da categoria de operação Organização com detalhamento das decisões. Elaoração própria.

\begin{tabular}{|c|c|c|c|}
\hline $\begin{array}{c}\text { Decisões pertencentes à categoria de } \\
\text { operação Organização }\end{array}$ & $\begin{array}{c}\text { RDC } \\
\mathbf{1 5 / 2 0 1 2}\end{array}$ & $\begin{array}{c}\text { Turrini, } \\
\text { Moriya \& } \\
\text { Bronzatti } \\
\text { (2011) }\end{array}$ & $\begin{array}{c}\text { Neto \& } \\
\text { Malik } \\
\mathbf{( 2 0 1 2}\end{array}$ \\
\hline 1. Definição das demandas & & \\
\hline $\begin{array}{c}\text { 1.1. Identificação das unidades consumidoras } \\
\text { Centro cirúrgico (eletivo, urgência e } \\
\text { emergência) }\end{array}$ & & $\mathrm{x}$ & \\
\hline Centro Obstétrico & & & $\mathrm{X}$ \\
\hline Unidades de internação & & & $\mathrm{X}$ \\
\hline Ambulatórios & & & $\mathrm{X}$ \\
\hline UTI & & & $\mathrm{X}$ \\
\hline 1.2. Definição dos níveis de serviço & $\mathrm{X}$ & \\
\hline 1.3. Priorização das demandas atendidas & & & \\
\hline 14. Mecanismos de coordenação & & $\mathrm{x}$ & \\
\hline $\begin{array}{c}\text { 14.1. Mecanismos de coordenação e } \\
\text { relações hierárquicas }\end{array}$ & $\mathrm{x}$ & & \\
\hline
\end{tabular}

Tabela 6 - Fontes e conteúdos utilizados para articulação das decisões do modelo proposto. Elaboração própria.

\begin{tabular}{|c|c|c|c|}
\hline $\begin{array}{l}\text { Categoria de } \\
\text { operacão }\end{array}$ & Descrição & Ano & Autores \\
\hline & $\begin{array}{l}\text { Decisões referentes a força de trabalho, } \\
\text { sistemas de recompensa e controle. }\end{array}$ & 2008 & $\begin{array}{l}\text { Bozarth \& } \\
\text { Handfield }\end{array}$ \\
\hline Organização & $\begin{array}{l}\text { Envolve decisões sobre a estrutura de } \\
\text { operações, papel e responsabilidades } \\
\text { das pessoas na gestão e decisões sobre } \\
\text { quais tipos de sistemas de controle e } \\
\text { recompensas }\end{array}$ & 2007 & $\begin{array}{l}\text { Rowbotham, } \\
\text { Galloway \& } \\
\text { Azhashemi }\end{array}$ \\
\hline \multirow{3}{*}{$\begin{array}{l}\text { Fornecimento e } \\
\text { integração } \\
\text { vertical }\end{array}$} & $\begin{array}{l}\text { Alternativa para obter capacidade de } \\
\text { volume dentro da organização: } \\
\text { subcontratação e desenvolvimento de } \\
\text { rede de fornecedores. Inclui custos de } \\
\text { transporte. }\end{array}$ & 2008 & Greasley \\
\hline & $\begin{array}{l}\text { Menos capacidade é requerida } \\
\text { internamente quando terceiriza } \\
\text { operação. Vantagens na terceirização: } \\
\text { exigência de menos capital investido } \\
\text { em instalações de produção e entrega, } \\
\text { flexibilidade. Desvantagens: } \\
\text { terceirizada não atender de forma } \\
\text { conforme e não atender aos } \\
\text { requerimentos. }\end{array}$ & 2008 & Greasley \\
\hline & $\begin{array}{l}\text { Comunicação efetiva entre compras e } \\
\text { operações é essencial para estabelecer } \\
\text { as corretas especificações dos } \\
\text { materiais e escolher o correto } \\
\text { fornecedor, que atenda as } \\
\text { especificações requeridas. }\end{array}$ & 2008 & Greasley \\
\hline
\end{tabular}




\begin{tabular}{|c|c|c|c|}
\hline $\begin{array}{c}\text { Categoria de } \\
\text { operação }\end{array}$ & Descrição & Ano & Autores \\
\hline \multirow{5}{*}{$\begin{array}{l}\text { Fornecimento e } \\
\text { integração } \\
\text { vertical }\end{array}$} & $\begin{array}{l}\text { O papel da função de compras é obter } \\
\text { materiais com qualidade e quantidade } \\
\text { adequadas disponíveis para uso no } \\
\text { momento certo e no preço certo. }\end{array}$ & 2007 & $\begin{array}{l}\text { Rowbotham, } \\
\text { Galloway \& } \\
\text { Azhashemi }\end{array}$ \\
\hline & $\begin{array}{l}\text { Decisões sobre quanto da operação } \\
\text { pode ser terceirizada, seleção de } \\
\text { fornecedores, acompanhamento dos } \\
\text { indicadores de desempenho do } \\
\text { fornecedor. }\end{array}$ & 2007 & $\begin{array}{l}\text { Rowbotham, } \\
\text { Galloway \& } \\
\text { Azhashemi }\end{array}$ \\
\hline & $\begin{array}{l}\text { Decisões sobre centralização e } \\
\text { descentralização. Vantagens da } \\
\text { centralização: economia de escala, } \\
\text { fácil comunicação, maior flexibilidade, } \\
\text { maior responsividade, operação mais } \\
\text { segura. }\end{array}$ & 2007 & $\begin{array}{l}\text { Rowbotham, } \\
\text { Galloway \& } \\
\text { Azhashemi }\end{array}$ \\
\hline & $\begin{array}{l}\text { Vantagem de ter parte ou todo } \\
\text { descentralizado: instalação perto da } \\
\text { fonte de matéria-prima ou força de } \\
\text { trabalho, especialização, economia de } \\
\text { escala. }\end{array}$ & 2007 & $\begin{array}{l}\text { Rowbotham, } \\
\text { Galloway \& } \\
\text { Azhashemi }\end{array}$ \\
\hline & $\begin{array}{l}\text { Identificação e quantidade de produtos } \\
\text { e serviços fornecidos, relações entre } \\
\text { comprador-fornecedor. }\end{array}$ & 2008 & $\begin{array}{l}\text { Bozarth \& } \\
\text { Handfield }\end{array}$ \\
\hline \multirow[b]{2}{*}{$\begin{array}{l}\text { Sistemas de } \\
\text { desenvolvimento } \\
\text { de processos }\end{array}$} & $\begin{array}{l}\text { Sistemas de compra, estratégias de } \\
\text { terceirização, seleção de fornecedores, } \\
\text { medida de desempenho do fornecedor }\end{array}$ & 2008 & $\begin{array}{l}\text { Bozarth \& } \\
\text { Handfield }\end{array}$ \\
\hline & $\begin{array}{l}\text { Projeto e implementação dos processos } \\
\text { de transformação que melhor atendam } \\
\text { as necessidades do consumidor e da } \\
\text { empresa. Mapeamento de processos. } \\
\text { Melhoria contínua. Desenvolvimento } \\
\text { de processos. Papel da organização e } \\
\text { dos fornecedores. }\end{array}$ & 2008 & $\begin{array}{l}\text { Bozarth \& } \\
\text { Handfield }\end{array}$ \\
\hline \multirow{3}{*}{$\begin{array}{l}\text { Informação e } \\
\text { tecnologia de } \\
\text { processo }\end{array}$} & $\begin{array}{l}\text { Decisões sobre projeto do sistema de } \\
\text { produção ou entrega de serviço e } \\
\text { organização da operação dos recursos } \\
\text { para atualizar e desenvolver novos } \\
\text { produtos e serviços. }\end{array}$ & 2007 & $\begin{array}{l}\text { Rowbotham, } \\
\text { Galloway \& } \\
\text { Azhashemi }\end{array}$ \\
\hline & $\begin{array}{l}\text { Decisões sobre processo de manufatura } \\
\text { e serviços, equipamentos de manuseio } \\
\text { manual, equipamentos de transporte, } \\
\text { sistemas de computação. }\end{array}$ & 2008 & $\begin{array}{l}\text { Bozarth \& } \\
\text { Handfield }\end{array}$ \\
\hline & $\begin{array}{l}\text { Decisões sobre tipo de equipamentos, } \\
\text { tecnologia e sistemas de acordo com a } \\
\text { qualidade, custo, velocidade, entrega e } \\
\text { flexibilidade. }\end{array}$ & 2007 & $\begin{array}{l}\text { Rowbotham, } \\
\text { Galloway \& } \\
\text { Azhashemi }\end{array}$ \\
\hline
\end{tabular}




\begin{tabular}{|c|c|c|c|}
\hline $\begin{array}{c}\text { Categoria de } \\
\text { operação }\end{array}$ & Descrição & Ano & Autores \\
\hline \multirow{4}{*}{ Capacidade } & $\begin{array}{l}\text { Alta tecnologia tende a requerer } \\
\text { maiores habilidades, melhor } \\
\text { manutenção e serviços específicos. }\end{array}$ & 2007 & $\begin{array}{l}\text { Rowbotham, } \\
\text { Galloway \& } \\
\text { Azhashemi }\end{array}$ \\
\hline & $\begin{array}{l}\text { As economias de escala referem-se aos } \\
\text { custos de capital da construção de uma } \\
\text { nova instalação e dos custos fixos de } \\
\text { operação de uma instalação. Os custos } \\
\text { de capital da construção de uma } \\
\text { instalação não aumentam } \\
\text { proporcionalmente à medida que sua } \\
\text { capacidade aumenta, então, uma } \\
\text { instalação com o dobro da capacidade } \\
\text { de outra instalação não terá custos de } \\
\text { capital duas vezes maiores. }\end{array}$ & 2008 & $\begin{array}{l}\text { Bozarth \& } \\
\text { Handfield }\end{array}$ \\
\hline & $\begin{array}{l}\text { As decisões de capacidade devem ser } \\
\text { tomadas de forma sistemática usando } \\
\text { as seguintes etapas: medir a demanda, } \\
\text { capacidade de medição, capacidade de } \\
\text { reconciliação e demanda. }\end{array}$ & 2008 & $\begin{array}{l}\text { Bozarth \& } \\
\text { Handfield }\end{array}$ \\
\hline & $\begin{array}{l}\text { Estabeleça níveis de capacidade } \\
\text { estratégica ("tijolos e argamassa") e } \\
\text { níveis de capacidade tática (força de } \\
\text { trabalho, inventário). Decisão: } \\
\text { quantidade de capacidade, tipo de } \\
\text { capacidade, calendário de mudanças de } \\
\text { capacidade. }\end{array}$ & 2008 & $\begin{array}{l}\text { Bozarth \& } \\
\text { Handfield }\end{array}$ \\
\hline \multirow{3}{*}{$\begin{array}{l}\text { Sistemas de } \\
\text { qualidade }\end{array}$} & $\begin{array}{l}\text { Decisões sobre como a capacidade da } \\
\text { operação deve ser ajustada em resposta } \\
\text { a mudanças na previsão ou na } \\
\text { demanda do mercado por seus } \\
\text { produtos e serviços. }\end{array}$ & 2007 & $\begin{array}{l}\text { Rowbotham, } \\
\text { Galloway \& } \\
\text { Azhashemi }\end{array}$ \\
\hline & $\begin{array}{l}\text { A qualidade de projeto satisfatória } \\
\text { requer uma compreensão dos } \\
\text { requisitos do cliente e especificação de } \\
\text { produto ou serviço. A entrega à } \\
\text { especificação pode ser alcançada pela } \\
\text { operação conforme ou inspeção de } \\
\text { defeitos. }\end{array}$ & 2007 & $\begin{array}{l}\text { Rowbotham, } \\
\text { Galloway \& } \\
\text { Azhashemi }\end{array}$ \\
\hline & $\begin{array}{l}\text { Todos os custos associados à } \\
\text { prevenção do fracasso e melhoria da } \\
\text { qualidade: formação de pessoal e } \\
\text { clientes: abastecimento de } \\
\text { componentes de qualidade e } \\
\text { manutenção de relações com } \\
\text { fornecedores; abastecimento de planta } \\
\text { de qualidade; manutenção de planta; } \\
\text { montagem adequada da planta; } \\
\text { redundância no produto e no processo; } \\
\text { projeto de produtos e processos. }\end{array}$ & 2007 & $\begin{array}{l}\text { Rowbotham, } \\
\text { Galloway \& } \\
\text { Azhashemi }\end{array}$ \\
\hline
\end{tabular}




\begin{tabular}{|c|c|c|c|}
\hline $\begin{array}{l}\text { Categoria de } \\
\text { operação }\end{array}$ & Descrição & Ano & Autores \\
\hline $\begin{array}{l}\text { Sistemas de } \\
\text { qualidade }\end{array}$ & $\begin{array}{l}\text { Todos os custos associados com } \\
\text { monitoramento de desempenho e } \\
\text { detecção de falha. Estes incluem: } \\
\text { inspeção; teste; custos de estoque de } \\
\text { bens para inspeção ou teste; materiais } \\
\text { testados. }\end{array}$ & 2007 & $\begin{array}{l}\text { Rowbotham, } \\
\text { Galloway \& } \\
\text { Azhashemi }\end{array}$ \\
\hline & $\begin{array}{l}\text { O controle requer medição e um } \\
\text { padrão de desempenho para comparar } \\
\text { a medida. }\end{array}$ & 2007 & $\begin{array}{l}\text { Rowbotham, } \\
\text { Galloway \& } \\
\text { Azhashemi }\end{array}$ \\
\hline $\begin{array}{l}\text { Sistemas de } \\
\text { recursos humanos }\end{array}$ & $\begin{array}{l}\text { A função pessoal é responsável por } \\
\text { recrutar e desenvolver a força de } \\
\text { trabalho necessária por várias funções } \\
\text { internas. Como tal, pode influenciar o } \\
\text { desempenho da função de operações } \\
\text { ao ter a estratégia de recrutamento } \\
\text { correta e selecionar e capacitar as } \\
\text { pessoas certas para os empregos } \\
\text { corretos. O pessoal também é } \\
\text { responsável pela saúde e segurança de } \\
\text { todos os funcionários. }\end{array}$ & 2007 & $\begin{array}{l}\text { Rowbotham, } \\
\text { Galloway \& } \\
\text { Azhashemi }\end{array}$ \\
\hline \multirow{6}{*}{$\begin{array}{l}\text { Planejamento do } \\
\text { trabalho e } \\
\text { sistemas de } \\
\text { controle }\end{array}$} & $\begin{array}{l}\text { Decisões sobre como o pessoal da } \\
\text { operação é selecionado, organizado e } \\
\text { desenvolvido, e qual o papel e } \\
\text { combinação de habilidades que eles } \\
\text { devem fornecer para contribuir com a } \\
\text { gestão da operação. }\end{array}$ & 2007 & $\begin{array}{l}\text { Rowbotham, } \\
\text { Galloway \& } \\
\text { Azhashemi }\end{array}$ \\
\hline & $\begin{array}{l}\text { Carregamento (determinar capacidade } \\
\text { e volumes), seqüienciamento (decidir } \\
\text { sobre a ordem de execução do } \\
\text { trabalho) e agendamento (alocando um } \\
\text { tempo de início e término para uma } \\
\text { ordem do cliente). }\end{array}$ & 2008 & Greasley \\
\hline & $\begin{array}{l}\text { Programação e gerenciamento do fluxo } \\
\text { de trabalho através de uma } \\
\text { organização e da cadeia de } \\
\text { suprimentos; combinação da demanda } \\
\text { do cliente com as atividades da cadeia } \\
\text { de suprimentos. }\end{array}$ & 2008 & $\begin{array}{l}\text { Bozarth \& } \\
\text { Handfield }\end{array}$ \\
\hline & $\begin{array}{l}\text { Previsão, planejamento tático, } \\
\text { gerenciamento de estoque, } \\
\text { planejamento e controle de producão. }\end{array}$ & 2008 & $\begin{array}{l}\text { Bozarth \& } \\
\text { Handfield }\end{array}$ \\
\hline & $\begin{array}{l}\text { Organização do fluxo ordenado de } \\
\text { recursos para que os objetivos possam } \\
\text { ser atendidos. Verificar o desempenho } \\
\text { da operação em relação aos padrões } \\
\text { esperados. }\end{array}$ & 2007 & $\begin{array}{l}\text { Rowbotham, } \\
\text { Galloway \& } \\
\text { Azhashemi }\end{array}$ \\
\hline & $\begin{array}{l}\text { Decisões sobre como a operação deve } \\
\text { planejar suas atividades futuras e } \\
\text { decidir, alocar e controlar seus } \\
\text { recursos para atender a expectativa de } \\
\text { demanda. }\end{array}$ & 2007 & $\begin{array}{l}\text { Rowbotham, } \\
\text { Galloway \& } \\
\text { Azhashemi }\end{array}$ \\
\hline
\end{tabular}




\begin{tabular}{|c|c|c|c|}
\hline $\begin{array}{c}\text { Categoria de } \\
\text { operação }\end{array}$ & Descrição & Ano & Autores \\
\hline \multirow{3}{*}{ Instalações } & $\begin{array}{l}\text { Decisões sobre a quantidade de } \\
\text { estoque que a operação deve realizar e } \\
\text { onde ela deve estar localizada. }\end{array}$ & 2007 & $\begin{array}{l}\text { Rowbotham, } \\
\text { Galloway \& } \\
\text { Azhashemi }\end{array}$ \\
\hline & $\begin{array}{l}\text { Layout: colocação física de recursos } \\
\text { como equipamentos e instalações de } \\
\text { armazenamento a fim de facilitar o } \\
\text { fluxo eficiente de clientes ou materiais } \\
\text { através do sistema de fabricação ou } \\
\text { serviço. }\end{array}$ & 2008 & Greasley \\
\hline & $\begin{array}{l}\text { Efeito significativo no custo e } \\
\text { eficiência da operação e pode implicar } \\
\text { em investimento substancial de tempo } \\
\text { e dinheiro. }\end{array}$ & 2008 & Greasley \\
\hline $\begin{array}{l}\text { Medição e } \\
\text { sistemas de } \\
\text { recompensa }\end{array}$ & $\begin{array}{l}\text { Decisões quanto ao tamanho, número } \\
\text { de instalações e localização da } \\
\text { operação, quais atividades devem ser } \\
\text { alocadas para a operação e onde as } \\
\text { instalações da operação devem estar } \\
\text { localizadas. }\end{array}$ & 2007 & $\begin{array}{l}\text { Rowbotham, } \\
\text { Galloway \& } \\
\text { Azhashemi }\end{array}$ \\
\hline \multirow{3}{*}{ Custo } & $\begin{array}{l}\text { Decisões sobre como o desempenho da } \\
\text { operação deve ser medido e } \\
\text { melhorado, quem deve estar envolvido } \\
\text { no processo de melhoria e como o } \\
\text { processo deve ser gerenciado. Forma } \\
\text { como a operação organiza seus } \\
\text { recursos para evitar falhas e lidar com } \\
\text { a interrupção se a falha ocorrer. }\end{array}$ & 2007 & $\begin{array}{l}\text { Rowbotham, } \\
\text { Galloway \& } \\
\text { Azhashemi }\end{array}$ \\
\hline & $\begin{array}{l}\text { O trade-off econômico clássico entre } \\
\text { os custos mostra que, quando o custo } \\
\text { de alcançar boa qualidade (isto é, } \\
\text { custos de prevenção e avaliação) } \\
\text { aumenta, o custo da má qualidade } \\
\text { (custos de falha interna e externa) } \\
\text { diminui. }\end{array}$ & 2008 & Greasley \\
\hline & $\begin{array}{l}\text { O custo significa fazer coisas de forma } \\
\text { econômica. Envolve o objetivo de } \\
\text { obter a combinação certa de recursos e } \\
\text { instalações para fornecer produtos e } \\
\text { serviços de bom valor a baixo custo. A } \\
\text { eficiência de custos pode ser alcançada } \\
\text { através do aumento da capacidade de } \\
\text { utilização, redução de despesas gerais, } \\
\text { equipamentos e instalações multi-usos } \\
\text { e maior produtividade. }\end{array}$ & 2007 & $\begin{array}{l}\text { Rowbotham, } \\
\text { Galloway \& } \\
\text { Azhashemi }\end{array}$ \\
\hline
\end{tabular}

O resultado das etapas de construção é a estruturação do modelo de referência para tomada de decisão de projeto de CMEs. As decisões e as respectivas articulações são apresentadas na subseção 4.3. 


\section{2}

\section{Validação do modelo}

A estrutura do modelo de referência foi apresentada para as chefias do CME HUPE e CME PPC (chefias do complexo da UERJ) para executar a etapa de validação do modelo com especialistas da área. A qualificação técnica dos especialistas é apresentada na Tabela 7.

Tabela 7 - Qualificação profissional dos especialistas avaliadores. Elaboração própria.

\begin{tabular}{|l|l|l|}
\hline $\begin{array}{l}\text { Qualificação } \\
\text { profissional }\end{array}$ & Chefia CME HUPE & Chefia CME PPC \\
\hline Nível de instrução & Mestre em Enfermagem & Doutora em Enfermagem \\
\hline Atuação profissional & Coordenador CME/HUPE & Coordenadora CME/PPC \\
\hline Atividade de ensino & $\begin{array}{l}\text { Prof. Faculdade de } \\
\text { Enfermagem da } \\
\text { Universidade Veiga de } \\
\text { Almeida (UVA) }\end{array}$ & $\begin{array}{l}\text { Prof. Faculdade de } \\
\text { Enfermagem da } \\
\text { Universidade do Estado do } \\
\text { Rio de Janeiro (UERJ) }\end{array}$ \\
\hline
\end{tabular}

As entrevistas de validação do modelo com os especialistas foram realizadas em dias separados para cada especialista, isto é, cada especialista emitiu seu parecer sobre o modelo de forma individual.

Houve proposta de mudanças de alguns conteúdos no detalhamento das decisões, a serem expostos na Tabela 40, apresentada no Apêndice deste documento. A Tabela 40 apresenta as propostas de incremento e modificação de conteúdo, sem mudança na lista de decisão e precedência, sendo tais ajustes rastreados por chefia. Os conteúdos do modelo não enquadrados nas descrições anteriores foram aprovados pelas chefias do complexo UERJ.

As mudanças propostas pelos avaliadores compostos pelas chefias do complexo UERJ serão incorporadas na estrutura do modelo apresentada na seção 4.3 .

Ressalta-se que as mudanças propostas na validação são localizadas nos níveis estratégicos e tático, não tendo mudanças nas decisões do nível operacional.

\section{3}

\section{Estrutura e refinamento do modelo de referência}

A estrutura do modelo de referência é formada por 31 decisões principais a serem tomadas quanto ao projeto de operação de um CME. As subdecisões das decisões principais também são apresentadas no modelo. As decisões são articuladas através da numeração da ordenação de tomada de decisão. As 
subdecisões possuem a numeração da decisão principal seguida da subnumeração. Quando duas subdecisões possuem a mesma numeração, a precedência de decisão é indiferente. A descrição e o detalhamento das decisões e respectivas subdecisões são apresentados nas tabelas localizadas abaixo de cada bloco de decisão.

O refinamento da estrutura do modelo de tomada de decisão proposto consiste na incorporação das mudanças propostas na etapa de validação (seção $4.2)$.

As decisões principais do modelo de referência proposto, a articulação entre as decisões e a localização das mesmas nas categorias de operação são apresentadas através do framework proposto na Figura 5. 

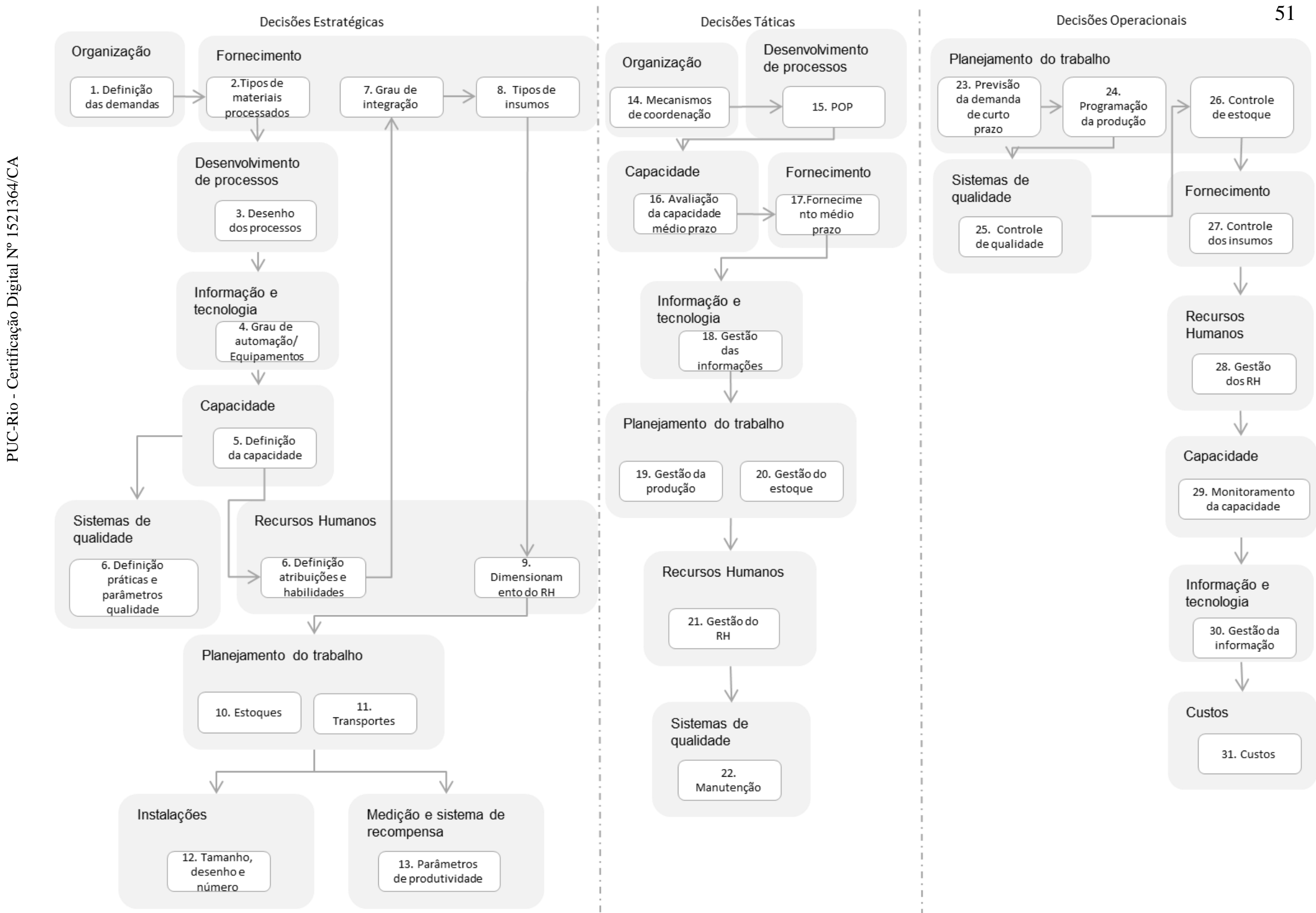

Figura 5 - Framework do modelo de referência de tomada de decisão de projeto de operação de CMEs. Elaboração própria. 
Decisões Estratégicas

\begin{tabular}{|c|c|c|c|c|c|c|}
\hline \multirow{5}{*}{$\begin{array}{l}\text { 1. Definição } \\
\text { das demandas }\end{array}$} & \multicolumn{6}{|c|}{ 1.1. Identificação das unidades consumidoras } \\
\hline & $\begin{array}{l}\text { Centro } \\
\text { Cirúrgico }\end{array}$ & $\begin{array}{l}\text { Centro } \\
\text { Obstétrico }\end{array}$ & $\begin{array}{l}\text { Unidades de } \\
\text { internação }\end{array}$ & Ambulatórios & UTI & Imagem \\
\hline & \multicolumn{6}{|c|}{$\begin{array}{l}\text { Eletivo } \\
\text { Urgência } \\
\text { Emergência }\end{array}$} \\
\hline & \multicolumn{6}{|c|}{ 1.2. Definição dos níveis de serviço } \\
\hline & \multicolumn{6}{|c|}{ 1.3. Priorização das demandas atendidas } \\
\hline
\end{tabular}

Figura 6 - Estrutura do modelo de referência referente à decisão um. Elaboração própria.

Tabela 8 - Regras de projeto para executar o modelo de tomada de decisão referente à decisão um. Elaboração própria.

\section{Definição das demandas}

\subsection{Identificação das unidades consumidoras}

\begin{tabular}{|c|c|c|c|c|}
\hline $\begin{array}{l}\text { Centro Cirúrgico } \\
\text { (CC) }\end{array}$ & $\begin{array}{l}\text { Centro } \\
\text { obstétrico }\end{array}$ & $\begin{array}{l}\text { Unidades de } \\
\text { internação }\end{array}$ & Ambulatórios & UTI \\
\hline $\begin{array}{l}\text { Geralmente visto } \\
\text { como mais um } \\
\text { setor do hospital, } \\
\text { deve ser visto } \\
\text { como a unidade } \\
\text { central do } \\
\text { hospital no século } \\
\text { XXI, visto que o } \\
\text { hospital atende } \\
\text { mais pacientes } \\
\text { graves e estes } \\
\text { serão pacientes } \\
\text { cirúrgicos em } \\
\text { algumas fases de } \\
\text { seu tratamento } \\
\text { (Neto \&Malik, } \\
\text { 2012). }\end{array}$ & $\begin{array}{l}\text { Estrutura } \\
\text { para } \\
\text { realização de } \\
\text { partos (Neto } \\
\& \text { Malik, } \\
\text { 2012). }\end{array}$ & $\begin{array}{l}\text { Estruturas } \\
\text { para atender } \\
\text { as } \\
\text { necessidades } \\
\text { do paciente } \\
\text { internado } \\
\text { (Neto } \\
\text { \&Malik, } \\
\text { 2012). }\end{array}$ & $\begin{array}{l}\text { Contempla } \\
\text { consultas médicas e } \\
\text { da equipe } \\
\text { multiprofissional, } \\
\text { procedimentos } \\
\text { cirúrgicos } \\
\text { tecnicamente } \\
\text { adequados ao } \\
\text { ambiente } \\
\text { ambulatorial, } \\
\text { procedimentos } \\
\text { diagnósticos, } \\
\text { procedimentos } \\
\text { terapêuticos de } \\
\text { reabilitação, } \\
\text { hemoterapia, } \\
\text { medicamentosos e } \\
\text { comportamentais, } \\
\text { além de ações de } \\
\text { educação em saúde, } \\
\text { individuais ou em } \\
\text { grupo (Neto } \\
\text { \&Malik, 2012). }\end{array}$ & $\begin{array}{l}\text { Unidade voltada para o } \\
\text { atendimento de } \\
\text { pacientes clinicamente } \\
\text { instáveis, que } \\
\text { necessitam de } \\
\text { monitoramento, apoio } \\
\text { de equipamentos de } \\
\text { ventilação mecânica e, } \\
\text { sobretudo, estar sob } \\
\text { vigilância contínua e } \\
\text { direta de uma equipe } \\
\text { multiprofissional } \\
\text { (Neto \&Malik, 2012). }\end{array}$ \\
\hline
\end{tabular}




\begin{tabular}{|c|c|c|c|c|}
\hline $\begin{array}{l}\text { Centro cirúrgico } \\
\text { eletivo: centro } \\
\text { destinado a } \\
\text { cirurgias não } \\
\text { urgentes e } \\
\text { emergentes, isto } \\
\text { é, que podem ser } \\
\text { agendadas sem } \\
\text { que haja risco de } \\
\text { morte para o } \\
\text { paciente (Neto } \\
\& \text { Malik, 2012). }\end{array}$ & & & & \\
\hline $\begin{array}{l}\text { Centro cirúrgico } \\
\text { de urgência / } \\
\text { emergência: } \\
\text { centro destinado a } \\
\text { cirurgias de } \\
\text { urgência e } \\
\text { emergência (Neto } \\
\text { \&Malik, 2012). }\end{array}$ & & & & \\
\hline \multicolumn{5}{|c|}{ 1.1. Definição dos níveis de serviço } \\
\hline $\begin{array}{l}\text { Centro Cirúrgico } \\
\text { (CC) }\end{array}$ & $\begin{array}{l}\text { Centro } \\
\text { obstétrico }\end{array}$ & $\begin{array}{l}\text { Unidades de } \\
\text { internação }\end{array}$ & Ambulatórios & UTI \\
\hline $\begin{array}{l}\text { Centro cirúrgico } \\
\text { eletivo: o } \\
\text { atendimento à } \\
\text { demanda pode ser } \\
\text { programado (Neto } \\
\& \text { Malik, 2012). }\end{array}$ & $\begin{array}{l}\text { O } \\
\text { atendimento } \\
\text { à demanda } \\
\text { pode ser } \\
\text { programado } \\
\text { ou atuar em } \\
\text { regime de } \\
\text { emergência } \\
\text { (Neto } \\
\text { \&Malik, } \\
\text { 2012). }\end{array}$ & $\begin{array}{l}\text { O } \\
\text { atendimento } \\
\text { à demanda } \\
\text { pode ser } \\
\text { programado } \\
\text { (Neto } \\
\text { \&Malik, } \\
\text { 2012). }\end{array}$ & $\begin{array}{l}\text { O atendimento à } \\
\text { demanda pode ser } \\
\text { programado (Neto } \\
\& \text { Malik, 2012). }\end{array}$ & $\begin{array}{l}\text { Pode ser programado } \\
\text { ou atuar em regime de } \\
\text { emergência (Neto } \\
\& \text { Malik, 2012). }\end{array}$ \\
\hline $\begin{array}{l}\text { Centro cirúrgico } \\
\text { de urgência: o } \\
\text { atendimento à } \\
\text { demanda pode ser } \\
\text { programado em } \\
\text { até 30h. } \\
\text { Centro cirúrgico } \\
\text { de emergência: } \\
\text { atendimento } \\
\text { imediato (Neto } \\
\text { \&Malik, 2012). }\end{array}$ & & & & \\
\hline \multicolumn{5}{|c|}{ 1.2. Priorização das demandas atendidas } \\
\hline $\begin{array}{l}\text { Centro Cirúrgico } \\
\text { (CC) }\end{array}$ & $\begin{array}{l}\text { Centro } \\
\text { obstétrico }\end{array}$ & $\begin{array}{l}\text { Unidades de } \\
\text { internação }\end{array}$ & Ambulatórios & UTI \\
\hline $\begin{array}{l}\text { Atendimento } \\
\text { prioritário } \\
\text { (Turrini, Moriya, } \\
\text { Bronzatti, 2011). }\end{array}$ & & & & \\
\hline
\end{tabular}




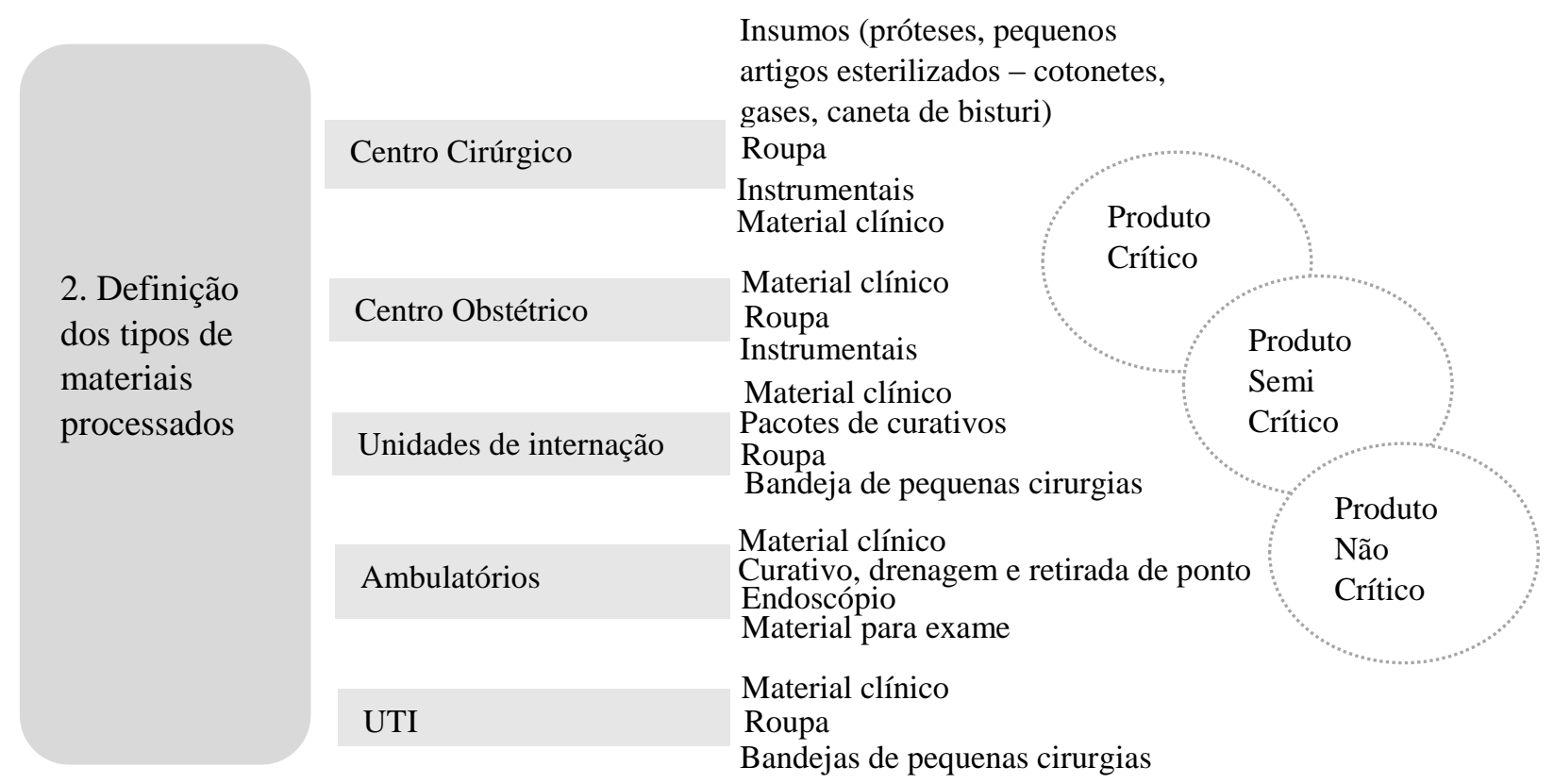

Figura 7 - Estrutura do modelo de referência referente à decisão dois. Elaboração própria.

Tabela 9- Regras de projeto para executar o modelo de tomada de decisão referente à decisão dois. Elaboração própria.

2. Definição dos tipos de materiais processados

\begin{tabular}{|c|c|c|c|c|}
\hline $\begin{array}{l}\text { Centro } \\
\text { Cirúrgico (CC) }\end{array}$ & $\begin{array}{l}\text { Centro } \\
\text { obstétrico }\end{array}$ & $\begin{array}{l}\text { Unidades de } \\
\text { internacão }\end{array}$ & Ambulatórios & UTI \\
\hline $\begin{array}{l}\text { Instrumentos } \\
\text { cirúrgicos, } \\
\text { catéteres } \\
\text { cardíacos e } \\
\text { urinários, } \\
\text { implantes, } \\
\text { roupa } \\
\text { (Guideline, } \\
\text { 2008). }\end{array}$ & $\begin{array}{l}\text { Instrumental, } \\
\text { roupa e } \\
\text { material clínico } \\
\text { (Guideline, } \\
\text { 2008). }\end{array}$ & $\begin{array}{l}\text { Material clínico } \\
\text { (equipamentos } \\
\text { de terapia } \\
\text { respiratória e } \\
\text { anestesia, cânula } \\
\text { endotraqueal, } \\
\text { equipamento } \\
\text { respiratório, } \\
\text { cuba-rim, bacias, } \\
\text { etc.), roupa e } \\
\text { bandejas de } \\
\text { pequenas } \\
\text { cirurgias } \\
\text { (Guideline, } \\
\text { 2008). }\end{array}$ & $\begin{array}{l}\text { Material } \\
\text { clínico, } \\
\text { endoscópios e } \\
\text { bandeja de } \\
\text { pequenas } \\
\text { cirurgias } \\
\text { (Guideline, } \\
\text { 2008). }\end{array}$ & $\begin{array}{l}\text { Material } \\
\text { clínico, roupa } \\
\text { e bandejas de } \\
\text { pequenas } \\
\text { cirurgias } \\
\text { (Guideline, } \\
\text { 2008). }\end{array}$ \\
\hline
\end{tabular}

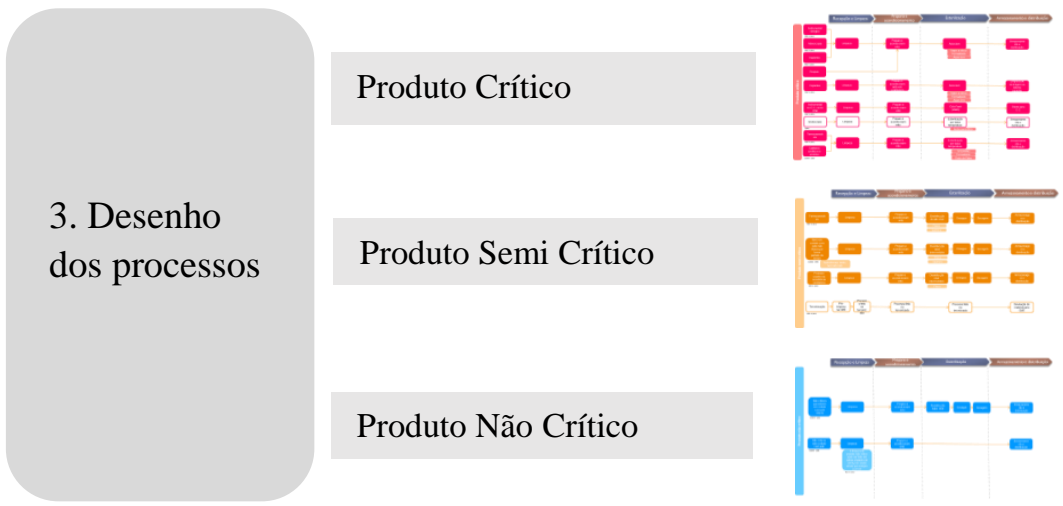

Figura 8 - Estrutura do modelo de referência referente à decisão três. Elaboração própria. 
Tabela 10- Regras de projeto para executar o modelo de tomada de decisão referente à decisão três. Elaboração própria.

\begin{tabular}{|c|c|c|}
\hline Produtos críticos & Produtos semicríticos & Produtos não críticos \\
\hline $\begin{array}{l}\text { Artigos destinados aos } \\
\text { procedimentos invasivos } \\
\text { em pele e mucosas } \\
\text { adjacentes, nos tecidos } \\
\text { subepiteliais e no sistema } \\
\text { vascular, bem como todos } \\
\text { que estejam diretamente } \\
\text { conectados com esse } \\
\text { sistema. Estes requerem } \\
\text { esterilização (Neto } \\
\& \text { Malik, 2012). }\end{array}$ & $\begin{array}{l}\text { Artigos que entram em } \\
\text { contato com a pele não } \\
\text { íntegra, porém esse } \\
\text { contato é restrito às } \\
\text { camadas da pele ou com } \\
\text { mucosas íntegras. } \\
\text { Requerem desinfecção de } \\
\text { médio ou de alto nível ou } \\
\text { esterilização (Neto } \\
\text { \&Malik, 2012). }\end{array}$ & $\begin{array}{l}\text { Artigos destinados ao contato } \\
\text { com a pele íntegra e também } \\
\text { os que não entram em contato } \\
\text { direto com o paciente. } \\
\text { Requerem limpeza ou } \\
\text { desinfecção de baixo ou } \\
\text { médio nível, dependendo do } \\
\text { uso a que se destinam ou do } \\
\text { último uso realizado (Neto } \\
\text { \&Malik, 2012). }\end{array}$ \\
\hline $\begin{array}{l}\text { Instrumentos cirúrgicos, } \\
\text { catéteres cardíacos e } \\
\text { urinários, implantes, } \\
\text { sondas de ultrassom } \\
\text { utilizadas em cavidades do } \\
\text { corpo (Guideline, 2008). }\end{array}$ & $\begin{array}{l}\text { Equipamentos de terapia } \\
\text { respiratória e anestesia, } \\
\text { alguns endoscópios, } \\
\text { lâminas de laringoscópio, } \\
\text { sondas de manometria } \\
\text { esofágica, cistoscópios, } \\
\text { cateteres de manometria } \\
\text { anorretal e anéis de ajuste } \\
\text { de diafragma (Guideline, } \\
\text { 2008). }\end{array}$ & $\begin{array}{l}\text { Termômetro, materiais usados } \\
\text { em banho de leito com bacias, } \\
\text { cuba-rim, estetoscópio, roupas } \\
\text { de cama do paciente etc. } \\
\text { (Guideline, 2008). }\end{array}$ \\
\hline
\end{tabular}

A presente pesquisa sugere o desenho dos processos existentes no CME a partir dos roteiros de processamento para os diferentes produtos, de acordo com o nível de criticidade, apresentados nas Figura 9, Figura 8 e Figura 9. Os roteiros de processamento traçados para os produtos crítico, semicrítico e não crítico foram elaborados a partir do mapeamento dos processos realizados nos CMEs pertencentes ao complexo UERJ, entrevistas realizadas com as chefias dos CMEs UERJ e enfermeiros responsáveis pelos turnos e discussões com a diretoria do HUPE e chefias dos CMEs para proposição final dos roteiros.

Desenhar os processos do CME a partir dos roteiros justifica-se pela peculiaridade de processamento existente para cada tipo de produto dentro de cada categoria de criticidade (crítico, semicrítico e não crítico). Detalhar as peculiaridades existentes para processar cada tipo de produto no desenho dos processos permite a assertividade de ação pelos profissionais que operam o processamento, visto que, uma vez identificado o tipo de produto na etapa de recebimento do material na área de recepção e limpeza, pode-se encaminhar o produto para uma estrutura de processamento específica. 


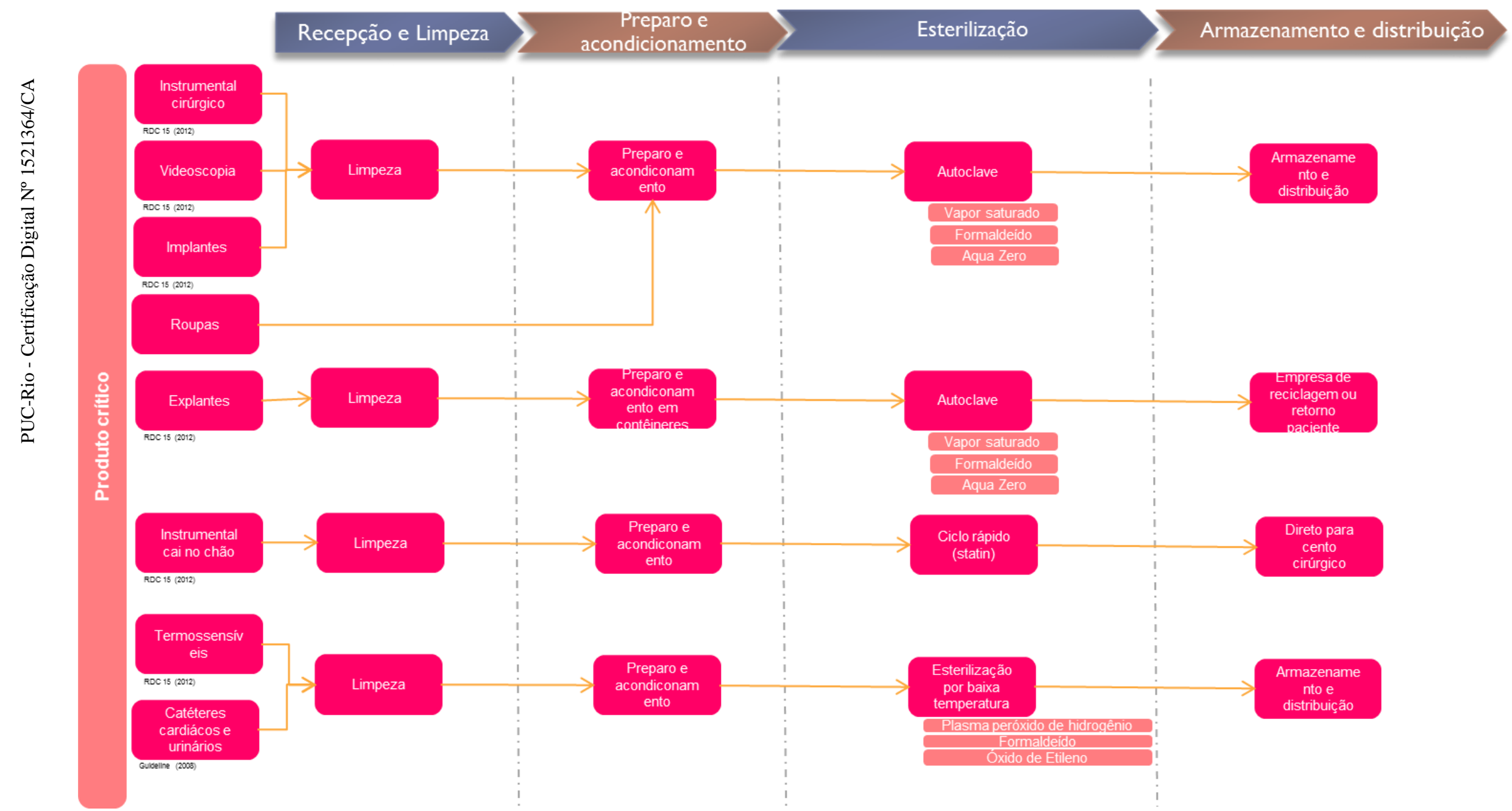

Figura 9 - Framework dos possíveis roteiros de processamento para os produtos críticos. Elaboração própria. 


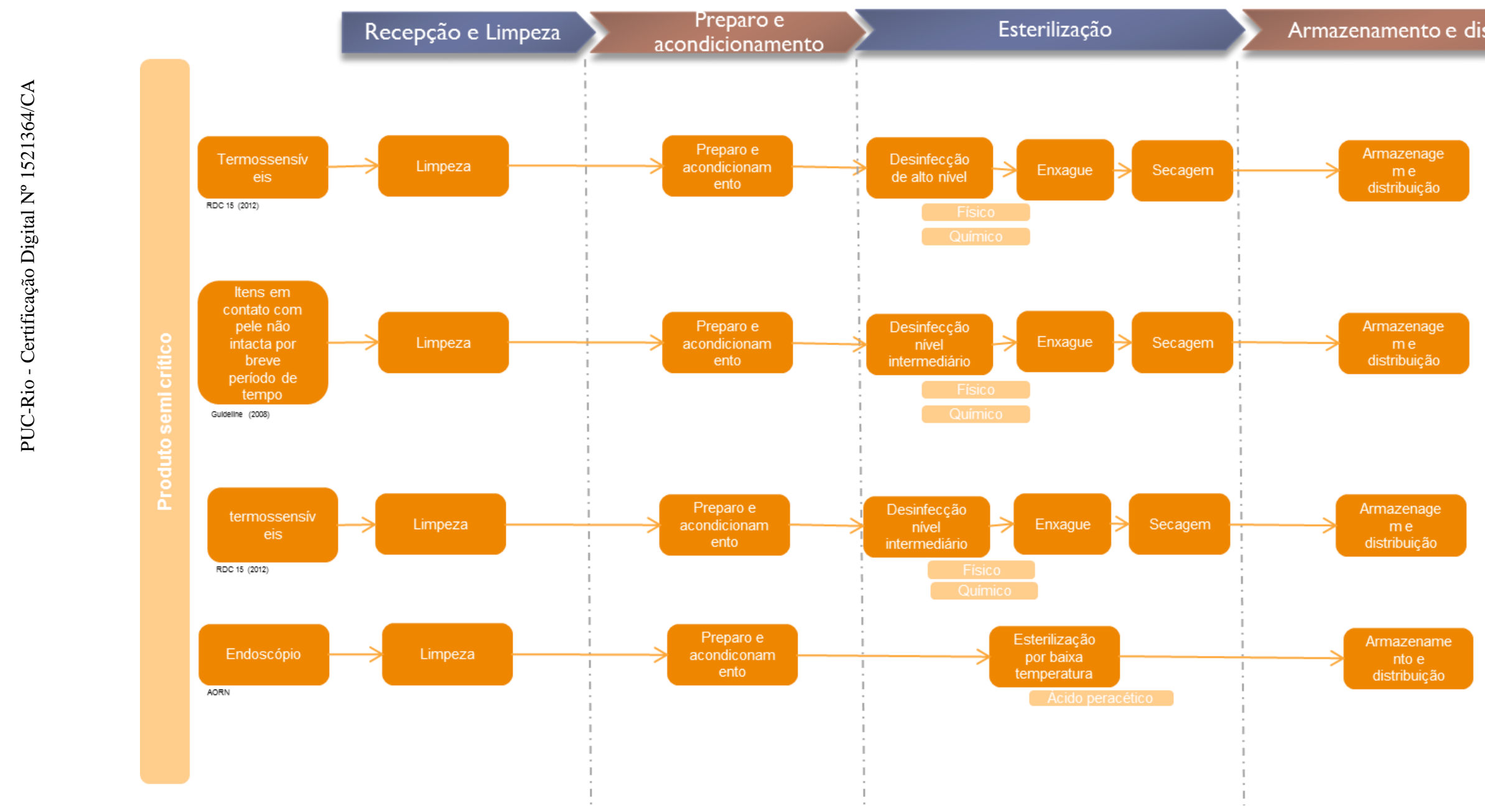

Figura 10 - Framework dos possíveis roteiros de processamento para os produtos semi críticos. Elaboração própria. 


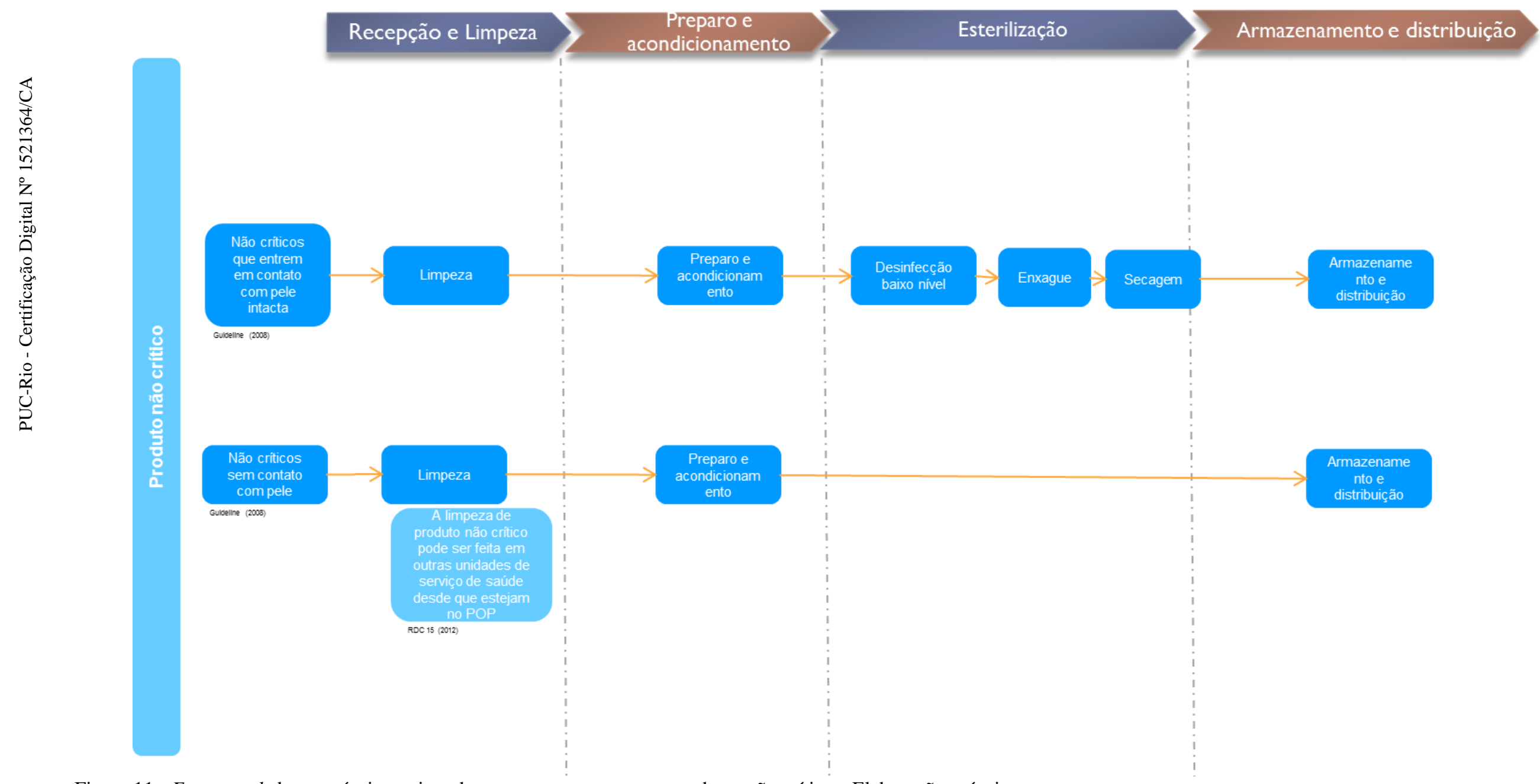

Figura 11 - Framework dos possíveis roteiros de processamento para os produtos não críticos. Elaboração própria. 
4.1. Definição do grau de automação

Sistema de registro de informação

4. Grau de automação / Equipamentos

Sistema de rastreamento do material

RFID

Leitor magnético

\subsection{Equipamentos}

$\begin{array}{llll}\text { Recepção } & \text { Preparo } & \text { Esterilização } & \text { Armazenagem } \\ \text { Lavadora } & \text { Seladora térmica } & \text { Autoclave } & \text { Esterilizador plasma } \\ \text { ultrassônica } & & \text { peróxido de hidrogênio } \\ \text { Termodesinfectadora } & \text { Esterilizador ciclo rápido (statin) } \\ & \text { Incubadoras }\end{array}$

Figura 12 - Estrutura do modelo de referência referente à decisão quatro. Elaboração própria.

Tabela 11 - Regras de projeto para executar o modelo de tomada de decisão referente à decisão quatro. Elaboração própria.

\begin{tabular}{|l|l|}
\hline \multicolumn{1}{|c|}{ 4. Grau de automação / Equipamentos } \\
\hline \multicolumn{1}{|c|}{ 4.1. Definição do grau de automação } \\
\hline \multicolumn{1}{|c|}{ Sistema de registro de informação } & \multicolumn{1}{c|}{ Sistema de rastreamento do material } \\
\hline $\begin{array}{l}\text { Documentação dos processos de } \\
\text { esterilização no CME Classe II e na } \\
\text { empresa processadora para garantir a } \\
\text { rastreabilidade de cada lote processado } \\
\text { RDC 15, 2012). }\end{array}$ & $\begin{array}{l}\text { Utilização do recurso de código de barras, aplicado } \\
\text { tanto aos instrumentos quanto às caixas-padrão de } \\
\text { instrumental. Quando os instrumentos ou caixas são } \\
\text { dotados de um código de barras, é possível fazer o } \\
\text { monitoramento do item e também obter informações } \\
\text { exatas sobre a quantidade de algum item em } \\
\text { particular que está em circulação, de uma forma } \\
\text { melhor do que quando se possui apenas o sistema } \\
\text { estático de inventário (Graziano et al., 2011). }\end{array}$ \\
\hline $\begin{array}{l}\text { Instalação de pontos de controle nos } \\
\text { diversos locais do CME, como expurgo, } \\
\text { área de preparo, esterilização e } \\
\text { armazenagem e distribuição, compilação } \\
\text { pelo computador. Os dados armazenados } \\
\text { incluem registros tanto sobre o } \\
\text { processamento quanto sobre os funcionários } \\
\text { que realizaram as atividades, pois cada } \\
\text { operador tem uma senha de acesso } \\
\text { individual (Graziano et al., 2011). }\end{array}$ & $\begin{array}{l}\text { Uso da tecnologia RFID para rastreamento dos } \\
\text { instrumentos cirúrgicos a fim de controlar saída, } \\
\text { percurso e entrada dos materiais no CME (Klundert, } \\
\text { Muls e Schadd, 2008). }\end{array}$ \\
\hline $\begin{array}{l}\text { Sistema de assistência para área de limpeza } \\
\text { de CME para suporte aos trabalhadores no } \\
\text { contexto de informação para o correto } \\
\text { tratamento dos instrumentais médicos e } \\
\text { para a correta carga nas lavadoras } \\
\text { ultrassônicas e desinfectadoras. Esse } \\
\text { sistema dá suporte aos trabalhadores na } \\
\text { mudança dinâmica nos estoques de } \\
\text { instrumentais médicos (Rüther et al., 2013). }\end{array}$ & $\begin{array}{l}\text { Sistema de identificação eletrônico: os instrumentos } \\
\text { são controlados por sistemas ópticos ou leitor } \\
\text { magnético. Com esse sistema, o material pode ser } \\
\text { acompanhado por meio de um software a partir de } \\
\text { sua chegada ao hospital até o momento de seu } \\
\text { processamento (Graziano et al., 2011). }\end{array}$ \\
\hline
\end{tabular}




\begin{tabular}{|c|c|c|c|}
\hline & & \multicolumn{2}{|c|}{$\begin{array}{l}\text { Benefícios com a adoção de sistema de rastreamento } \\
\text { do material: otimização do tempo do funcionário na } \\
\text { montagem da caixa, menor conhecimento a respeito } \\
\text { dos nomes dos instrumentos, melhor controle de } \\
\text { desvios e desaparecimentos e controle da qualidade } \\
\text { do material (Graziano et al., 2011). }\end{array}$} \\
\hline \multicolumn{4}{|c|}{ 1.1. Equipamentos } \\
\hline $\begin{array}{l}\text { Recepção e } \\
\text { Limpeza }\end{array}$ & $\begin{array}{l}\text { Preparo e } \\
\text { acondicionamento }\end{array}$ & Esterilização & $\begin{array}{l}\text { Armazenagem e } \\
\text { Distribuição }\end{array}$ \\
\hline \multirow{3}{*}{$\begin{array}{l}\text { Lavadora } \\
\text { ultrassônica (Neis } \\
\text { et al., 2012). }\end{array}$} & $\begin{array}{l}\text { Secadora (Neis et al., } \\
\text { 2012). }\end{array}$ & $\begin{array}{l}\text { Autoclave Termoseladora } \\
\text { (RDC 15, 2012). }\end{array}$ & \\
\hline & $\begin{array}{l}\text { Termodesinfectadora } \\
\text { (Neis et al., 2012). }\end{array}$ & $\begin{array}{l}\text { Equipamento de } \\
\text { esterilização de plasma de } \\
\text { peróxido de hidrogênio } \\
\text { (Sterrad) (Neis et al., } \\
\text { 2012). }\end{array}$ & \\
\hline & $\begin{array}{l}\text { Termoseladora (RDC } \\
15,2012) \text {. }\end{array}$ & $\begin{array}{l}\text { Incubadora (Neis et al., } \\
\text { 2012). }\end{array}$ & \\
\hline
\end{tabular}

5.1. Definição da quantidade máxima produzida de cada tipo de produto processado

Especificação dos produtos

Tempo de processamento para cada tipo de produto

5. Definição da capacidade

Fator de segurança

Grau de perecibilidade da operação

Variação da demanda

Adequações de insumos

5.2. Identificação de capacidades alternativas

Figura 13 - Estrutura do modelo de referência referente à decisão cinco. Elaboração própria. 
Tabela 12 - Regras de projeto para executar o modelo de tomada de decisão referente à decisão cinco. Elaboração própria.

\section{Definição da capacidade}

1.1. Definição da quantidade máxima produzida de cada tipo de produto processado

\begin{tabular}{|c|c|c|c|}
\hline \multirow{2}{*}{$\begin{array}{l}\text { Especificação } \\
\text { dos produtos }\end{array}$} & \multirow{2}{*}{$\begin{array}{c}\text { Tempo de } \\
\text { processamento para } \\
\text { cada tipo de produto }\end{array}$} & \multicolumn{2}{|c|}{ Fator de segurança } \\
\hline & & $\begin{array}{c}\text { Grau de } \\
\text { perecibilidade da } \\
\text { operação }\end{array}$ & Variação da demanda \\
\hline $\begin{array}{l}\text { Especificação do } \\
\text { produto e serviço } \\
\text { para definição } \\
\text { dos tipos de } \\
\text { capacidades de } \\
\text { acordo com o } \\
\text { roteiro de } \\
\text { produção } \\
\text { definido pelo } \\
\text { produto } \\
\text { processado (Paes, } \\
\text { 2011). }\end{array}$ & $\begin{array}{l}\text { Definição do tempo de } \\
\text { processamento para } \\
\text { cada tipo de produto a } \\
\text { partir dos ciclos padrões } \\
\text { das lavadoras } \\
\text { ultrassônicas, } \\
\text { termossecadoras, } \\
\text { seladoras e autoclaves } \\
\text { (Paes, 2011) e tempo } \\
\text { padrão de } \\
\text { processamento (COFEN } \\
527,2016 \text { ). }\end{array}$ & $\begin{array}{l}\text { Definição do } \\
\text { fator de } \\
\text { segurança a partir } \\
\text { da definição dos } \\
\text { objetivos de } \\
\text { desempenho e } \\
\text { perecibilidade da } \\
\text { operação, grau de } \\
\text { variabilidade da } \\
\text { demanda ou do } \\
\text { suprimento (Paes, } \\
\text { 2011). }\end{array}$ & $\begin{array}{l}\text { Registro histórico das } \\
\text { demandas nas unidades } \\
\text { consumidoras para } \\
\text { avaliação das variações a } \\
\text { fim de definir a margem } \\
\text { máxima de variação a ser } \\
\text { coberta no fator de } \\
\text { segurança (Slack et al., } \\
\text { 2009). }\end{array}$ \\
\hline \multicolumn{4}{|c|}{ 1.2. Identificação de capacidades alternativas } \\
\hline
\end{tabular}

6.1. Definição das práticas de controle de qualidade

6.1. Definição dos parâmetros de segurança do paciente

6. Qualidade e $\mathrm{RH}$

6.2. Definição das atribuições do RH

6.2. Definição das habilidades do RH

6.2. Definição da segurança profissional

Figura 14 - Estrutura do modelo de referência referente à decisão seis. Elaboração própria. 
Tabela 13 - Regras de projeto para executar o modelo de tomada de decisão referente à decisão seis. Elaboração própria. 6. Qualidade e RH

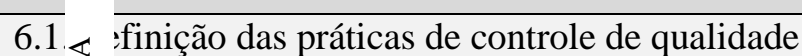

(6)

Usc coc : microscópio para auxiliar detecção de sujeiras (não é rotina no Brasil) (Graziano et al., $\underset{\sim}{\sim} 11)$.

茫

焉

.$\overline{0}$

Usc đẹ I técnica de substâncias químicas que impregnam em proteínas para auxiliar detecção de s: :ira (não é rotina no Brasil) (Graziano et al., 2011).

Ů

Def $\hat{\Upsilon}_{i}$ ção da qualificação de instalação, qualificação de operação e qualificação de

des penho, para os equipamentos utilizados na limpeza automatizada e na esterilização de prođutos para saúde, com periodicidade mínima anual. Sempre que a carga de esterilização apresentar desafios superiores àquela utilizada na qualificação de desempenho, esta qualificação deve ser refeita (RDC 15, 2012).

Qualificação térmica e a calibração dos instrumentos de controle e medição dos equipamentos de esterilização a vapor e termodesinfecção e as requalificações de operação

devem ser realizadas por laboratório capacitado, com periodicidade mínima anual (RDC 15,

2012).

Equipamentos de limpeza automatizada e esterilização devem ter seu processo requalificado após mudança de local de instalação, mau funcionamento, reparos em partes do

equipamento ou suspeita de falhas no processo de esterilização. Na requalificação dos

equipamentos de esterilização deve-se incluir o uso de indicadores biológicos e químicos (RDC 15, 2012).

Leitoras de indicadores biológicos (esterilização) e as seladoras térmicas (preparo e acondicionamento) devem ser calibradas, no mínimo, anualmente (RDC 15, 2012).
6.1. Definição dos parâmetros de segurança do paciente

Os pacientes devem ser acompanhados pelo serviço de saúde que realizou o procedimento para identificar sinais e sintomas sugestivos de infecção por micobactérias de crescimento rápido (MCR). Nos primeiros 90 dias, o acompanhamento deve ser mensal. Após este período, os pacientes devem ser orientados a procurar o serviço de saúde caso ocorra qualquer anormalidade relacionada ao procedimento cirúrgico, até completar 24 meses (RDC 8, 2009).

Os casos suspeitos e confirmados de infecção por MCR devem ser informados à autoridade sanitária local e eletronicamente, pelo formulário de "Notificação de Infecção Relacionada à Assistência à Saúde por Micobacteriose não Tuberculosa", disponível no endereço eletrônico da Anvisa (RDC 8, 2009). 


\begin{tabular}{|c|c|c|}
\hline $\begin{array}{l}\text { Monitoramento do processo de esterilização deve ser realizado em cada carga em pacote } \\
\text { testa desafio com integradores químicos (classes } 5 \text { ou } 6 \text { ), segundo rotina definida pelo } \\
\text { pró J JME ou pela empresa processadora. O monitoramento do processo de esterilização } \\
\text { con仓 } \text { idicadores físicos deve ser registrado a cada ciclo de esterilização (RDC 15, 2012). }\end{array}$ & & \\
\hline 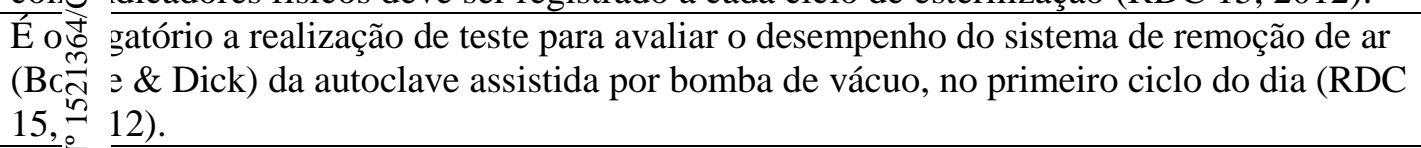 & & \\
\hline $\begin{array}{l}\text { Nã_( } \\
\text { des } \\
\text { permitido à alteração dos parâmetros estabelecidos na qualificação de operação e de } \\
\text { penho de qualquer ciclo dos equipamentos de esterilização (RDC } 15,2012) \text {. }\end{array}$ & & \\
\hline 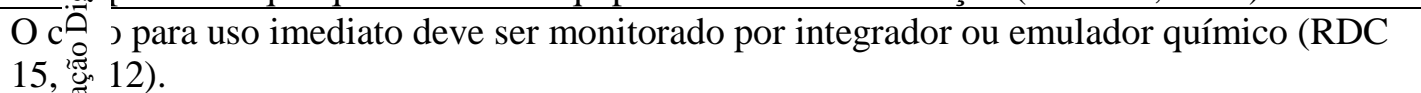 & & \\
\hline 6.2. & $\begin{array}{l}\text { 6.2. Definição das habilidades do } \\
\text { RH }\end{array}$ & 6.3. Definição da segurança profissional \\
\hline 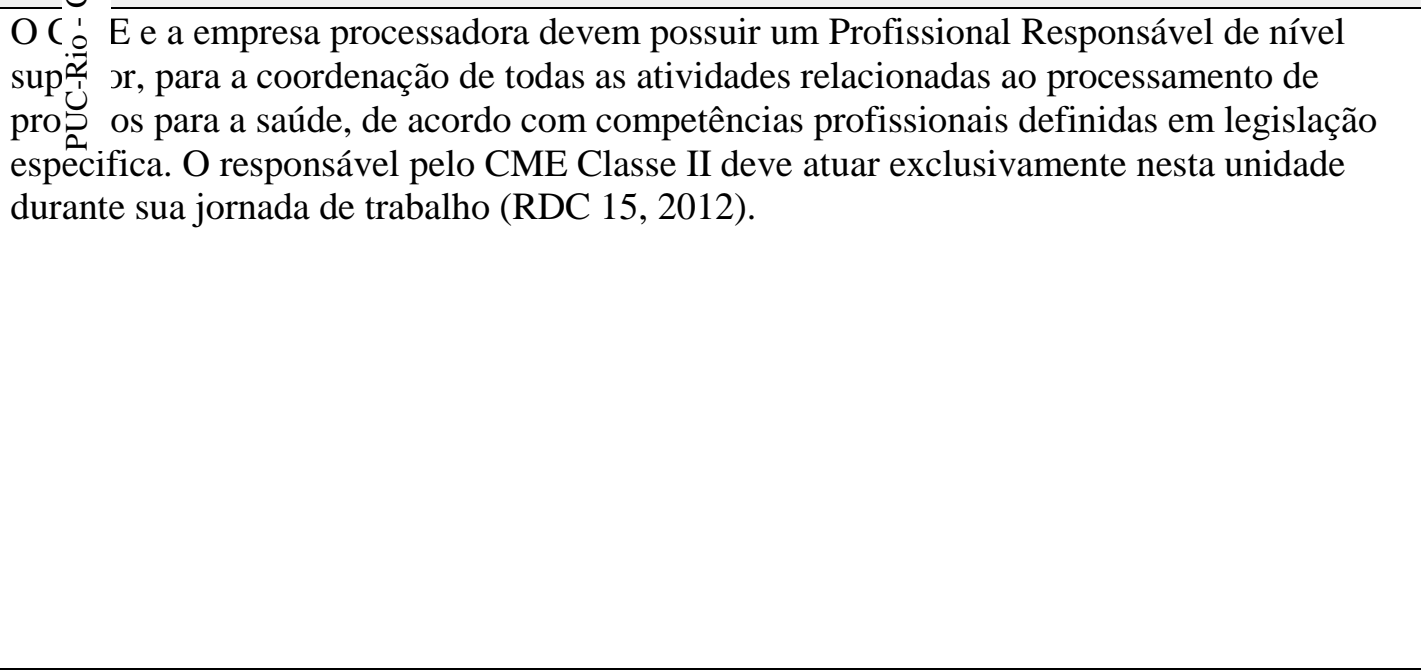 & $\begin{array}{l}\text { Habilidades requeridas pelos } \\
\text { operadores da esterilização: } \\
\text { compreensão geral sobre } \\
\text { esterilização, conhecimento sobre } \\
\text { os instrumentais cirúrgicos, } \\
\text { montagem de caixas e bandejas de } \\
\text { instrumentais, operações de } \\
\text { lavagem e empacotamento, } \\
\text { compreensão sobre o } \\
\text { funcionamento das autoclaves, } \\
\text { formas de controle da qualidade da } \\
\text { esterilização, higiene e regras de } \\
\text { vestimentas e limpeza, papel dos } \\
\text { operadores no processo de } \\
\text { esterilização (Goullet, 2013). }\end{array}$ & $\begin{array}{l}\text { O trabalhador do CME e da empresa } \\
\text { processadora deve utilizar vestimenta } \\
\text { privativa, touca e calçado fechado em todas } \\
\text { as áreas técnicas e restritas (RDC } 15,2012)\end{array}$ \\
\hline $\begin{array}{l}\text { Compete ao Responsável Técnico do serviço de saúde e ao Responsável Legal da empresa } \\
\text { processadora: Garantir a implementação das normas de processamento de produtos para }\end{array}$ & & $\begin{array}{l}\text { O trabalhador do CME e da empresa } \\
\text { processadora deve utilizar os seguintes }\end{array}$ \\
\hline
\end{tabular}




\begin{tabular}{|c|c|}
\hline 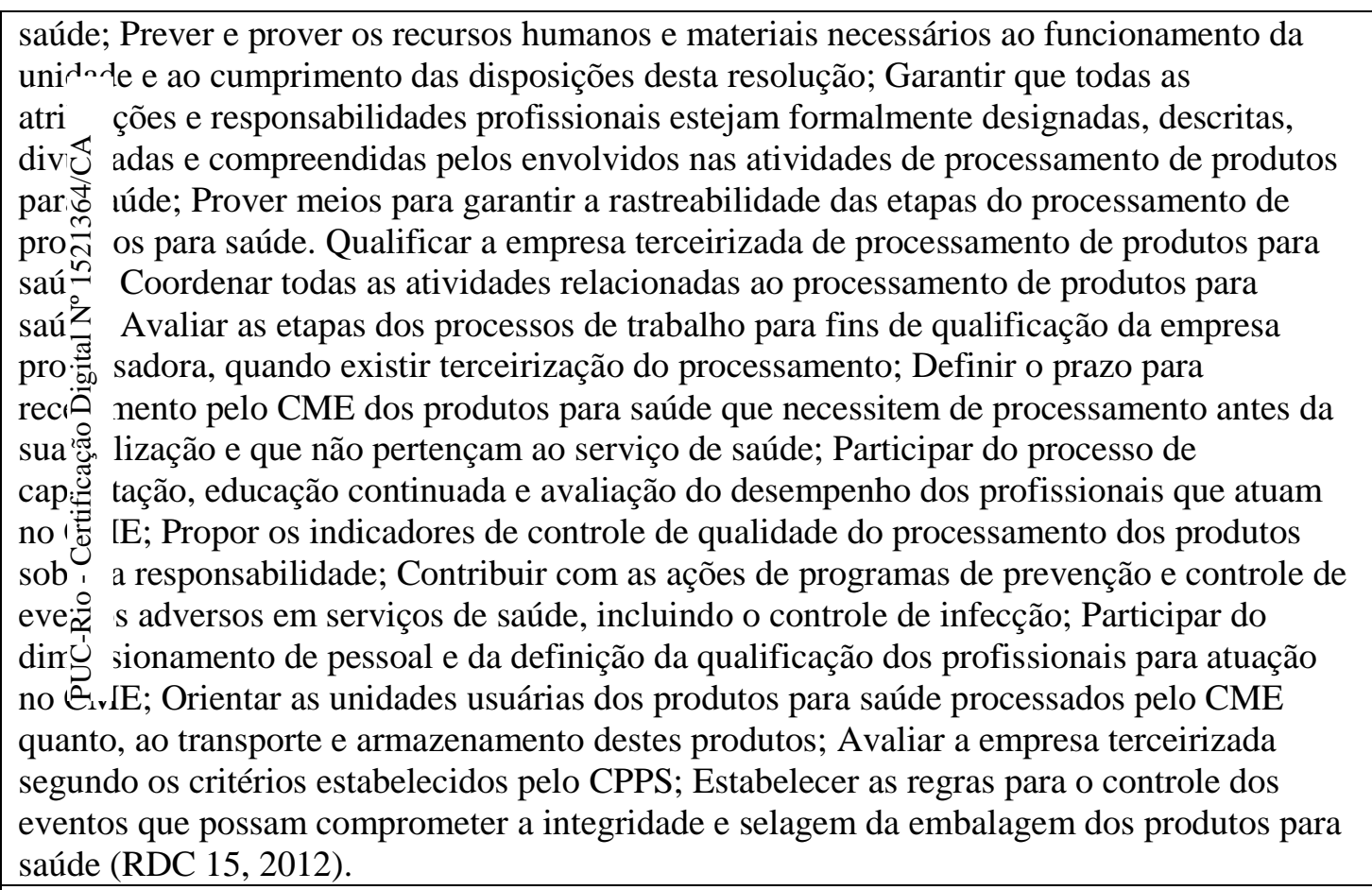 & $\begin{array}{l}\text { Equipamentos de Proteção Individual } \\
\text { (EPI): } \\
\text { Recepção: óculos de proteção e máscara } \\
\text { (ou protetor facial), luvas, avental } \\
\text { impermeável manga longa, calçado fechado } \\
\text { (impermeável antiderrapante); } \\
\text { Limpeza: óculos de proteção, máscara, } \\
\text { luvas (borracha cano longo), avental } \\
\text { impermeável manga longa, protetor } \\
\text { auricular, calçado fechado (impermeável } \\
\text { antiderrapante); } \\
\text { Preparo e acondicionamento: máscara, } \\
\text { luvas, protetor auricular (se necessário), } \\
\text { calçado fechado; } \\
\text { Desinfecção química: óculos de proteção, } \\
\text { máscara, luvas (borracha cano longo), } \\
\text { avental impermeável manga longa, calçado } \\
\text { fechado (impermeável antiderrapante). } \\
\text { Quando não especificado, o equipamento } \\
\text { de proteção deve ser compatível com o } \\
\text { risco inerente à atividade (RDC 15, 2012). }\end{array}$ \\
\hline $\begin{array}{l}\text { O responsável pelo CME deve supervisionar todas as atividades relacionadas ao } \\
\text { processamento de instrumentais e produtos para saúde, incluindo as realizadas por empresas } \\
\text { terceirizadas (RDC } 8,2009 \text { ). }\end{array}$ & $\begin{array}{l}\text { Os trabalhadores não devem deixar o local } \\
\text { de trabalho com os equipamentos de } \\
\text { proteção individual e as vestimentas } \\
\text { utilizadas em suas atividades (RDC } 15 \text {, } \\
\text { 2012). }\end{array}$ \\
\hline $\begin{array}{l}\text { Os Técnicos e Auxiliares de Enfermagem que atuam em CME, ou em empresas } \\
\text { processadoras de produtos para saúde, realizam as atividades previstas nos POPs, sob } \\
\text { orientação e supervisão do Enfermeiro (COFEN 424, 2012). }\end{array}$ & $\begin{array}{l}\text { Para a descarga de secadoras e } \\
\text { termodesinfetadoras e carga e descarga de } \\
\text { autoclaves é obrigatória a utilização de } \\
\text { luvas de proteção térmica impermeável } \\
\text { (RDC 15, 2012). }\end{array}$ \\
\hline
\end{tabular}


7.1. CME centralizada, semicentralizada ou descentralizada

7. Grau de integração (terceirização)

Recepção Preparo $\quad$ Esterilização $>$ Armazenagem

Centralizada: todos os artigos são processados no CME.

Semicentralizada: parte dos artigos é processada fora do CME. Ex: Limpeza dos artigos feita nas unidades de internação, desinfecção feita por empresa terceirizada.

Descentralizada: cada unidade hospitalar executa todo o processo de esterilização.

Figura 15 - Estrutura do modelo de referência referente à decisão sete. Elaboração própria.

Tabela 14 - Regras de projeto para executar o modelo de tomada de decisão referente à decisão sete. Elaboração própria.

\section{Grau de integração (terceirização)}

\begin{tabular}{|l|l|l|l|l|}
\hline $\begin{array}{l}\text { Recepção e } \\
\text { Limpeza }\end{array}$ & $\begin{array}{l}\text { Preparo e } \\
\text { Acondicionamento }\end{array}$ & Desinfecção & Esterilização & $\begin{array}{l}\text { Armazenagem e } \\
\text { Distribuição }\end{array}$ \\
\hline
\end{tabular}

Centralizado: os materiais de uma unidade assistencial de saúde são totalmente processados no CME (Silveira, 2015).

\begin{tabular}{|c|c|c|}
\hline $\begin{array}{l}\text { Semicentralizado: os materiais } \\
\text { são preparados nas diversas } \\
\text { unidades e encaminhados ao } \\
\text { CME para esterilização } \\
\text { (Silveira, 2015). Ex: Limpeza } \\
\text { dos artigos feita nas unidades de } \\
\text { internação. }\end{array}$ & $\begin{array}{l}\text { Ex: } \\
\text { Desinfecção } \\
\text { feita por } \\
\text { empresa } \\
\text { terceirizada. }\end{array}$ & $\begin{array}{l}\text { O processamento } \\
\text { de produtos para } \\
\text { saúde não críticos } \\
\text { pode ser realizado } \\
\text { em outras } \\
\text { unidades do } \\
\text { serviço de saúde } \\
\text { desde que de } \\
\text { acordo com } \\
\text { Procedimento } \\
\text { Operacional } \\
\text { Padronizado - } \\
\text { POP definido } \\
\text { pelo CME (RDC } \\
\text { 15, 2012). }\end{array}$ \\
\hline
\end{tabular}

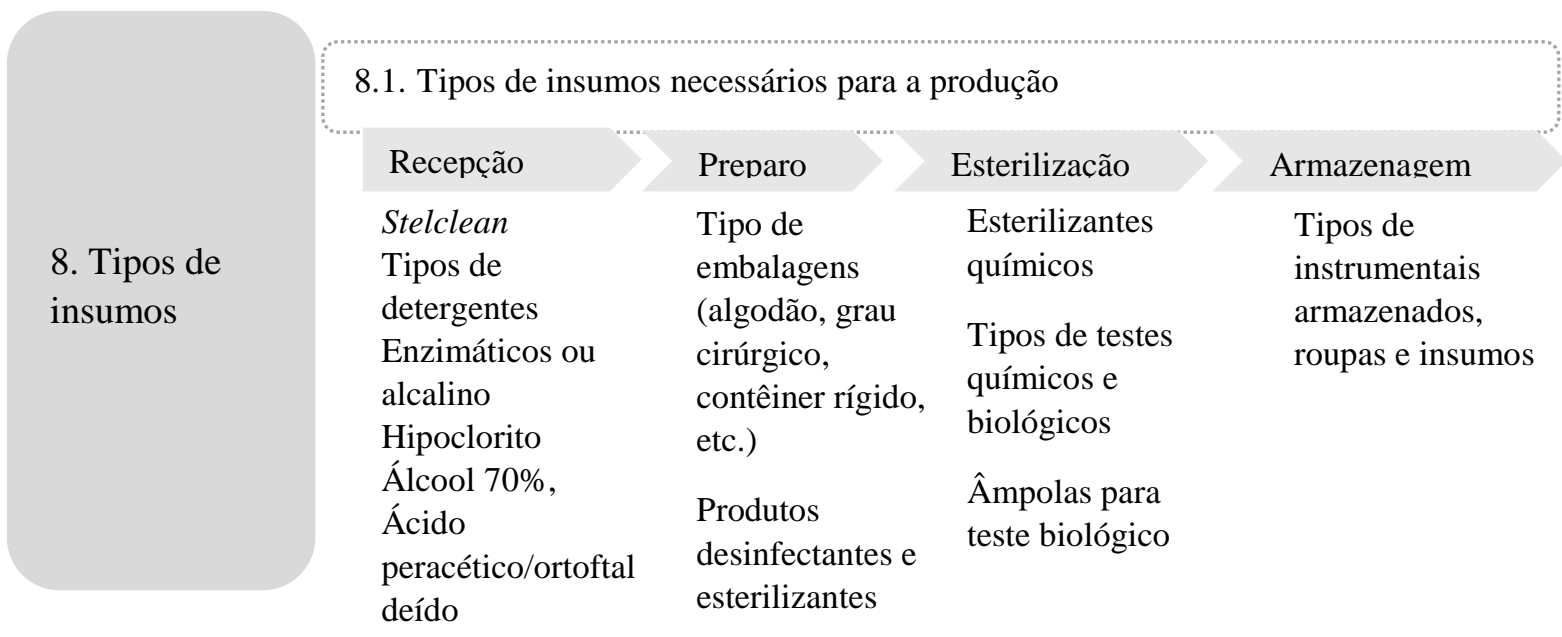

Figura 16 - Estrutura do modelo de referência referente à decisão oito. Elaboração própria. 
Tabela 15 - Regras de projeto para executar o modelo de tomada de decisão referente à decisão oito. Elaboração própria. 8. Tipos de insumos

\begin{tabular}{|c|c|c|c|}
\hline $\mathrm{R}_{\varangle} \overline{\text { pção e Limpeza }}$ & Preparo e Acondicionamento & Esterilização & Armazenagem e Distribuição \\
\hline 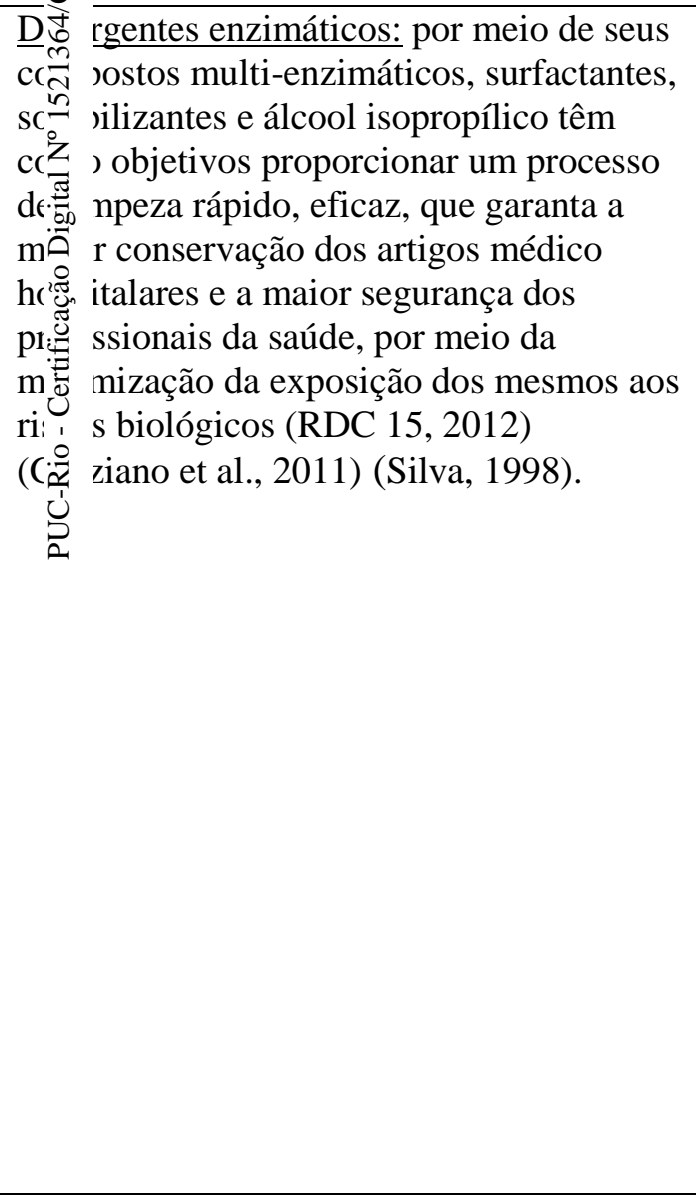 & $\begin{array}{l}\text { Embalagens: O CME e a empresa } \\
\text { processadora devem utilizar } \\
\text { embalagens que garantam a } \\
\text { manutenção da esterilidade do } \\
\text { conteúdo, bem como a sua } \\
\text { transferência sob técnica asséptica. As } \\
\text { embalagens utilizadas para a } \\
\text { esterilização de produtos para saúde } \\
\text { devem estar regularizadas junto à } \\
\text { Anvisa, para uso específico em } \\
\text { esterilização. Não é permitido o uso } \\
\text { de embalagens de papel kraft, papel } \\
\text { toalha, papel manilha, papel jornal e } \\
\text { lâminas de alumínio, assim como as } \\
\text { embalagens tipo envelope de plástico } \\
\text { transparente não destinadas ao uso em } \\
\text { equipamentos de esterilização. Não é } \\
\text { permitido o uso de caixas metálicas } \\
\text { sem furos para esterilização de } \\
\text { produtos para saúde. O CME que } \\
\text { utiliza embalagem de tecido de } \\
\text { algodão, deve possuir um plano } \\
\text { contendo critérios de aquisição e } \\
\text { substituição do arsenal de embalagem } \\
\text { de tecido mantendo os registros desta } \\
\text { movimentação. Não é permitido o uso } \\
\text { de embalagens de tecido de algodão }\end{array}$ & $\begin{array}{l}\text { Água: A água utilizada no processo } \\
\text { de geração do vapor das autoclaves } \\
\text { deve atender às especificações do } \\
\text { fabricante da autoclave (RDC } 15, \\
\text { 2012). }\end{array}$ & $\begin{array}{l}\text { Tipos de instrumentais armazenados } \\
\text { (Graziano et al., 2011). }\end{array}$ \\
\hline
\end{tabular}




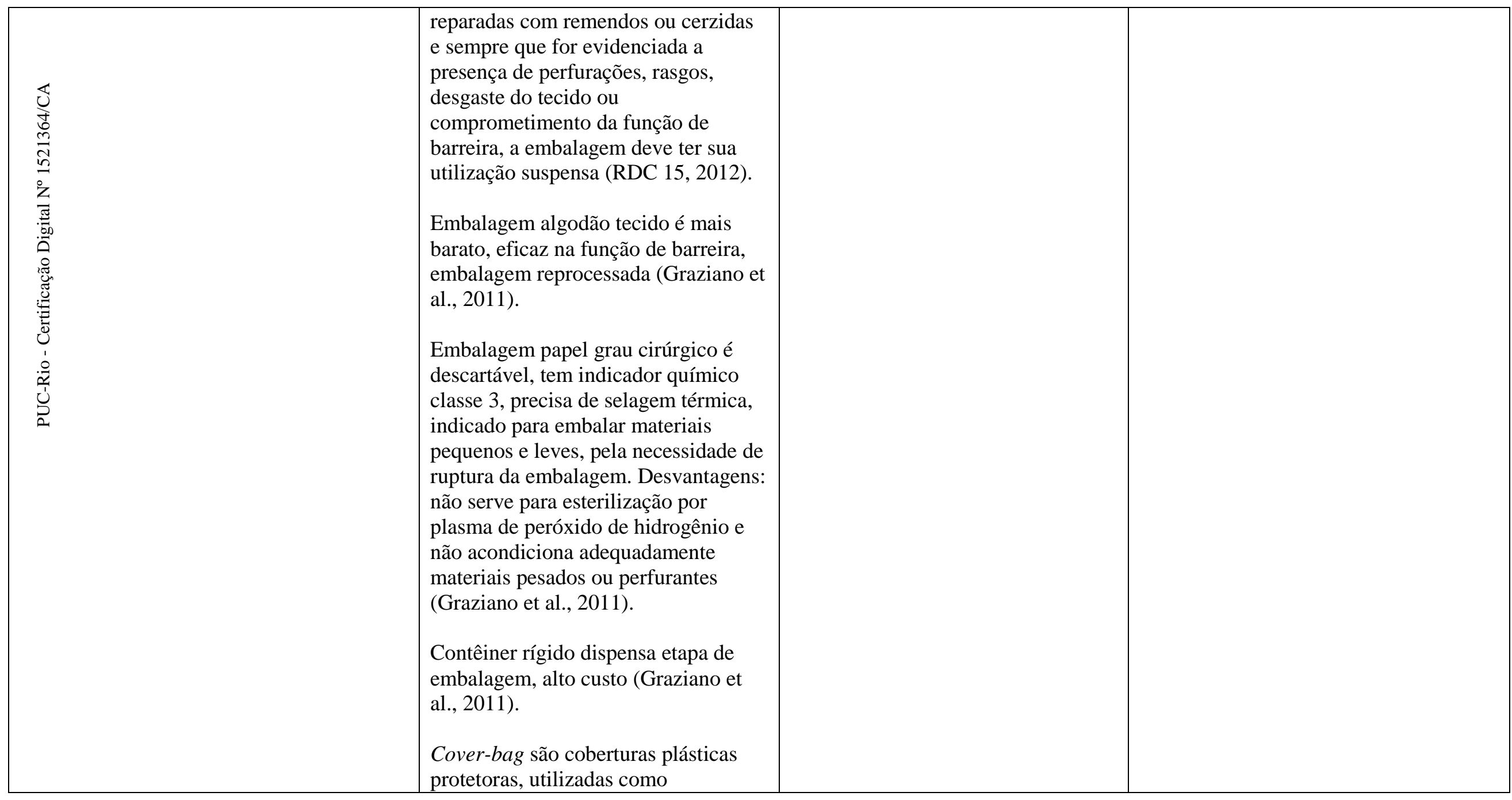




\begin{tabular}{|c|c|c|c|}
\hline 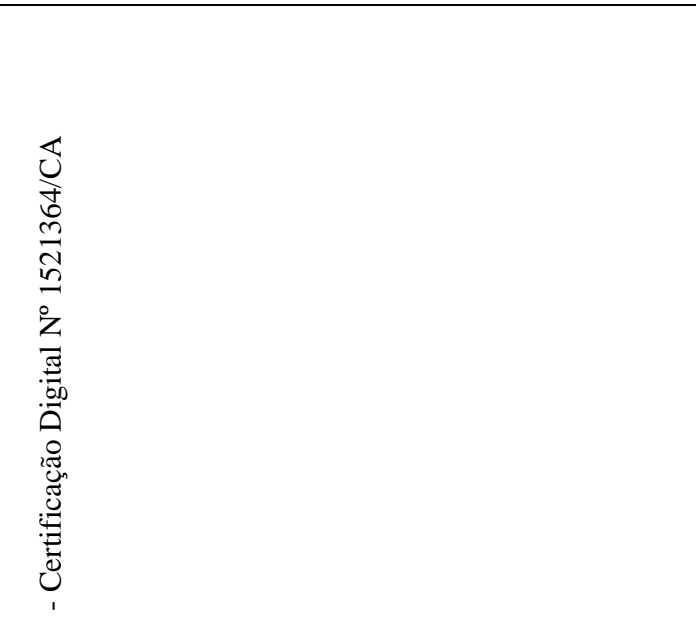 & $\begin{array}{l}\text { embalagems secundárias, envolvendo } \\
\text { principalmente materiais pesados, } \\
\text { como caixas cirúrgicas. São colocadas } \\
\text { depois das caixas estarem } \\
\text { esterilizadas e frias, mas o mais } \\
\text { próximo possível da esterilização. } \\
\text { Protege a embalagem primária de } \\
\text { perfurações e abrasões, poeira, } \\
\text { contaminação por palpação. Materiais } \\
\text { de uso imediato não devem receber a } \\
\text { cobertura plástica. Cover-bag não é } \\
\text { biodegradável nem reciclável e } \\
\text { aumenta o volume de resíduos } \\
\text { despejados (Graziano et al., 2011). }\end{array}$ & & \\
\hline 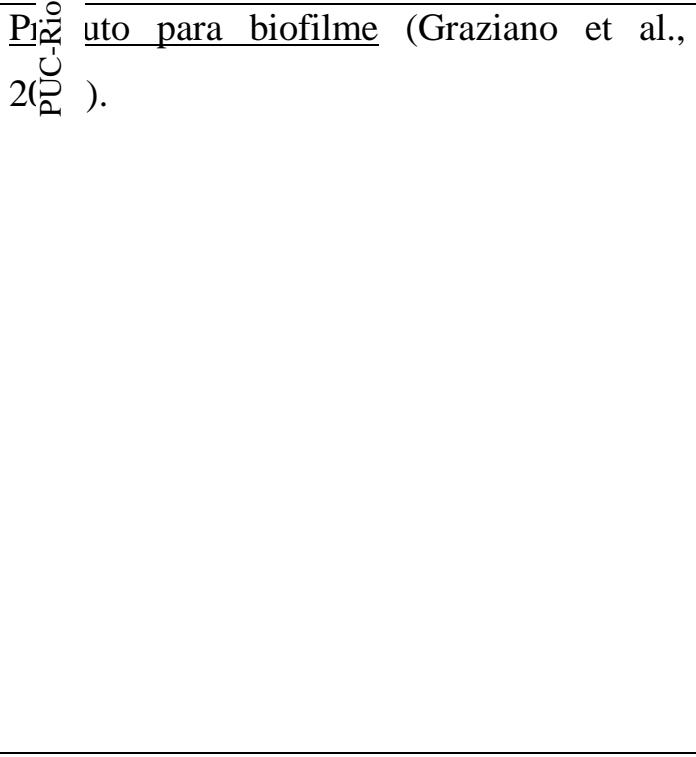 & $\begin{array}{l}\text { Rótulos: É obrigatória a identificação } \\
\text { nas embalagens dos produtos para } \\
\text { saúde submetidos à esterilização por } \\
\text { meio de rótulos ou etiquetas. O rótulo } \\
\text { dos produtos para saúde processados } \\
\text { deve ser capaz de se manter legível e } \\
\text { afixado nas embalagens durante a } \\
\text { esterilização, transporte, } \\
\text { armazenamento, distribuição e até o } \\
\text { momento do uso. O rótulo de } \\
\text { identificação da embalagem deve } \\
\text { conter: nome do produto; número do } \\
\text { lote; data da esterilização; data limite } \\
\text { de uso; método de esterilização; nome } \\
\text { do responsável pelo preparo (RDC } \\
\text { 15, 2012). }\end{array}$ & $\begin{array}{l}\text { Esterilizantes químicos (esterilização } \\
\text { e desinfecção, dependendo do tempo } \\
\text { de exposição): Glutaraldeído (banido } \\
\text { do Brasil), formaldeído (uso restrito } \\
\text { devido a toxicidade e existência de } \\
\text { outros métodos para esterilização), } \\
\text { óxido de etileo (EtO)(eficaz na } \\
\text { esterilização a frio, utiliza ciclo de } \\
\text { 4h, seguido de aeração forçada por } \\
\text { 12h ou no ambiente por } 7 \text { dias, } \\
\text { inflamável, irritante de mucosas, uso } \\
\text { restrito a complexas instalações, uso } \\
\text { industrial, devido ao tempo de } \\
\text { processamento e transporte, este } \\
\text { processo exige um inventário maior, } \\
\text { o que aumenta o custo), ácido } \\
\text { peracéltico (método de esterilização }\end{array}$ & \\
\hline
\end{tabular}




\begin{tabular}{|c|c|c|c|}
\hline 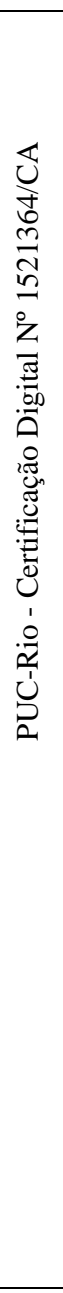 & & $\begin{array}{l}\text { a frio e tem uso quase restrito a } \\
\text { endoscópios, colonoscópios e outros } \\
\text { aparelhos óticos invasivos, em } \\
\text { substituição ao glutaraldeído } \\
\text { (Guideline, 2008). } \\
\\
\text { Álcool Formaldeído foi eliminado } \\
\text { como um esterilizante químico } \\
\text { recomendado ou desinfetante de alto } \\
\text { nível porque é irritante e tóxico e } \\
\text { não é comumente usado (Guideline, } \\
\text { 2008). Fica proibido o uso, de forma } \\
\text { isolada, de produtos que contenham } \\
\text { paraformaldeído ou formaldeído, } \\
\text { para desinfecção e esterilização de } \\
\text { artigos, superfícies e equipamentos, } \\
\text { em ambientes domiciliares ou } \\
\text { coletivos e em serviços submetidos } \\
\text { ao controle e fiscalização sanitária. } \\
\text { O uso de produtos que contenham } \\
\text { paraformaldeído ou formaldeído } \\
\text { somente será permitido quando } \\
\text { associado a um equipamento de } \\
\text { esterilização registrado na Anvisa e } \\
\text { obedecendo às condições de uso } \\
\text { exigidas pelo fabricante do } \\
\text { equipamento, garantindo a segurança } \\
\text { e eficácia do processo de } \\
\text { esterilização (RDC } 91,2008 \text { ). }\end{array}$ & \\
\hline & $\begin{array}{l}\text { Produtos desinfectantes: glutaraldeído } \\
\text { (uso proibido no Brasil), formaldeído }\end{array}$ & $\begin{array}{l}\text { Os dois produtos mais utilizados } \\
\text { para o reprocessamento de }\end{array}$ & \\
\hline
\end{tabular}




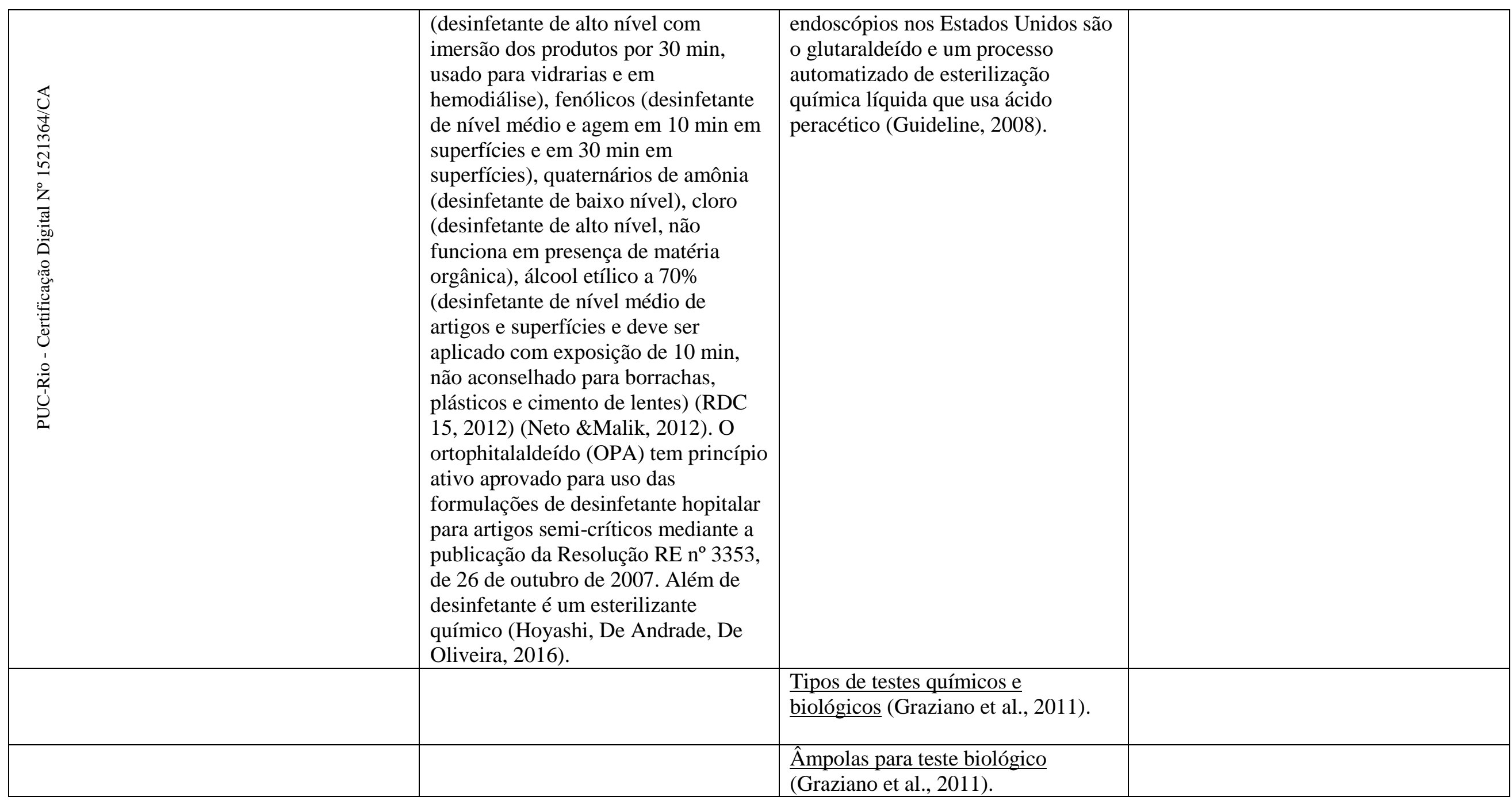


9.1. Dimensionamento do RH por área

Carga de trabalho sobre o tempo de processamento

9.

Dimensionam ento do RH

\subsubsection{Cálculo da carga de trabalho}

Produção da unidade x tempo padrão da atividade por área

9.1.2. Determinação do tempo padrão (COFEN n $527 / 2016)$
Recepção
Preparo
Esterilização
Armazenagem

Figura 17 - Estrutura do modelo de referência referente à decisão nove. Elaboração própria.

Tabela 16 - Regras de projeto para executar o modelo de tomada de decisão referente à decisão nove. Elaboração própria.

\section{Dimensionamento do RH}

\subsection{Dimensionamento do RH por área}

Definição da carga de trabalho de enfermagem, entendida como o produto da quantidade média de pacientes assistidos, segundo o grau de dependência da equipe de enfermagem ou do tipo de atendimento prestado, pelo tempo médio de assistência utilizado, por cliente, de acordo com o grau de dependência ou atendimento realizado (Gaidzinski et al., 2005) (Costa \& Fugulin, 2011).

9.1.1. Cálculo da carga de trabalho

Variável carga de trabalho obtida no CME por meio da identificação das ações realizadas e da determinação do tempo de trabalho despendido na execução de cada atividade envolvida nas diferentes etapas do processamento de materiais (Costa e Fugulin, 2011).

A Carga de trabalho dos profissionais de enfermagem para a unidade CME deve fundamentar-se na produção da unidade (número de kits ou pacotes processados), multiplicada pelo tempo padrão das atividades realizadas, nas diferentes áreas (COFEN 527, 2016)

9.1.2. Determinanção do tempo padrão (COFEN 527/2016)

\begin{tabular}{|c|c|c|c|}
\hline Recepção e Limpeza & $\begin{array}{l}\text { Preparo e } \\
\text { Acondicionamento }\end{array}$ & Esterilização & $\begin{array}{l}\text { Armazenagem e } \\
\text { Distribuição }\end{array}$ \\
\hline $\begin{array}{l}\text { Recepção e } \\
\text { recolhimento dos } \\
\text { materiais contaminados: } \\
2 \mathrm{~min}(0,033 \mathrm{~h})\end{array}$ & $\begin{array}{l}\text { Secagem e distribuição } \\
\text { dos materiais após } \\
\text { limpeza: } 3 \text { min }(0,05 \text { h) }\end{array}$ & $\begin{array}{l}\text { Montagem da carga } \\
\text { de esterilização: } 8 \\
\text { min }(0,133 \text { h) }\end{array}$ & $\begin{array}{l}\text { Montagem dos carros } \\
\text { de transporte das } \\
\text { unidades: } 5 \text { min }(0,083 \\
\text { h) }\end{array}$ \\
\hline $\begin{array}{l}\text { Limpeza dos materiais: } \\
2 \mathrm{~min}(0,033 \mathrm{~h})\end{array}$ & $\begin{array}{l}\text { Inspeção, teste, separação } \\
\text { e secagem dos materiais: } \\
3 \text { min }(0,05 \mathrm{~h})\end{array}$ & $\begin{array}{l}\text { Retirada da carga } \\
\text { estéril e verificação } \\
\text { da esterilização: } 3 \\
\text { min }(0,05 \text { h) }\end{array}$ & $\begin{array}{l}\text { Organização e controle } \\
\text { do ambiente e } \\
\text { materiais estéreis: } 1 \\
\text { min }(0,016 \mathrm{~h})\end{array}$ \\
\hline $\begin{array}{l}\text { Recepção dos materiais } \\
\text { em consignação: } 6 \text { min } \\
(0,1 \mathrm{~h})\end{array}$ & $\begin{array}{l}\text { Montagem e embalagem } \\
\text { dos materiais: } 3 \min (0,05 \\
\text { h) }\end{array}$ & $\begin{array}{l}\text { Guarda dos } \\
\text { Materiais: } 4 \mathrm{~min} \\
(0,066 \mathrm{~h})\end{array}$ & $\begin{array}{l}\text { Distribuição dos } \\
\text { materiais e roupas } \\
\text { estéreis: } 2 \text { min }(0,033 \\
\text { h) }\end{array}$ \\
\hline $\begin{array}{l}\text { Conferência dos } \\
\text { materiais consignados } \\
\text { após cirurgia: } 5 \text { min } \\
(0,083 \mathrm{~h})\end{array}$ & $\begin{array}{l}\text { Montagem dos materiais } \\
\text { de assistência ventilatória: } \\
2 \text { min }(0,033 \mathrm{~h})\end{array}$ & & \\
\hline $\begin{array}{l}\text { Devolução dos } \\
\text { materiais em } \\
\text { consignação: } 3 \mathrm{~min} \\
(0,05 \mathrm{~h})\end{array}$ & & & \\
\hline
\end{tabular}


10. Estoques

10.1.Dimensionamento do estoque

$\mathrm{N}^{\circ}$ de cirurgias por período e composição do mapa cirúrgico, mínimo $20 \%$ dos insumos

10.2.Definição das práticas de controle de qualidade do estoque

Manuseio técnico do estoque

Condições ambientais mínimas exigidas

10.3.Definição da política de controle de estoque

Figura 18 - Estrutura do modelo de referência referente à decisão dez. Elaboração própria.

Tabela 17 - Regras de projeto para executar o modelo de tomada de decisão referente à decisão dez. Elaboração própria.

\begin{tabular}{|c|c|}
\hline \multicolumn{2}{|l|}{ 10. Estoqu } \\
\hline \multicolumn{2}{|l|}{ 10.1. Dimensionamento do estoqu } \\
\hline \multicolumn{2}{|c|}{$\begin{array}{l}\text { Custo de estoque: custo de colocação de pedido, aquisição da mercadoria, manutenção dos } \\
\text { estoques, custo da falta (Rios, Figueiredo, Araujo, 2012). }\end{array}$} \\
\hline \multicolumn{2}{|c|}{$\begin{array}{l}\text { Previsão de consumo: } \mathrm{N}^{\circ} \text { de cirurgias por período e composição do mapa cirúrgico (Graziano et } \\
\text { al., 2011) (Turrini, Moriya, Bronzatti, 2011). }\end{array}$} \\
\hline \multicolumn{2}{|c|}{$\begin{array}{l}\text { Sazonalidade: O custo total de compra pode aumentar durante a época de pico de demanda por } \\
\text { causa de eventuais dificuldades do fabricante em produzir toda a quantidade demandada, ou pela } \\
\text { necessidade de lead times mais curtos. Além disso, a sazonalidade pode agravar o problema das } \\
\text { perdas por perecibilidade (Rios, Figueiredo, Araujo, 2012). }\end{array}$} \\
\hline \multicolumn{2}{|c|}{$\begin{array}{l}\text { Segmentação de itens em estoque: características distintas dos itens, como prazo de validade, } \\
\text { custo da falta, quantidade de fornecedores, demanda ou consumo sazonal, custos unitários de } \\
\text { aquisição e gastos com ressuprimento (Rios, Figueiredo, Araujo, 2012). }\end{array}$} \\
\hline \multicolumn{2}{|c|}{$\begin{array}{l}\text { Estoque de segurança: dimensionamento da quantidade de materiais para proteção contra } \\
\text { incertezas (Rios, Figueiredo, Araujo, 2012). }\end{array}$} \\
\hline \multicolumn{2}{|c|}{$\begin{array}{l}\text { Estoque centralizado e descentralizado: quantidade de estoque que se localiza na área de } \\
\text { armazenagem da CME e estoque estabelecido nas unidades consumidoras (Rios, Figueiredo, } \\
\text { Araujo, 2012). }\end{array}$} \\
\hline \multicolumn{2}{|c|}{ 10.2. Definição das práticas de controle de qualidade do estoque } \\
\hline $\begin{array}{l}\text { Manuseio do estoque (Graziano et al., } \\
\text { 2011) }\end{array}$ & $\begin{array}{l}\text { Condições ambientais mínimas exigidas (RDC 15, } \\
\text { 2012) }\end{array}$ \\
\hline \multicolumn{2}{|c|}{ 10.3. Definição da política de controle de estoque } \\
\hline \multicolumn{2}{|c|}{$\begin{array}{l}\text { Lote Econômico (LEC): quantidade ótima de produtos por ressuprimento através da minimização } \\
\text { dos custos totais, levando-se em conta a demanda pelo item e os custos de colocação do pedido, de } \\
\text { aquisição do item e de oportunidade de manter esse dinheiro empatado em estoques. Exige } \\
\text { previsibilidade da demanda (Rios, Figueiredo, Araujo, 2012). }\end{array}$} \\
\hline Nível de Reposição (NR): nível máximo de & \\
\hline
\end{tabular}


11.1. Tipo de transporte de materiais para o recebimento, operação e distribuição

Volume, tempo em trânsito, preservação das condições dos materiais.

11.

Transporte

11.2. Definição do transporte de materiais esterilizados (quando terceirizados)

Definição da opção de serviço: Preço, tempo em trânsito e variabilidade, danos e perdas.

Definição do tipo de modal e veículo.

Figura 19 - Estrutura do modelo de referência referente à decisão onze. Elaboração própria.

Tabela 18 - Regras de projeto para executar o modelo de tomada de decisão referente à decisão onze. Elaboração própria.

\section{Transporte}

11.1. Tipo de transporte de materiais para o recebimento, operação e distribuição

O transporte de produtos para saúde processados deve ser feito em recipientes fechados e em condições que garantam a manutenção da identificação e a integridade da embalagem (RDC 15, 2012).

Qualquer outra forma de transporte dos produtos para saúde processados deve ser submetida à aprovação prévia pelo órgão de vigilância sanitária emissor do licenciamento (RDC 15, 2012). Transporte das unidades consumidoras para o CME: monta-cargas, carrinhos transportadores, etc. (Graziano et al., 2011)

O transporte dos produtos para saúde a serem encaminhados para processamento nas empresas processadoras ou no CME de funcionamento centralizado deve ser feito em recipiente exclusivo para este fim, rígido, liso, com sistema de fechamento estanque, contendo a lista de produtos a serem processados e o nome do serviço solicitante (RDC 15, 2012).

Os produtos para saúde processados por empresa processadora ou no CME de funcionamento centralizado devem ser transportados para o serviço de saúde em recipientes fechados que resistam às ações de punctura e ruptura, de forma a manter a integridade da embalagem e a esterilidade do produto. Os recipientes devem estar identificados com o nome da empresa processadora ou do CME de funcionamento centralizado, o nome do serviço a que se destina e conter uma lista anexa com a relação de produtos processados (RDC 15, 2012).

11.2. Definição do transporte de materiais esterilizados (quando terceirizados)

Definição da opção de serviço: Preço, tempo em trânsito e variabilidade, danos e perdas (Ballou, 2010).

Quando o transporte dos produtos para saúde for realizado pela empresa processadora, os veículos de transporte devem ser de uso exclusivo para este fim (RDC 15, 2012).
Definição do tipo de modal (rodoviário, ferroviário, aquaviário, dutoviário, aéreo) e veículo (Ballou, 2010). 
12.1.Definição do tamanho das instalações

O dimensionamento das áreas do CME Classe I deve ser efetuado em função da demanda e dos métodos de processamento utilizados.

Parâmetros de dimensionamento definidos na RDC 15/2012 e RDC 50/ 2002.

12.

Instalações

\subsection{Definição do desenho das instalações}

Fluxo direcionado sempre da área suja para a área limpa.

Obrigatória a separação física da área de recepção e limpeza dos produtos para saúde das demais áreas.

12.3. Definiçãa do número e localização das instalações

Mínimo 4 áreas com possível +1 (área de desinfecção).

Fácil acesso em relação às unidades consumidoras

Figura 20 - Estrutura do modelo de referência referente à decisão doze. Elaboração própria.

Tabela 19 - Regras de projeto para executar o modelo de tomada de decisão referente à decisão doze. Elaboração própria.

\section{Instalações}

\subsection{Definição do tamanho das instalações}

O dimensionamento das áreas do CME Classe I deve ser efetuado em função da demanda (organização) e dos métodos de processamento (processos) utilizados (RDC 15, 2012). Obtenção da demanda a partir da demanda diária de material nas unidades consumidoras, $\mathrm{n}^{\circ}$ de leitos, $\mathrm{n}^{\circ}$ salas de operação, média de cirurgias (Graziano et al., 2011).

Parâmetros de dimensionamento definidos na RDC 50/ 2002:

\begin{tabular}{|c|c|c|}
\hline Unidade / ambiente & $\begin{array}{l}\text { Quantificação } \\
\text { mínima }\end{array}$ & Dimensão mínima \\
\hline Recepção & 1 & \multirow[t]{2}{*}{$0,08 \mathrm{~m}^{2}$ por leito com área mínima de $8,0 \mathrm{~m}^{2}$} \\
\hline $\begin{array}{l}\text { Área para lavagem } \\
\text { dos materiais }\end{array}$ & 1 & \\
\hline $\begin{array}{l}\text { Área para recepção } \\
\text { de roupa limpa }\end{array}$ & 1 & $4,0 \mathrm{~m}^{2}$ \\
\hline $\begin{array}{c}\text { Área para preparo de } \\
\text { materiais e roupa } \\
\text { limpa }\end{array}$ & 1 & $0,25 \mathrm{~m}^{2}$ por leito com área mínima de $12,0 \mathrm{~m}^{2}$ \\
\hline $\begin{array}{c}\text { Área para } \\
\text { esterilização física }\end{array}$ & 1 & \multirow[t]{2}{*}{$\begin{array}{c}\text { A depender do equipamento utilizado. } \\
\text { Distância mínima entre as autoclaves }=20 \mathrm{~cm}\end{array}$} \\
\hline $\begin{array}{c}\text { Área para } \\
\text { esterilização química }\end{array}$ & 1 & \\
\hline $\begin{array}{c}\text { Sala de } \\
\text { armazenagem }\end{array}$ & 1 & $0,2 \mathrm{~m}^{2}$ por leito com o mínimo de $10,0 \mathrm{~m}^{2}$ \\
\hline $\begin{array}{c}\text { Área para } \\
\text { armazenamento }\end{array}$ & 1 & $25 \%$ da área de armazenagem de material esterilizado \\
\hline
\end{tabular}

OBS: Não foram considerados aqui os itens do programa de necessidades para esterilização química gasosa e nem de centro de material esterilizado simplificado.

\subsection{Definição do desenho das instalações}

Fluxo direcionado sempre da área suja para a área limpa (RDC 15, 2012).

Levar em consideração o tipo do arranjo físico da operação de esterilização (celular), os fluxos sem cruzamentos, áreas separadas de materiais sujos e limpos e as métricas estabelecidas pelo marco regulatório (Mussel, 2013).

O CME Classe I deve possuir, no mínimo, barreira técnica entre o setor sujo e os setores limpos. Para o CME Classe II e na empresa processadora é obrigatória a separação física da área de recepção e limpeza 
dos produtos para saúde das demais áreas (RDC 15, 2012).

Consideração do fluxo logístico, principalmente para repor itens esterilizados da sala de cirurgia o mais cedo possível (Klundert, Muls e Schadd, 2008).

Quando o veículo de transporte de produtos para saúde for o mesmo para produtos processados e produtos ainda não processados, a área de carga do veículo deve ser fisicamente dividida em ambientes distintos com acessos independentes e devidamente identificados (RDC 15, 2012).

\begin{tabular}{|c|c|c|c|}
\hline $\begin{array}{l}\text { Layout da área de } \\
\text { recepção e limpeza }\end{array}$ & $\begin{array}{l}\text { Layout da área de } \\
\text { preparo e } \\
\text { esterilização }\end{array}$ & $\begin{array}{l}\text { Layout da área de } \\
\text { desinfecção }\end{array}$ & Layout da área de armazenagem \\
\hline $\begin{array}{l}\text { Localizada dentro da } \\
\text { sala de recepção e } \\
\text { limpeza. Essa área } \\
\text { deve dispor de, pelo } \\
\text { menos, uma bancada } \\
\text { com dimensões que } \\
\text { permitam a } \\
\text { conferência dos } \\
\text { materiais de forma a } \\
\text { garantir a segurança } \\
\text { do processo (RDC } \\
\text { 15, 2012). }\end{array}$ & $\begin{array}{l}\text { A sala de preparo e } \\
\text { esterilização do CME } \\
\text { Classe II e da } \\
\text { empresa } \\
\text { processadora devem } \\
\text { dispor de (RDC 15, } \\
\text { 2012): } \\
\text { I - Equipamento para } \\
\text { transporte com } \\
\text { rodízio, em } \\
\text { quantitativo de } \\
\text { acordo com o volume } \\
\text { de trabalho; } \\
\text { II - Secadora de } \\
\text { produtos para saúde e } \\
\text { pistolas de ar } \\
\text { comprimido } \\
\text { medicinal, gás inerte } \\
\text { ou ar filtrado, seco e } \\
\text { isento de óleo; } \\
\text { III - Seladoras de } \\
\text { embalagens; e } \\
\text { IV - Estações de } \\
\text { trabalho e cadeiras ou } \\
\text { bancos ergonômicos } \\
\text { com altura regulável. }\end{array}$ & $\begin{array}{l}\text { Deve conter bancada } \\
\text { com uma cuba para } \\
\text { limpeza e uma cuba } \\
\text { para enxágue com } \\
\text { profundidade e } \\
\text { dimensionamento } \\
\text { que permitam a } \\
\text { imersão completa do } \\
\text { produto ou } \\
\text { equipamento, } \\
\text { mantendo } \\
\text { distanciamento } \\
\text { mínimo entre as } \\
\text { cubas de forma a não } \\
\text { permitir a } \\
\text { transferência } \\
\text { acidental de líquidos } \\
\text { (RDC 15, 2012). }\end{array}$ & $\begin{array}{l}\text { I - Equipamento de transporte } \\
\text { com rodízio; II - Escadas, se } \\
\text { necessário; e III - Prateleiras ou } \\
\text { cestos aramados (RDC 15, } \\
\text { 2012). } \\
\text { Local limpo e seco, sob proteção } \\
\text { da luz solar direta e submetidos } \\
\text { à manipulação mínima (RDC 15, } \\
\text { 2012). }\end{array}$ \\
\hline $\begin{array}{l}\text { Os equipamentos } \\
\text { destinados à limpeza } \\
\text { automatizada devem } \\
\text { ser instalados em } \\
\text { área que não obstrua } \\
\text { a circulação da sala } \\
\text { de recepção e } \\
\text { limpeza, obedecendo } \\
\text { às especificações } \\
\text { técnicas do } \\
\text { fabricante (RDC 15, } \\
\text { 2012). }\end{array}$ & & & $\begin{array}{l}\text { O armazenamento de produtos } \\
\text { para saúde deve ser centralizado } \\
\text { em local exclusivo e de acesso } \\
\text { restrito, não podendo ocorrer em } \\
\text { área de circulação, mesmo que } \\
\text { temporariamente. }\end{array}$ \\
\hline \multicolumn{4}{|c|}{ 12.3. Definição do número e localização das instalações } \\
\hline \multicolumn{4}{|c|}{$\begin{array}{l}\text { Mínimo } 4 \text { áreas com possível +1 área de desinfecção: I - Sala de recepção e limpeza (setor sujo); II - } \\
\text { Sala de preparo e esterilização (setor limpo); III - Sala de desinfecção química, quando aplicável (setor } \\
\text { limpo); IV - Área de monitoramento do processo de esterilização (setor limpo); e V - Sala de } \\
\text { armazenamento e distribuição de materiais esterilizados (setor limpo) (RDC 15, 2012). }\end{array}$} \\
\hline
\end{tabular}


O posisionamento do CME no hospital foi determinado pela proximidade e pelo fácil acesso às principais unidades consumidoras (Silveira, 2015).

13.

Parâmetros de produtividade e desempenho

\subsection{Definição dos indicadores de produtividade}

Tempo de processamento dos artigos. Ex: Tempo ideal da pré-desinfecção: 15 minutos.

\subsection{Definição dos indicadores de desempenho de operação}

Objetivo da limpeza: diminuir a população de microrganismos nos instrumentos sujos para facilitar a lavagem e proteger a equipe durante a manipulação.

Objetivo do empacotamento: embarreirar microrganismos e organizar os dispositivos de forma que permita um desempenho satisfatório da esterilização.

Objetivo da esterilização: eliminar microrganismos. Indicadores biológicos e químicos são utilizados para garantir o bom progresso do ciclo de esterilização.

Figura 21 - Estrutura do modelo de referência referente à decisão treze. Elaboração própria.

Tabela 20 - Regras de projeto para executar o modelo de tomada de decisão referente à decisão treze. Elaboração própria.

\section{Parâmetros de produtividade e desempenho}

\subsection{Definição dos indicadores de produtividade}

Tempo de processamento dos artigos selecionados como amostras. Ex: Tempo ideal da pré-desinfecção: 15 minutos (Sancinetti, e Gatto, 2007).

Produção por hora/funcionário (Sancinetti, e Gatto, 2007).

Tempo de processamento de artigos e disponibilidade de pessoal (Sancinetti, e Gatto, 2007).

13.2. Definição dos indicadores de desempenho de operação

A definição clara das etapas da operação também permite projetar indicadores que meçam de maneira eficaz o desempenho da operação.

\begin{tabular}{|c|c|c|c|c|}
\hline $\begin{array}{l}\text { Objetivo da pré- } \\
\text { desinfecção }\end{array}$ & $\begin{array}{l}\text { Objetivo da } \\
\text { limpeza }\end{array}$ & $\begin{array}{l}\text { Objetivo da } \\
\text { verificação }\end{array}$ & $\begin{array}{c}\text { Objetivo do } \\
\text { empacotamento }\end{array}$ & $\begin{array}{l}\text { Objetivo da } \\
\text { esterilização }\end{array}$ \\
\hline $\begin{array}{l}\text { Diminuir a população de } \\
\text { microrganismos nos } \\
\text { instrumentos sujos para } \\
\text { facilitar a lavagem e } \\
\text { proteger a equipe durante a } \\
\text { manipulação (Di Mascolo } \\
\text { et al., 2006). } \\
\text { O processo de limpeza visa } \\
\text { a remoção da sujidade } \\
\text { visível e, por conseqüência, } \\
\text { a retirada da carga } \\
\text { microbiana inicial em 99,9 } \\
\text { (Schmidt, } \\
\text { Yonekura e Gil, 2008). }\end{array}$ & $\begin{array}{l}\text { Eliminar } \\
\text { manchas, com a } \\
\text { ação da equipe } \\
\text { conjugada à ação } \\
\text { mecânica para } \\
\text { obter uma } \\
\text { limpeza funcional } \\
\text { do dispositivo (Di } \\
\text { Mascolo et al., } \\
\text { 2006). }\end{array}$ & $\begin{array}{l}\text { Garantir que } \\
\text { nenhuma } \\
\text { deterioração } \\
\text { afete a } \\
\text { segurança, } \\
\text { integridade ou } \\
\text { funcionamento } \\
\text { do dispositivo } \\
\text { (Di Mascolo et } \\
\text { al., 2006). }\end{array}$ & $\begin{array}{l}\text { Embarreirar } \\
\text { microrganismos } \\
\text { e organizar os } \\
\text { dispositivos de } \\
\text { forma que } \\
\text { permita um } \\
\text { desempenho } \\
\text { satisfatório da } \\
\text { esterilização (Di } \\
\text { Mascolo et al., } \\
\text { 2006). }\end{array}$ & $\begin{array}{l}\text { Eliminar } \\
\text { microrganismos. } \\
\text { Indicadores } \\
\text { biológicos e } \\
\text { químicos são } \\
\text { utilizados para } \\
\text { garantir o bom } \\
\text { progresso do } \\
\text { ciclo de } \\
\text { esterilização (Di } \\
\text { Mascolo et al., } \\
\text { 2006). }\end{array}$ \\
\hline
\end{tabular}




\section{Decisões Táticas}

14.

Mecanismos

de

coordenação

14.1.Mecanismos de coordenação e relações hierárquicas

Responsável técnico do CME

Comitê de Processamento de Produtos (CPPS)

Centro Cirúrgico (mapa cirúrgico)

Área de compras

Lavanderia/ rouparia

Almoxarifado

OPME

Farmácia (água destilada, álcool, etc.)

Figura 22 - Estrutura do modelo de referência referente à decisão quatorze. Elaboração própria.

Tabela 21 - Regras de projeto para executar o modelo de tomada de decisão referente à decisão quatorze. Elaboração própria.

\section{Mecanismos de coordenação}

\subsection{Mecanismos de coordenação e relações hierárquicas}

Responsável técnico da CME (RDC 15, 2012).

Comitê de Processamento de Produtos (CPPS): O serviço de saúde que realize mais de quinhentas cirurgias/mês, excluindo partos, deve constituir um Comitê de Processamento de Produtos para Saúde - CPPS, composto minimamente, por um representante: I - da diretoria do serviço de saúde; II - responsável pelo CME; III - do serviço de enfermagem; IV - da equipe médica; V - da CCIH (Comissão de Controle de Infecção Hospitalar). Define critérios de aceitabilidade de produtos para saúde, não pertencentes ao serviço, esterilizados em empresas processadoras quando a tecnologia necessária para a esterilização do produto não estiver disponível na CME do serviço de saúde (RDC 15, 2012).

Interações enre Centro Cirúrgico (mapa cirúrgico) e CME (Neto \&Malik, 2012).

Interações entre lavanderia e CME (Neto \&Malik, 2012).

Interações entre almoxarifado e CME (Neto \&Malik, 2012).

Interações entre OPME e CME (Neto \&Malik, 2012).

15.

Elaboração do Procedimento Operacional Padrão (POP)

\subsection{Elaboração dos POPs}

Incorporação das práticas de qualidade nos processos

Incorporação dos parâmetros de segurança do paciente

Incorporação das atribuições do RH

Incorporação dos parâmetros de segurança profissional

Incorporação dos parâmetros de produtividade e desempenho

Estabelecimento de formas de monitoramento da execução dos POPs

Figura 23 - Estrutura do modelo de referência referente à decisão quinze. Elaboração própria. 
Tabela 22 - Regras de projeto para executar o modelo de tomada de decisão referente à decisão quinze. Elaboração própria.

\begin{tabular}{|l|}
\hline \multicolumn{1}{|c|}{ 15. Elaboração do Procedimento Operacional Padrão (POP) } \\
\hline 15.1. $\quad$ Elaboração dos POPs \\
\hline $\begin{array}{l}\text { Cada etapa do processamento do instrumental cirúrgico e dos produtos para saúde deve seguir um } \\
\text { Procedimento Operacional Padrão - POP, elaborado com base em referencial científico. Este } \\
\text { documento deve ser amplamente divulgado no CME e estar disponível para consulta (RDC 8, 2009). }\end{array}$ \\
\hline Incorporação das práticas de qualidade nos processos (RDC 15, 2012). \\
\hline Incorporação dos parâmetros de segurança do paciente (RDC 15, 2012). \\
\hline Incorporação das atribuições do RH (RDC 15, 2012). \\
\hline Incorporação dos parâmetros de segurança profissional (RDC 15, 2012). \\
\hline Incorporação dos parâmetros de produtividade e desempenho (RDC 15, 2012). \\
\hline Esbelecimento de formas de monitoramento da execução dos POPs (RDC 15, 2012). \\
\hline
\end{tabular}

16.1.Avaliação da capacidade no médio prazo

Avaliação das demandas futuras

16. Avaliação Flutuações das demandas

da capacidade no médio

prazo

Medição da capacidade de volume de produção

Medição da capacidade de insumos

Figura 24 - Estrutura do modelo de referência referente à decisão dezesseis. Elaboração própria.

Tabela 23 - Regras de projeto para executar o modelo de tomada de decisão referente à decisão dezesseis. Elaboração própria.

\begin{tabular}{|l|}
\hline \multicolumn{1}{|c|}{ 16. Avaliação da capacidade no médio prazo } \\
\hline 16.1. Avaliação da capacidade no médio prazo \\
\hline $\begin{array}{l}\text { Avaliação das demandas futuras: previsão de demanda e análise da previsão para medir a capacidade } \\
\text { a ser oferecida pela CME (Slack et al., 2009). }\end{array}$ \\
\hline $\begin{array}{l}\text { Flutuações das demandas: Análise da demanda histórica e da previsão de demanda para identificar } \\
\text { as variações de demanda a fim de medir a capacidade a ser oferecida pelo CME. Para gerenciar a } \\
\text { diferença entre capacidade e demanda, há três estratégias: absorver as mudanças ou flutuações da } \\
\text { demanda, alterar a capacidade de produção durante as flutuações e gerenciar a demanda, tentando } \\
\text { ajustá-la à capacidade disponível (Slack et al., 2009). }\end{array}$ \\
\hline $\begin{array}{l}\text { Medição da capacidade de volume de produção: Calcular a capacidade a ser oferecida pelo CME por } \\
\text { tipo de produto processado com base na previsão de demanda e identificação das flutuações das } \\
\text { demandas (Slack et al., 2009). }\end{array}$ \\
\hline $\begin{array}{l}\text { Medição da capacidade de insumos: Cálculo da quantidade de insumos necessária para processar os } \\
\text { produtos demandados pelas unidades consumidoras (Slack et al., 2009). }\end{array}$ \\
\hline
\end{tabular}


17.1.Previsão de fornecimento

Área de compras

Lavanderia

Almoxarifado

OPME

17.

Fornecimento médio prazo

Figura 25 - Estrutura do modelo de referência referente à decisão dezessete. Elaboração própria.

Tabela 24 - Regras de projeto para executar o modelo de tomada de decisão referente à decisão dezessete. Elaboração própria.

\section{Fornecimentono médio prazo}

17.1. Previsão de fornecimento

Planejamento periódico de compras de materiais e equipamentos e que o investimento seja atrelado à demanda de cada unidade usuária, não ultrapassando os limites programados para tal investimento (Graziano et al., 2011).

Área de compras: previsão de fornecimento de insumos (ex: integradores para testes químicos, grau cirúrgico, etc.) para processamento dos artigos médicos no CME (Neto \& Malik, 2012).

Lavanderia: previsão de fornecimento de roupas a serem processadas no CME (Neto \& Malik, 2012).

Almoxarifado: previsão de fornecimento de insumos (ex: detergentes enzimáticos, etc.) para processamento dos artigos médicos no CME (Neto \& Malik, 2012).

OPME: previsão de fornecimento de próteses a serem processados no CME (Neto \& Malik, 2012).

17.2. Tipo de aquisição de insumos e serviços

Compra: O CME e as empresas processadoras só podem processar produtos para saúde regularizados junto à Anvisa (RDC 15, 2012). O planejamento da caixa-padrão deverá ser feito de forma que sua utilização possa servir a outras cirurgias de porte semelhante. Simplifica o processo de compra, diminuindo a possibilidade de confusão entre os diversos tipos de materiais semelhantes; Reduz compras de emergência, geralmente realizadas com custos maiores (Graziano et al., 2011).

Comodato: equipamentos (ex: lavadoras ultrassônicas) (Graziano et al., 2011).

Terceirização: Empresa processadora regularizada junto aos órgãos sanitários. A terceirização deve ser formalizada mediante contrato de prestação de serviço. A empresa processadora deve realizar todas as fases do processamento incluindo limpeza, inspeção, preparo e acondicionamento, esterilização, armazenamento e devolução para o serviço de saúde. O CPPS poderá definir critérios de aceitabilidade de produtos para saúde. (RDC 15, 2012). 


\subsection{Seleção dos fornecedores}

Verificação dos candidatos a fornecedores quanto ao atendimento às especificações dos insumos e produtos (Slack et al., 2009).

Verificação do menor preço para o atendimento ao mesmo grau de especificação de serviço (Slack et al., 2009).

18.

Gestão das informações
18.1.Forma de registro das informações

Registro manual

Registro em planilha (computador)

Registro automático (tecnologia RFID)

18.2.Forma de divulgação das informações

Treinamentos e capacitações

Periodicidade

Conteúdos gerais

Visual (cartazes dos postos de trabalho, etc.)

Virtual (tablets, etc.)

18.2.Forma de armazenamento das informações

Arquivos em papel

Base de dados

Figura 26 - Estrutura do modelo de referência referente à decisão dezoito. Elaboração própria.

Tabela 25 - Regras de projeto para executar o modelo de tomada de decisão referente à decisão dezoito. Elaboração própria.

\section{Gestão das informações}

\subsection{Forma de registro das informações}

Registro manual: O CME e a empresa processadora devem dispor de um sistema de informação manual ou automatizado com registro do monitoramento e controle das etapas de limpeza e desinfecção ou esterilização constante nesta resolução, bem como da manutenção e monitoramento dos equipamentos. Os registros devem ser arquivados, de forma a garantir a sua rastreabilidade, em conformidade com o estabelecido em legislação específica ou, na ausência desta, por um prazo mínimo de cinco anos, para efeitos de inspeção sanitária (RDC 15, 2012). Cada etapa do processamento do instrumental cirúrgico e dos produtos para saúde deve seguir Procedimento Operacional Padrão - POP elaborado com base em referencial científico atualizado e normatização pertinente (RDC 15, 2012).

Registro em planilha (computador) (RDC 15, 2012).

Registro automático (tecnologia RFID) (Klundert, Muls e Schadd, 2008).

\begin{tabular}{ll|ll} 
18.2. & Forma de divulgação das & 18.2. & Forma de armazenamento das informações
\end{tabular} informações

Treinamentos: Operação e tipologia dos Arquivos em papel (RDC 15, 2012). detergentes enzimáticos, habilidades requeridas para operações de esterilização (RDC 15, 2012). Visual (cartazes dos postos de trabalho, 
etc.) O POP deve ser amplamente

divulgado e estar disponível para

consulta (RDC 15, 2012).

Virtual (tablets, etc.)

19.

Gestão da produção
19.1. Definição dos horários de recebimento/ distribuição dos materiais a serem processados

\section{Por turnos}

Por especialidade

Por prioridade

19.2.Definição das metas de atravessamento dos materiais

Produtos críticos

Produtos semicríticos

Produtos não críticos

Figura 27 - Estrutura do modelo de referência referente à decisão dezenove. Elaboração própria.

Tabela 26 - Regras de projeto para executar o modelo de tomada de decisão referente à decisão dezenove. Elaboração própria.

\section{Gestão da produção}

19.1. Definição dos horários de recebimento dos materiais a serem processados

Por turnos: Necessidade de estipular um horário para entrega e recebimento de materiais.

Determinar horário de entrega e recebimento de materiais nos períodos da manhã, tarde e noite (Imai, 2003).

Por especialidade: Estabelecer horários de recebimento específicos por unidade consumidora (CC, unidades de internação) e/ou especialidade médica (ex: ortopedia horário de recebimento x, neurologia horário de recebimento y, etc.) (Imai, 2003).

Por prioridade: Definição de uma unidade consumidora a ser atendida prioritariamente (Ex: atendimento prioritário ao CC) (Turrini, Moriya, Bronzatti, 2011).

19.2. Definição das metas de atravessamento dos materiais

Definir as metas de atravessamento para os produtos críticos, semicríticos e não críticos (Hayes et al., 2008).

Melhorias no processo inicial (etapa de pré-desinfecção) melhoram de forma significativa o atravessamento dos materiais (Di Mascolo et al., 2006).

20.1.Definição das formas de monitoramento do estoque

20.

Manual

RFID

Gestão do estoque

\subsection{Organização do estoque}

Por especialidade

Por frequência de requisição de materiais

Por validade do processo de esterilização

Figura 28 - Estrutura do modelo de referência referente à decisão vinte. Elaboração própria. 
Tabela 27 - Regras de projeto para executar o modelo de tomada de decisão referente à decisão vinte. Elaboração própria.

\section{Gestão do estoque}

20.1. Definição das formas de monitoramento do estoque

Manual: Sistema de registro de entrada e saída de material (Graziano et al., 2011)

RFID: Sistema informatizado (caixas com código de barras). Os instrumentais que compõem as caixas de instrumental cirúrgico estão cadastrados utilizando uma codificação e cada instrumental tem um histórico dentro do sistema informatizado, onde constam os dados como: marca, código de fábrica, data da incorporação na caixa de instrumental; isto nos permite fazer uma análise da vida útil do instrumental, extravios, utilização entre outros controles (Graziano et al., 2011).

20.2. Organização do estoque

Por especialidade: Cada especialidade médica (ortopedia, neurologia, vascular, etc.) possui prateleiras específicas para a armazenagem no estoque.

Por frequência de requisição de materiais: Os materiais distribuídos com maior frequência são localizados próximos ao monta-carga ou a outra saída de expedição do material.

21.1. Definição do regime de escalas Periodicidade

21.

Gestão do RH

Figura 29 - Estrutura do modelo de referência referente à decisão vinte e um. Elaboração própria.
21.2. Segurança do profissional

Definição de EPI por área de operação (RDC 15/2012)

21.3. Reconhecimento profissional

Promoções

Recompensas por produtividade 
Tabela 28 - Regras de projeto para executar o modelo de tomada de decisão referente à decisão vinte e um. Elaboração própria.

\section{Gestão do RH}

\subsection{Definição do regime de escalas}

Determinar o período de tempo do turno e a periodicidade (Ex: distribuição dos turnos de seis horas (manhã e tarde) e turnos de 12 horas (finais de semana, feriados e noturno) (Graziano et al., 2011).

21.2. Segurança do profissional

Definição de EPI por área de operação (RDC 15/2012).

\begin{tabular}{|c|c|c|c|c|c|c|}
\hline $\begin{array}{l}\text { EPI sala/ } \\
\text { área }\end{array}$ & $\begin{array}{c}\text { Óculos } \\
\text { de } \\
\text { proteção }\end{array}$ & Máscara & Luvas & $\begin{array}{c}\text { Avental } \\
\text { impermeável } \\
\text { Manga longa }\end{array}$ & $\begin{array}{l}\text { Protetor } \\
\text { auricular }\end{array}$ & $\begin{array}{l}\text { Calçado } \\
\text { fechado }\end{array}$ \\
\hline Recepção & $\mathrm{X}$ & $\mathrm{X}$ & $\mathrm{X}$ & $\mathrm{X}$ & & $\begin{array}{l}\text { Impermeável } \\
\text { antiderrapante }\end{array}$ \\
\hline Limpeza & $\mathrm{X}$ & $\mathrm{X}$ & $\begin{array}{c}\text { Borracha } \\
\text { cano } \\
\text { longo }\end{array}$ & $\mathrm{X}$ & $\mathrm{X}$ & $\begin{array}{l}\text { Impermeável } \\
\text { antiderrapante }\end{array}$ \\
\hline $\begin{array}{l}\text { Preparo e } \\
\text { acondiciona } \\
\text { mento }\end{array}$ & & $\mathrm{X}$ & $\mathrm{X}$ & & $\begin{array}{c}\mathrm{Se} \\
\text { necessário }\end{array}$ & $\mathrm{X}$ \\
\hline $\begin{array}{l}\text { Desinfecção } \\
\text { química }\end{array}$ & $\mathrm{X}$ & $\mathrm{X}$ & $\begin{array}{c}\text { Borracha } \\
\text { cano } \\
\text { longo } \\
\end{array}$ & $\mathrm{X}$ & & $\begin{array}{l}\text { Impermeável } \\
\text { antiderrapante }\end{array}$ \\
\hline \multicolumn{7}{|c|}{ 21.3. Reconhecimento profissional } \\
\hline
\end{tabular}

22.

22.1.Manutenção dos equipamentos

Empresa comodata ou empresa terceirizada de manutenção/ próprio hospital

Manutenção

22.2.Manutenção das instalações

22.3. Manutenção do sistema de informação

Figura 30 - Estrutura do modelo de referência referente à decisão vinte e dois. Elaboração própria. 
Tabela 29 - Regras de projeto para executar o modelo de tomada de decisão referente à decisão vinte e dois. Elaboração própria.

\section{Manutenção}

22.1. Manutenção dos equipamentos

Na manutenção dos equipamentos, as informações resultantes das intervenções técnicas realizadas devem ser arquivadas para cada equipamento, contendo, no mínimo: I - Data da intervenção; II - Identificação do equipamento; III - Local de instalação; IV - Descrição do problema detectado e nome do responsável pela identificação do problema; V Descrição do serviço realizado, incluindo informações sobre as peças trocadas; VI Resultados da avaliação dos parâmetros físicos realizados após a intervenção e complementados com indicadores químicos e biológicos, quando indicado; VII - Nome do profissional que acompanhou a intervenção e do técnico que executou o procedimento (RDC 15/2012).

A manutenção pode ser realizada pelo próprio hospital (engenharia clínica) ou ser delegada para empresa comodata ou empresa terceirizada de manutenção (Neto \& Malik, 2012). As leitoras de indicadores biológicos (esterilização) e as seladoras térmicas (preparo e acondicionamento) devem ser calibradas, no mínimo, anualmente (RDC 15, 2012).

22.2. Manutenção das instalações

A manutenção pode ser realizada pelo próprio hospital (setor de obras e arquitetura) ou ser terceirizada (Neto \& Malik, 2012).

22.3. Manutenção do sistema de informação

A manutenção pode ser realizada pelo próprio hospital (setor de TI) ou ser terceirizada (Neto \& Malik, 2012).

\section{Decisões Operacionais}

23.

Previsão da demanda de curto prazo

\subsection{Recebimento do mapa cirúrgico}

Janela de tempo para recebimento do mapa

23.2.Informação de demandas históricas das demandas das unidades de internação

Figura 31 - Estrutura do modelo de referência referente à decisão vinte e três. Elaboração própria. 
Tabela 30 - Regras de projeto para executar o modelo de tomada de decisão referente à decisão vinte e três. Elaboração própria.

\section{Previsão da demanda de curto prazo}

\subsection{Recebimento do mapa cirúrgico}

Janela de tempo para recebimento do mapa: recebimento do mapa cirúrgico com antecedência para programar os produtos a serem disponibilizados para o atendimento ao centro cirúrgico (demanda prioritária) (Turrini, Moriya, Bronzatti, 2011).

23.2. Informação de demandas históricas das demandas das unidades de internação

Levantamento das necessidades das unidades usuárias, identificando a quantidade e especificidade para atender a demanda, com uma margem de segurança para situações não previstas, como alteração de perfil de pacientes internados, bem como a necessidade observada ou relatada pelos clientes que utilizam os materiais enviados pelo CME, por exemplo, as equipes cirúrgicas (Graziano et al., 2011) (Castilho \& Leite, 2001).

A previsão é realizada pela média histórica de consumo, média aritmética móvel, a partir do registro do consumo dos últimos seis meses (Turrini, Moriya, Bronzatti, 2011) (Neto, Reinhardt, 2002).

No CC a previsão de material deve considerar o número diário de cirurgias realizadas por especialidades (número médio e mensal de cirurgias de emergências/urgências e por especialidade), número e tipo médio de anestesias, horário de funcionamento e urgências (Graziano et al., 2011) (Neto, Reinhardt, 2002).

24.1.Estabelecimento dos roteiros de produção (sequenciamento)

Produtos críticos

24.

Programação da produção

Figura 32 - Estrutura do modelo de referência referente à decisão vinte e quatro. Elaboração própria.
Produtos semicríticos

Produtos não críticos

24.2.Programação da produção

Priorização do que vai ser processado

Alocação dos profissionais nas escalas 
Tabela 31 - Regras de projeto para executar o modelo de tomada de decisão referente à decisão vinte e quatro. Elaboração própria.

\section{Programação da produção}

24.1. Estabelecimento dos roteiros de produção (sequenciamento)

Estabelecimento da sequência de material sujo a ser processado pelas etapas de operação no CME (quais atividades executadas e equipamentos utilizados para cada tipo de produto dentro das categorias de criticidade (crítico, semicrítico e não crítico) (Ozturk, Begen, Zaric, 2014).

24.2. Programação da produção

A programação em paralelo é encontrada no serviço de esterilização. Métodos exatos para resolver o problema de programação dos lotes de diferentes tamanhos a fim de minimizar o tempo de atravessamento: heurísticas, metaheurísticas, algoritmos de aproximação, algoritmo genético e branch and bound baseado em heurística (Ozturk, Begen, Zaric, 2014).

Priorização do que vai ser processado: dado de entrada necessário para identificar o roteiro de produção e programar a capacidade a ser utilizada para atendimento das demandas.

Alocação dos profissionais nas escalas: quantidade de profissionais alocada em cada etapa de esterilização para atender à programação dos produtos nos roteiros de processamento estabelecidos.

\subsection{Monitoramento da qualidade}

Testes de controle de esterilização (químico, biológico e Bowie \& Dick)

Testes das condições ambientais

25.

Controle de qualidade

Figura 33 - Estrutura do modelo de referência referente à decisão vinte e cinco. Elaboração própria.
Inspeção dos produtos processados durantes as etapas de produção

25.2. Rastreamento dos produtos processados

Informações registradas nos lotes de produtos processados

Anexação das informações dos testes de qualidade no prontuário do paciente

25.3.Medição dos indicadores de operação 
Tabela 32 - Regras de projeto para executar o modelo de tomada de decisão referente à decisão vinte e cinco. Elaboração própria.

\section{Controle de qualidade}

25.1. Monitoramento da qualidade

Testes de controle de esterilização (químico, biológico e Bowie \& Dick): A área de monitoramento da esterilização de produtos para saúde deve dispor de incubadoras de indicadores biológicos. O monitoramento do processo de esterilização deve ser realizado em cada carga em pacote teste desafio com integradores químicos (classes 5 ou 6), segundo rotina definida pelo próprio CME ou pela empresa processadora. $\mathrm{O}$ monitoramento do processo de esterilização com indicadores físicos deve ser registrado a cada ciclo de esterilização. É obrigatória a realização de teste para avaliar o desempenho do sistema de remoção de ar (Bowie \& Dick) da autoclave assistida por bomba de vácuo, no primeiro ciclo do dia. Não é permitida a alteração dos parâmetros estabelecidos na qualificação de operação e de desempenho de qualquer ciclo dos equipamentos de esterilização. O ciclo para uso imediato deve ser monitorado por integrador ou emulador químico (RDC 15, 2012).

Testes das condições ambientais: verificação das condições ambientais estabelecidas na RDC 15/2012 para cada área de operação da CME.

Inspeção dos produtos processados durantes as etapas de produção: Validação da conformidade do produto durante o processamento da esterilização. A limpeza dos produtos para saúde, seja manual ou automatizada, deve ser avaliada por meio da inspeção visual, com o auxílio de lentes intensificadoras de imagem de, no mínimo, oito vezes de aumento, complementada, quando indicado, por testes químicos disponíveis no mercado (RDC 15, 2012).

25.2. $\quad$ Rastreamento dos produtos processados

Informações registradas nos lotes de produtos processados: I - nome do produto; II número do lote; III - data da esterilização; IV - data limite de uso; V - método de esterilização; VI - nome do responsável pelo preparo (RDC 15, 2012).

Anexação das informações dos testes de qualidade no prontuário do paciente (Graziano et al., 2011).

25.3. Medição dos indicadores de operação

Medição dos parâmetros de desempenho na execução das operações do CME (Neto \&Malik, 2012). 
26.1.Formas de controle do estoque

Manual

Sistema de informação

26.

Controle de estoque
26.2.Monitoramento do estoque

Controle periódico das condições ambientais

Controle periódico das condições físicas dos materiais em estoque

Controle periódico dos níveis de estoque

Data de validade dos produtos acabados

26.3.Elaboração de relatórios de controle

Saídas de materiais

Materiais não conformes para entrega

Figura 34 - Estrutura do modelo de referência referente à decisão vinte e seis. Elaboração própria.

Tabela 33 - Regras de projeto para executar o modelo de tomada de decisão referente à decisão vinte e seis. Elaboração própria.

\section{Controle de estoque}

26.1. Formas de controle do estoque

Manual: Caso a forma de registro escolhida seja a manual, o registo de recebimento e expedição de material esterilizado é manual (RDC 15, 2012).

Sistema de informação: Caso a forma de registro escolhida seja a automatizada, o registro de recebimento e expedição de material esterilizado é imputado nos pontos locais de sistema de informação (planilhas disponíveis em dispositivos, computadores) (RDC 15, 2012).

26.2. Monitoramento do estoque

Controle periódico das condições ambientais (RDC 15, 2012).

Controle periódico das condições físicas dos materiais em estoque (Graziano et al., 2011).

Controle periódico dos níveis de estoque (Slack et al., 2009).

Verificação da data de validade dos produtos acabados (RDC 15, 2012).

26.3. Elaboração de relatórios de controle

Saídas de materiais: registro das saídas de materiais da área de armazenagem e distribuição a fim de obter giro por produto por especialidade (RDC 15, 2012).

Materiais não conformes para entrega: registro de produtos identificados como não conformes no momento da expedição (RDC 15, 2012). 
27.

Controle dos insumos

\subsection{Mix dos insumos utilizados}

\section{Embalagens}

Detergentes enzimáticos

\section{Esterilizantes}

\subsection{Monitoramento dos insumos}

Quantidade/período

Data de validade

Figura 35 - Estrutura do modelo de referência referente à decisão vinte e sete. Elaboração própria.

Tabela 34 - Regras de projeto para executar o modelo de tomada de decisão referente à decisão vinte e sete. Elaboração própria.

\section{Controle dos insumos}

\subsection{Mix dos insumos utilizados}

Embalagens: Definição dos tipos de embalagens a serem utilizadas conforme o tipo de produto processado (Graziano et al., 2011).

Detergentes enzimáticos: Definição das quantidades de detergentes enzimáticos utilizados conforme a demanda de produtos processados (Graziano et al., 2011). Esterilizantes: esterilizantes/desinfectantes utilizados conforme o tipo de operação escolhido para esterilização e o tipo de produto submetido à operação de desinfecção (Graziano et al., 2011).

27.2. Monitoramento dos insumos

Quantidade/período: quantidade de insumos utilizados por período de tempo (Slack et al., 2009).

Data de validade: monitoramento da data de validade dos insumos utilizados no processo de esterilização (RDC 15, 2012).

28.

Gestão dos recursos humanos

\subsection{Treinamentos e capacitações periódicos}

Atualização da legislação e das práticas de qualidade

Revisão dos conteúdos gerais

Divulgação do POP

28.2. Medição dos indicadores de desempenho

Figura 36 - Estrutura do modelo de referência referente à decisão vinte e oito. Elaboração própria. 
Tabela 35 - Regras de projeto para executar o modelo de tomada de decisão referente à decisão vinte e oito. Elaboração própria.

\section{Gestão dos recursos humanos}

28.1. Treinamentos periódicos

Atualização da legislação e das práticas de qualidade: treinamentos para divulgação das atualizações existentes nas legislações específicas para CME e das práticas de qualidades estabelecidas pelo CME (RDC 15, 2012).

Revisão dos conteúdos gerais: Os profissionais do CME e da empresa processadora devem receber capacitação específica e periódica nos seguintes temas: I - classificação de produtos para saúde; II - conceitos básicos de microbiologia; III - transporte dos produtos contaminados; IV - processo de limpeza, desinfecção, preparo, inspeção, acondicionamento, embalagens, esterilização, funcionamento dos equipamentos existentes; V - monitoramento de processos por indicadores químicos, biológicos e físicos; VI - rastreabilidade, armazenamento e distribuição dos produtos para saúde; VII manutenção da esterilidade do produto (RDC 15, 2012).

Divulgação do POP: treinamentos de divulgação das atualizações e capacitações quanto aos processos de esterilização do CME (RDC 15, 2012).

28.2. Medição dos indicadores de desempenho

Medição dos indicadres de desempenho dos profissionais na execução das operações do CME (Neto \&Malik, 2012).

29.1.Monitoramento

Equipamentos

29.

Monitoramento da capacidade
Recursos humanos

29.2. Suprimento de capacidade

Capacidades alternativas (ativação de equipamentos, recursos humanos, terceirização, etc.)

Figura 37 - Estrutura do modelo de referência referente à decisão vinte e nove. Elaboração própria. 
Tabela 36 - Regras de projeto para executar o modelo de tomada de decisão referente à decisão vinte e nove. Elaboração própria.

\section{Monitoramento da capacidade}

\subsection{Monitoramento}

Gerenciar a capacidade é lidar com a diferença entre a demanda pelo serviço e a capacidade de operação em suprir a demanda e atender adequadamento os pacientes. Capacidade está intimamente ligada a como gerenciamos recursos, pessoas, equipamentos e instalações (Ballou, 2010).

Equipamentos: monitoramento da conformidade de funcionamento dos equipamentos para identificar a capacidade real de operação (Slack et al., 2009).

Recursos humanos: monitoramento da quantidade de profissionais executando as atividades em cada área de operação do CME a fim de avaliar e definir periodicamente a quantidade de pessoal adequado para atender as demandas locais de cada área de operação do CME (recepção, limpeza e preparo).

29.2. Suprimento de capacidade

Capacidades alternativas (ativação de equipamentos, recursos humanos, terceirização, etc.): ativação das capacidades alternativas conforme a variação da demanda e disponibilidade de equipamentos e recursos humanos (Slack et al., 2009).

30.1. Fluxos de informação

Entre as áreas de operação

Entre CME e demais entes hierárquicos

30.

Controle da informação

\subsection{Controle do registro de informações}

Recepção dos materiais sujos

Inspeção dos materiais

Lotes de esterilização

Resultados dos testes de controle (químico, biológico e Bowie \& Dick)

30.3. Arquivamento da informação

Figura 38 - Estrutura do modelo de referência referente à decisão trinta. Elaboração própria. 
Tabela 37 - Regras de projeto para executar o modelo de tomada de decisão referente à decisão trinta. Elaboração própria.

\begin{tabular}{|l|}
\hline \multicolumn{1}{|c|}{ 30. Controle da informação } \\
\hline 30.1. Fluxos de informação \\
\hline Entre as áreas de operação. \\
\hline Entre CME e demais entes hierárquicos. \\
\hline 30.2. Controle do registro de informações \\
\hline $\begin{array}{l}\text { Recepção dos materiais sujos: sistema de informação manual ou automatizado com } \\
\text { registro do monitoramento e controle das etapas de limpeza e desinfecção ou } \\
\text { esterilização constante nesta resolução, bem como da manutenção e monitoramento dos } \\
\text { equipamentos (RCD 15, 2012). Adoção do sistema de rastreamento por RFID permite o } \\
\text { registro automático das informações no recebimento dos materiais sujos no sistema de } \\
\text { informação. }\end{array}$ \\
\hline Inspeção dos materiais: registro das inspeçães realizadas (RCD 15, 2012). \\
\hline $\begin{array}{l}\text { Lotes de esterilização: registro de informações sobre o lote de esterilização em rótulo } \\
\text { (RCD 15, 2012). }\end{array}$ \\
\hline $\begin{array}{l}\text { Resultados dos testes de controle (químico, biológico e Bowie \& Dick): resultados } \\
\text { registrados e anexados ao prontuário do paciente (RCD 15, 2012). }\end{array}$ \\
\hline 30.3. Arquivamento da informação \\
\hline $\begin{array}{l}\text { O prazo de arquivamento para o registro histórico dos equipamentos de saúde deve ser } \\
\text { contado a partir da desativação ou transferência definitiva do equipamento de saúde do } \\
\text { serviço (RCD 15, 2012). }\end{array}$ \\
\hline
\end{tabular}

\section{Decisão objetivo}

31.1. Tipo de custeio

Custeio por absorção

31.

Custeio ABC

Custos

31.2. Tipo de custos

Custos de operação

Custos de terceirização

Figura 39 - Estrutura do modelo de referência referente à decisão trinta e um. Elaboração própria. 
Tabela 38 - Regras de projeto para executar o modelo de tomada de decisão referente à decisão trinta e um. Elaboração própria.

\section{Custos}

31.1. Tipo de custeio

Custeio por absorção (Klundert, Muls e Schadd, 2008) (Reymondon, Pellet \& Marcona, 2007).

Custeio ABC: 1) Diagnóstico institucional e unidade de análise; 2) Mapeamento dos processos e identificação das atividades; 3 ) Custeio das atividades e direcionadores de recursos; 4) Custeio dos objetos de custo e direcionadores de atividades (Klundert, Muls $\&$ Schadd, 2008).

31.1. Tipo de custos

Custos de operação: Custos de RH, custos materiais, custos relacionados à qualidade, incluindo custos de perda, avaliação e prevenção (Bozarth \& Handfield, 2008).

Custos de terceirização: custo de transporte, custo de estocar materiais esterilizados na sala de cirurgia e custos de instrumentos/materiais (Klundert, Muls \& Schadd, 2008).

A decisão custo é intitulada como decisão objetivo devido ao posicionamento da mesma na estrutura do modelo. É uma decisão definida após a obtenção da tomada de todas as decisões anteriores (30 decisões). Consequentemente, o modelo de decisão é iterativo, isto é, pode-se redefinir decisões de predecência anterior.

A descrição e o detalhamento das decisões principais e subdecisões que compõem o modelo de tomada de decisão (Tabela 6) constituem as regras de projeto para executar o modelo de tomada de decisão proposto. É um guia para conhecer as decisões e suas precedências, e saber as alternativas de implementação com as respectivas referências para consulta. 


\section{5 \\ Verificação prática: demonstração da aplicação do modelo}

Nessa seção é apresentada uma aplicação do modelo de referência de tomada de decisão de projeto de CMEs, elaborado e proposto nesta pesquisa, nos CMEs do complexo UERJ. O objetivo desta seção é demonstrar a aplicação do modelo. A partir da aplicação desdobram-se as análises e discussões do modelo frente ao contexto prático dos CMEs, sem o mérito de avaliar as operações dos CMEs da UERJ, visto que o objetivo principal desta pesquisa é a elaboração e proposição do modelo de referência, apresentado na seção 4 .

As informações dos CMEs, utilizadas na aplicação do modelo, foram extraídas a partir das entrevistas e mapeamento dos processos com os chefes e profissionais das unidades, conforme detalhado na subseção 3.4.

A aplicação do modelo levanta análises sobre o posicionamento das unidades estudadas no modelo. As análises desdobram-se nas discussões sobre a seguinte questão: atender os parâmetros dos instrumentais normativos é suficiente para viabilizar operações que minimizem os custos e atendam conforme os parâmetros de qualidade e segurança, mantendo a confiabilidade de entrega do produto esterilizado?

Ressalta-se que o objetivo desta seção não é avaliar os CMEs, e sim demonstrar a aplicação do modelo de referência proposto a unidades de operação de esterilização complexas com atendimento a diferentes unidades consumidoras.

\section{1}

\section{Método de aplicação do modelo de referência proposto}

Conforme descrito na subseção 3.4, os CMEs do complexo de saúde da UERJ atendem a demandas de diversas unidades consumidoras, cada qual com ampla variedade de especialidades. A demanda do centro cirúrgico do HUPE, por exemplo, contempla mais de 22 especialidades cirúrgicas, dentre elas, as de ortopedia, bucomaxilo, neurologia, etc. Cada especialidade possui instrumentais específicos. O CME PPC atende as demandas ambulatoriais e de odontologia. 
A partir das entrevistas e mapeamento dos processos, é possível extrair as informações necessárias para localizar onde os CMEs estão no modelo e fomentar a discussão sobre quais decisões propostas no modelo são tomadas pelos CMEs e como são tomadas, isto é, se decidem parcial ou minimamente ou acima do estabelecido pelos instrumentais normativos.

A Tabela 39 apresenta a aplicação do modelo proposto na seção 4 aos CMEs do complexo UERJ. A aplicação consiste em identificar quais decisões do modelo os CMEs adotam, como decidem e qual o grau de atendimento às decisões (parcial, minimamente ou acima do exigido pelos instrumentais normativos).

A estrutura apresentada mostra se os CMEs do complexo UERJ atendem ou não às decisões do modelo proposto através da resposta à pergunta "Atende ao modelo?", isto é, se os CMEs cumprem as decisões propostas no modelo de referência da presente pesquisa. Caso a resposta seja sim, os CMEs tomam a decisão proposta pelo modelo, caso a resposta seja não, os CMEs não decidem sobre o tópico proposto. Caso os CMEs tomem as decisões propostas, essa tomada de decisão pode ser parcial, mínima ou acima do exigido pelos instrumentais normativos, por isso a existência dos campos "Se sim, mínimo?", "Se sim, acima?". Tem decisões assinaladas pelos CMEs como atendendo ao modelo, mas sem apresentar se o atendimento é mínimo ou acima, pois são decisões não contempladas nos instrumentos normativos, sendo tal característica assinalada como "Não se aplica".

Antes de apresentar o posicionamento dos CMEs no modelo, cabe ressaltar que as operações do CME são minimamente consideradas dentro dos padrões de qualidade e segurança se atenderem aos instrumentos normativos nacionais, apresentados na subseção 3.3. Quando há tomada de decisão que atenda a uma alternativa acima do exigido na legislação, o CME enquadra-se acima do minimamente exigido. 


\subsection{Resultados e enquadramento dos CMEs no modelo}

A demonstração do modelo é apresentada através da aplicação aos CMEs do complexo da UERJ. Os resultados da aplicação do modelo são apresentados na Tabela 39.

A aplicação do modelo aos CMEs com operações previamente existentes permite a análise quanto ao posicionamento das mesmas diante das decisões propostas pelo modelo, isto é, permite a identificação das decisões tomadas, se as mesmas têm ações que atendem acima do estabelecido pelos instrumentos normativos ou se atendem pelo menos, ao mínimo estabelecido pelas legislações. As análises de posicionamento são descritas nesta seção.

O posicionamento dos CMEs diante do modelo proposto, por sua vez, levanta discussões sobre a suficiência de cumprir os parâmetros estabelecidos pelos instrumentos normativos para obter um modelo de operações eficiente e eficaz, atendendo aos objetivos de desempenho (qualidade, segurança e minimização de custo), apresentados na seção 5.3.

Tabela 39 - Aplicação do modelo de referência proposto aos CMEs pertencentes ao complexo UERJ. Elaboração própria.

\begin{tabular}{|c|c|c|c|c|c|c|}
\hline & \multicolumn{2}{|c|}{ Complexo UERJ } & \multirow{3}{*}{$\begin{array}{l}\text { Atende } \\
\text { ao } \\
\text { modelo } \\
?\end{array}$} & \multirow{3}{*}{$\begin{array}{l}\text { Se sim, } \\
\text { mínimo? }\end{array}$} & \multirow{3}{*}{$\begin{array}{l}\text { Se sim, } \\
\text { acima? }\end{array}$} \\
\hline & & CME HUPE & CME PPC & & & \\
\hline & & \multicolumn{2}{|c|}{ Decisões estratégicas } & & & \\
\hline \multirow{3}{*}{$\begin{array}{l}\text { 1. Definição } \\
\text { das } \\
\text { demandas }\end{array}$} & $\begin{array}{l}\text { 1.1. Identificação } \\
\text { das unidades } \\
\text { consumidoras }\end{array}$ & $\begin{array}{l}\text { CC, unidades } \\
\text { de internação, } \\
\text { UTI }\end{array}$ & Ambulatórios & Sim & $\mathrm{x}$ & \\
\hline & $\begin{array}{l}\text { 1.2. Definição dos } \\
\text { níveis de } \\
\text { serviço }\end{array}$ & $\begin{array}{l}\text { Demandas } \\
\text { tratadas } \\
\text { igualmente, } \\
\text { com } \\
\text { prioridades } \\
\text { pontuais. }\end{array}$ & $\begin{array}{l}\text { Demandas } \\
\text { tratadas } \\
\text { igualmente, } \\
\text { com } \\
\text { prioridades } \\
\text { pontuais. }\end{array}$ & Não & - & - \\
\hline & $\begin{array}{l}\text { 1.3. Priorização } \\
\text { das demandas } \\
\text { atendidas }\end{array}$ & $\begin{array}{l}\text { Sem } \\
\text { priorização; } \\
\text { primeiro } \\
\text { material que } \\
\text { chega é } \\
\text { processado } \\
\text { (FIFO) }\end{array}$ & $\begin{array}{l}\text { Sem } \\
\text { priorização; } \\
\text { primeiro } \\
\text { material que } \\
\text { chega é } \\
\text { processado } \\
\text { (FIFO) }\end{array}$ & Não & - & - \\
\hline
\end{tabular}




\begin{tabular}{|c|c|c|c|c|c|c|}
\hline & & \multicolumn{2}{|c|}{ Complexo UERJ } & \multirow{3}{*}{$\begin{array}{l}\text { Atende } \\
\text { ao } \\
\text { modelo } \\
?\end{array}$} & \multirow{3}{*}{$\begin{array}{l}\text { Se sim, } \\
\text { mínimo? }\end{array}$} & \multirow{3}{*}{$\begin{array}{l}\text { Se sim, } \\
\text { acima? }\end{array}$} \\
\hline & & CME HUPE & CME PPC & & & \\
\hline & & \multicolumn{2}{|c|}{ Decisões estratégicas } & & & \\
\hline $\begin{array}{l}\text { 2. Definição } \\
\text { dos tipos de } \\
\text { materiais } \\
\text { processados }\end{array}$ & - & $\begin{array}{l}\text { Segue o } \\
\text { modelo. }\end{array}$ & \begin{tabular}{|l} 
Segue o \\
modelo.
\end{tabular} & Sim & $\mathrm{x}$ & \\
\hline $\begin{array}{l}\text { 3. Desenho } \\
\text { dos } \\
\text { processos }\end{array}$ & - & $\begin{array}{l}\text { Sem desenho } \\
\text { dos processos } \\
\text { por } \\
\text { criticidade. } \\
\text { Forma de } \\
\text { execução das } \\
\text { operações } \\
\text { registrada nos } \\
\text { POPs. }\end{array}$ & $\begin{array}{l}\text { Sem desenho } \\
\text { dos processos } \\
\text { por } \\
\text { criticidade. } \\
\text { Forma de } \\
\text { execução das } \\
\text { operações } \\
\text { registrada nos } \\
\text { POPs. }\end{array}$ & Não & - & - \\
\hline \multirow[t]{2}{*}{$\begin{array}{l}\text { 4. Grau de } \\
\text { automação / } \\
\text { Equipament } \\
\text { os }\end{array}$} & $\begin{array}{l}\text { 4.1. Definição do } \\
\text { grau de } \\
\text { automação }\end{array}$ & $\begin{array}{l}\text { Sistema de } \\
\text { registro de } \\
\text { informação } \\
\text { manual. Sem } \\
\text { sistema de } \\
\text { rastreamento } \\
\text { de material no } \\
\text { processo. }\end{array}$ & \begin{tabular}{|l|} 
Sistema de \\
registro de \\
informação \\
manual. Sem \\
sistema de \\
rastreamento \\
de material no \\
processo.
\end{tabular} & Sim & $\mathrm{x}$ & \\
\hline & 4.2. Equipamentos & $\begin{array}{l}\text { Segue o } \\
\text { modelo. }\end{array}$ & $\begin{array}{l}\text { Segue o } \\
\text { modelo. }\end{array}$ & Sim & $\mathrm{x}$ & \\
\hline \multirow[t]{2}{*}{$\begin{array}{l}\text { 5. Definição } \\
\text { da } \\
\text { capacidade }\end{array}$} & $\begin{array}{l}\text { 5.1. Definição da } \\
\text { quantidade } \\
\text { máxima } \\
\text { produzida de } \\
\text { cada tipo de } \\
\text { produto } \\
\text { processado }\end{array}$ & $\begin{array}{l}\text { Não atende ao } \\
\text { modelo. }\end{array}$ & $\begin{array}{l}\text { Não atende ao } \\
\text { modelo. }\end{array}$ & Não & - & - \\
\hline & $\begin{array}{l}\text { 5.2. Identificação } \\
\text { de capacidades } \\
\text { alternativas } \\
\end{array}$ & Terceirização. & Terceirização. & Sim & $\mathrm{x}$ & \\
\hline
\end{tabular}




\begin{tabular}{|c|c|c|c|c|c|c|}
\hline & & \multicolumn{2}{|c|}{ Complexo UERJ } & \multirow{3}{*}{$\begin{array}{c}\text { Atende } \\
\text { ao } \\
\text { modelo } \\
?\end{array}$} & \multirow{3}{*}{$\begin{array}{c}\text { Se sim, } \\
\text { mínimo } \\
?\end{array}$} & \multirow{3}{*}{$\begin{array}{c}\text { Se } \\
\text { sim, } \\
\text { acima } \\
?\end{array}$} \\
\hline & & CME HUPE & CME PPC & & & \\
\hline & & \multicolumn{2}{|c|}{ Decisões estratégicas } & & & \\
\hline \multirow{5}{*}{$\begin{array}{l}\text { 6. Qualidade } \\
\text { e RH }\end{array}$} & $\begin{array}{l}\text { 6.1. Definição das } \\
\text { práticas de } \\
\text { controle de } \\
\text { qualidade }\end{array}$ & $\begin{array}{l}\text { Prevenção de } \\
\text { defeitos, } \\
\text { embalagens } \\
\text { com fita } \\
\text { especial para } \\
\text { autoclave, } \\
\text { indicadores } \\
\text { biológicos, } \\
\text { integradores } \\
\text { químicos, testes } \\
\text { de Bowie \& } \\
\text { Dick }\end{array}$ & $\begin{array}{l}\text { Inspeção } \\
\text { por lupa, } \\
\text { integradores } \\
\text { químicos, } \\
\text { teste de } \\
\text { Bowie \& } \\
\text { Dick, fita } \\
\text { classe II }\end{array}$ & Sim & $\mathrm{x}$ & \\
\hline & $\begin{array}{l}\text { 6.1. Definição dos } \\
\text { parâmetros de } \\
\text { segurança do } \\
\text { paciente }\end{array}$ & $\begin{array}{l}\text { Interação com a } \\
\text { Comissão de } \\
\text { Controle de } \\
\text { Infecção. }\end{array}$ & $\begin{array}{l}\text { Interação } \\
\text { com a } \\
\text { Comissão } \\
\text { de Controle } \\
\text { de Infecção. }\end{array}$ & Sim & $\mathrm{x}$ & \\
\hline & $\begin{array}{l}\text { 6.2. Definição das } \\
\text { atribuições do } \\
\text { RH }\end{array}$ & Segue RDC 15. & $\begin{array}{l}\text { Segue RDC } \\
15 .\end{array}$ & Sim & $\mathrm{x}$ & \\
\hline & $\begin{array}{l}\text { 6.2. Definição das } \\
\text { habilidades do } \\
\text { RH }\end{array}$ & $\begin{array}{l}\text { Profissionais } \\
\text { redirecionados } \\
\text { de outros } \\
\text { setores do } \\
\text { hospital para o } \\
\text { CME. }\end{array}$ & $\begin{array}{l}\text { Profissionai } \\
\text { s } \\
\text { redirecionad } \\
\text { os de outros } \\
\text { setores do } \\
\text { hospital } \\
\text { para o } \\
\text { CME. } \\
\end{array}$ & Não & - & - \\
\hline & $\begin{array}{c}\text { 6.2. Definição da } \\
\text { segurança } \\
\text { profissional }\end{array}$ & Segue RDC 15. & $\begin{array}{l}\text { Segue RDC } \\
15 .\end{array}$ & Sim & $\mathrm{x}$ & \\
\hline
\end{tabular}




\begin{tabular}{|c|c|c|c|c|c|c|}
\hline & & \multicolumn{2}{|c|}{ Complexo UERJ } & & & \\
\hline & & CME HUPE & CME PPC & \multirow{2}{*}{$\begin{array}{l}\text { Atende } \\
\text { ao } \\
\text { modelo } \\
?\end{array}$} & \multirow{2}{*}{$\begin{array}{c}\text { Se sim, } \\
\text { mínimo } \\
?\end{array}$} & \multirow{2}{*}{$\begin{array}{l}\text { Se sim, } \\
\text { acima? }\end{array}$} \\
\hline & & \multicolumn{2}{|c|}{ Decisões estratégicas } & & & \\
\hline $\begin{array}{l}\text { 7. Grau de } \\
\text { integração } \\
\text { (terceirizaçã } \\
\text { o) }\end{array}$ & $\begin{array}{l}\text { 7.1. CME } \\
\text { centralizada, } \\
\text { semicentraliza } \\
\text { da ou } \\
\text { descentralizad } \\
\text { a }\end{array}$ & $\begin{array}{l}\text { Centralizada } \\
\text { para produtos } \\
\text { críticos, } \\
\text { semicentralizad } \\
\text { a para produtos } \\
\text { não críticos } \\
\text { (limpeza e } \\
\text { empacotamento } \\
\text { realizados pelas } \\
\text { unidades de } \\
\text { internação) e } \\
\text { descentralizada } \\
\text { para } \\
\text { processamento } \\
\text { de materiais } \\
\text { termossensíveis } \\
\text { (terceirizada). } \\
\end{array}$ & $\begin{array}{l}\text { Centralizada } \\
\text { para produtos } \\
\text { críticos e não } \\
\text { críticos e } \\
\text { descentralizad } \\
\text { a para } \\
\text { processament } \\
\text { o de materiais } \\
\text { termossensíve } \\
\text { is } \\
\text { (terceirizada). }\end{array}$ & Sim & $\mathrm{X}$ & \\
\hline $\begin{array}{l}\text { 8. Tipos de } \\
\text { insumos }\end{array}$ & $\begin{array}{l}\text { 8.1. Tipos de } \\
\text { insumos } \\
\text { necessários } \\
\text { para a } \\
\text { produção }\end{array}$ & $\begin{array}{l}\text { Possuem todos } \\
\text { os insumos } \\
\text { listados no } \\
\text { modelo, acima } \\
\text { das } \\
\text { especificações } \\
\text { mínimas } \\
\text { (melhores } \\
\text { integradores } \\
\text { químicos, } \\
\text { embalagens, } \\
\text { stelclean). }\end{array}$ & $\begin{array}{l}\text { Possuem } \\
\text { todos os } \\
\text { insumos } \\
\text { listados no } \\
\text { modelo, } \\
\text { acima das } \\
\text { especificações } \\
\text { mínimas } \\
\text { (melhores } \\
\text { integradores } \\
\text { químicos, } \\
\text { embalagens, } \\
\text { stelclean). }\end{array}$ & Sim & & $\mathrm{x}$ \\
\hline $\begin{array}{l}9 . \\
\text { Dimensiona } \\
\text { mento do } \\
\text { RH }\end{array}$ & $\begin{array}{l}\text { 9.1. Dimensioname } \\
\text { nto do RH por } \\
\text { área }\end{array}$ & $\begin{array}{l}\text { Dimensioname } \\
\text { nto do número } \\
\text { de profissionais } \\
\text { é estimado de } \\
\text { acordo com a } \\
\text { demanda por } \\
\text { área de } \\
\text { operação do } \\
\text { CME. }\end{array}$ & $\begin{array}{l}\text { Dimensionam } \\
\text { ento do } \\
\text { número de } \\
\text { profissionais é } \\
\text { estimado de } \\
\text { acordo com a } \\
\text { demanda por } \\
\text { área de } \\
\text { operação do } \\
\text { CME. }\end{array}$ & Não & - & - \\
\hline & $\begin{array}{l}\text { 9.1.1. Cálculo da } \\
\text { carga de trabalho }\end{array}$ & - & - & Não & - & - \\
\hline & $\begin{array}{l}9.1 .2 . \\
\text { Determinanção do } \\
\text { tempo padrão }\end{array}$ & - & - & Não & - & - \\
\hline
\end{tabular}




\begin{tabular}{|c|c|c|c|c|c|c|}
\hline & & \multicolumn{2}{|c|}{ Complexo UERJ } & \multirow{3}{*}{$\begin{array}{l}\text { Atende } \\
\text { ao } \\
\text { modelo } \\
?\end{array}$} & \multirow{3}{*}{$\begin{array}{l}\text { Se sim, } \\
\text { mínimo } \\
?\end{array}$} & \multirow{3}{*}{$\begin{array}{l}\text { Se sim, } \\
\text { acima? }\end{array}$} \\
\hline & & CME HUPE & CME PPC & & & \\
\hline & & \multicolumn{2}{|c|}{ Decisões estratégicas } & & & \\
\hline \multirow{3}{*}{ 10. Estoques } & $\begin{array}{l}10.1 . \\
\text { Dimensionamento } \\
\text { do estoque }\end{array}$ & - & - & Não & - & - \\
\hline & $\begin{array}{l}\text { 10.2. Definição das } \\
\text { práticas de } \\
\text { controle de } \\
\text { qualidade do } \\
\text { estoque }\end{array}$ & $\begin{array}{l}\text { Treinamento } \\
\text { para manuseio } \\
\text { de materiais }\end{array}$ & \begin{tabular}{|l} 
Controle das \\
condições \\
ambientais, \\
treinamento \\
para manuseio \\
de materiais \\
\end{tabular} & Sim & $\begin{array}{l}\text { Não se } \\
\text { aplica }\end{array}$ & $\begin{array}{l}\text { Não se } \\
\text { aplica }\end{array}$ \\
\hline & $\begin{array}{l}\text { 10.3. Definição da } \\
\text { política de } \\
\text { controle de } \\
\text { estoque }\end{array}$ & - & - & Não & - & - \\
\hline \multirow{2}{*}{$\begin{array}{l}11 . \\
\text { Transporte }\end{array}$} & $\begin{array}{l}\text { 11.1. Tipo de } \\
\text { transporte de } \\
\text { materiais } \\
\text { para o } \\
\text { recebimento, } \\
\text { operação e } \\
\text { distribuição }\end{array}$ & $\begin{array}{l}\text { Monta carga } \\
\text { para CC, } \\
\text { manual para as } \\
\text { unidades de } \\
\text { internação, } \\
\text { carrinhos de } \\
\text { grade. }\end{array}$ & $\begin{array}{l}\text { Não tem } \\
\text { monta carga, } \\
\text { transporte } \\
\text { manual. }\end{array}$ & Sim & $\begin{array}{l}\text { Não se } \\
\text { aplica }\end{array}$ & $\begin{array}{l}\text { Não se } \\
\text { aplica }\end{array}$ \\
\hline & $\begin{array}{l}\text { 11.2. Definição do } \\
\text { transporte de } \\
\text { materiais } \\
\text { esterilizados } \\
\text { (quando } \\
\text { terceirizados) }\end{array}$ & $\begin{array}{l}\text { Não é decidido } \\
\text { pelo CME. }\end{array}$ & $\begin{array}{l}\text { Não é } \\
\text { decidido pelo } \\
\text { CME. }\end{array}$ & Sim & $\begin{array}{l}\text { Não se } \\
\text { aplica }\end{array}$ & $\begin{array}{l}\text { Não se } \\
\text { aplica }\end{array}$ \\
\hline \multirow[t]{3}{*}{$\begin{array}{l}12 . \\
\text { Instalações }\end{array}$} & $\begin{array}{l}\text { 12.1. Definição do } \\
\text { tamanho das } \\
\text { instalações }\end{array}$ & \begin{tabular}{|l} 
Faltam \\
requisitos da \\
legislação a \\
serem \\
atendidos. O \\
projeto de \\
layout original \\
não foi \\
executado em \\
completude.
\end{tabular} & $\begin{array}{l}\text { Parte elétrica: } \\
\text { queda de } \\
\text { energia, rede } \\
\text { elétrica é } \\
\text { muito antiga. } \\
\text { Falta de cano } \\
\text { de água } \\
\text { (canos para } \\
\text { por pias) }\end{array}$ & Não & - & - \\
\hline & $\begin{array}{c}\text { 12.2. Desenho das } \\
\text { instalações }\end{array}$ & $\begin{array}{l}\text { Segue o } \\
\text { modelo. }\end{array}$ & $\begin{array}{l}\text { Segue o } \\
\text { modelo. }\end{array}$ & Sim & $\mathrm{x}$ & \\
\hline & \begin{tabular}{|l} 
12.3. Número e \\
localização \\
das \\
instalações
\end{tabular} & $\begin{array}{l}\text { Segue o } \\
\text { modelo. }\end{array}$ & $\begin{array}{l}\text { Segue o } \\
\text { modelo. }\end{array}$ & Sim & $\mathrm{x}$ & \\
\hline
\end{tabular}




\begin{tabular}{|c|c|c|c|c|c|c|}
\hline & & \multicolumn{2}{|c|}{ Complexo UERJ } & & & \\
\hline & & CME HUPE & CME PPC & \multirow{2}{*}{$\begin{array}{l}\text { Atende } \\
\text { ao } \\
\text { modelo } \\
?\end{array}$} & \multirow{2}{*}{$\begin{array}{c}\text { Se sim, } \\
\text { mínimo } \\
?\end{array}$} & \multirow{2}{*}{$\begin{array}{l}\text { Se sim } \\
\text { acima? }\end{array}$} \\
\hline & & \multicolumn{2}{|c|}{ Decisões estratégicas } & & & \\
\hline \multirow{2}{*}{$\begin{array}{l}13 . \\
\text { Parâmetros de } \\
\text { produtividade } \\
\text { e desempenho }\end{array}$} & \begin{tabular}{|l|} 
13.1. Definição \\
dos \\
indicadores \\
de \\
produtivida \\
de
\end{tabular} & $\begin{array}{l}\text { Não trabalham } \\
\text { com } \\
\text { indicadores de } \\
\text { produtividade. }\end{array}$ & \begin{tabular}{|l|} 
Não \\
trabalham \\
com \\
indicadores de \\
produtividade.
\end{tabular} & Não & - & - \\
\hline & \begin{tabular}{|l} 
13.2. Definição \\
dos \\
indicadores \\
de \\
desempenh \\
o de \\
operação
\end{tabular} & $\begin{array}{l}\text { Somente } \\
\text { trabalham com } \\
\text { indicador de } \\
\text { infecção } \\
\text { hospitalar. Não } \\
\text { trabalham com } \\
\text { indicadores de } \\
\text { desempenho de } \\
\text { processos. }\end{array}$ & \begin{tabular}{|l} 
Somente \\
trabalham \\
com indicador \\
de infecção \\
hospitalar. \\
Não \\
trabalham \\
com \\
indicadores de \\
desempenho \\
de processos.
\end{tabular} & Não & - & - \\
\hline & & \multicolumn{2}{|c|}{ Decisões táticas } & & & \\
\hline $\begin{array}{l}14 . \\
\text { Mecanismos } \\
\text { de } \\
\text { coordenação }\end{array}$ & \begin{tabular}{|l} 
14.1. Mecanismo \\
s de \\
coordenaçã \\
o e relações \\
hierárquicas
\end{tabular} & \begin{tabular}{|l|}
$\begin{array}{l}\text { Segue o } \\
\text { modelo. }\end{array}$ \\
\end{tabular} & $\begin{array}{l}\text { Segue o } \\
\text { modelo. }\end{array}$ & Sim & $\mathrm{x}$ & \\
\hline \begin{tabular}{|l|}
15. \\
Elaboração do \\
Procedimento \\
Operacional \\
Padrão (POP)
\end{tabular} & $\begin{array}{c}\text { 15.1. Elaboração } \\
\text { dos POPs }\end{array}$ & Segue RDC 15. & $\begin{array}{l}\text { Segue RDC } \\
15 .\end{array}$ & Sim & $\mathrm{x}$ & \\
\hline $\begin{array}{l}\text { 16. Avaliação } \\
\text { da capacidade } \\
\text { no médio } \\
\text { prazo }\end{array}$ & \begin{tabular}{|l} 
16.1. Avaliação \\
da \\
capacidade \\
no médio \\
prazo
\end{tabular} & $\begin{array}{l}\text { Não há } \\
\text { avaliação da } \\
\text { capacidade. }\end{array}$ & $\begin{array}{l}\text { Não há } \\
\text { avaliação da } \\
\text { capacidade. }\end{array}$ & Não & - & - \\
\hline
\end{tabular}




\begin{tabular}{|c|c|c|c|c|c|c|}
\hline & & \multicolumn{2}{|c|}{ Complexo UERJ } & & & \\
\hline & & CME HUP & $\begin{array}{l}\text { CME } \\
\text { PPC }\end{array}$ & \multirow{2}{*}{$\begin{array}{l}\text { Atende } \\
\text { ao } \\
\text { modelo } \\
\quad ?\end{array}$} & \multirow{2}{*}{$\begin{array}{l}\text { Se sim, } \\
\text { mínimo } \\
?\end{array}$} & \multirow{2}{*}{$\begin{array}{l}\text { Se sim, } \\
\text { acima? }\end{array}$} \\
\hline & & \multicolumn{2}{|c|}{ Decisões táticas } & & & \\
\hline \multirow{3}{*}{$\begin{array}{l}17 . \\
\text { Fornecimento } \\
\text { médio prazo }\end{array}$} & $\begin{array}{l}\text { 17.1. Previsão de } \\
\text { fornecimento }\end{array}$ & $\begin{array}{l}\text { Não há } \\
\text { previsão de } \\
\text { fornecimento. }\end{array}$ & $\begin{array}{l}\text { Não há } \\
\text { previsão de } \\
\text { fornecimento. }\end{array}$ & Não & - & - \\
\hline & $\begin{array}{l}\text { 17.2. } \text { Tipo de } \\
\text { aquisição de } \\
\text { insumos e } \\
\text { serviços }\end{array}$ & $\begin{array}{l}\text { Área de } \\
\text { compras: } \\
\text { equipamentos } \\
\text { e manutenção } \\
\text { comodato, } \\
\text { compra de } \\
\text { insumos, } \\
\text { terceirização } \\
\text { de operação } \\
\text { de } \\
\text { desinfecção } \\
\text { de } \\
\text { termossensíve } \\
\text { is. }\end{array}$ & $\begin{array}{l}\text { Área de } \\
\text { compras: } \\
\text { equipamentos } \\
\text { e manutenção } \\
\text { comodato, } \\
\text { compra de } \\
\text { insumos, } \\
\text { terceirização } \\
\text { de operação } \\
\text { de } \\
\text { desinfecção } \\
\text { de } \\
\text { termossensíve } \\
\text { is. }\end{array}$ & Sim & $\mathrm{x}$ & \\
\hline & $\begin{array}{l}\text { 17.3. Seleção dos } \\
\text { fornecedores }\end{array}$ & \begin{tabular}{|l} 
Especificaçõe \\
s dos produtos \\
estabelecidos \\
pelo CME. \\
Seleção dos \\
fornecedores \\
feita pela área \\
de compras.
\end{tabular} & $\begin{array}{l}\text { Especificaçõe } \\
\text { s dos produtos } \\
\text { estabelecidos } \\
\text { pelo CME. } \\
\text { Seleção dos } \\
\text { fornecedores } \\
\text { feita pela área } \\
\text { de compras. }\end{array}$ & Sim & $\mathrm{x}$ & \\
\hline \multirow{3}{*}{$\begin{array}{l}18 . \\
\text { Gestão das } \\
\text { informações }\end{array}$} & $\begin{array}{l}\text { 18.1. Forma de } \\
\text { registro das } \\
\text { informações }\end{array}$ & $\begin{array}{l}\text { Registro } \\
\text { manual }\end{array}$ & $\begin{array}{l}\text { Registro } \\
\text { manual }\end{array}$ & Sim & $\mathrm{x}$ & \\
\hline & $\begin{array}{l}\text { 18.2. Forma de } \\
\text { divulgação } \\
\text { das } \\
\text { informações }\end{array}$ & $\begin{array}{l}\text { Treinamentos } \\
\text { e cartazes. }\end{array}$ & $\begin{array}{l}\text { Treinamentos } \\
\text { e cartazes. }\end{array}$ & Sim & $\mathrm{x}$ & \\
\hline & $\begin{array}{l}\text { 18.3. Forma de } \\
\text { armazenamen } \\
\text { to das } \\
\text { informações }\end{array}$ & $\begin{array}{l}\text { Arquivos em } \\
\text { papel. }\end{array}$ & $\begin{array}{l}\text { Arquivos em } \\
\text { papel. }\end{array}$ & Sim & $\mathrm{x}$ & \\
\hline
\end{tabular}




\begin{tabular}{|c|c|c|c|c|c|c|}
\hline & & \multicolumn{2}{|c|}{ Complexo UERJ } & & & \\
\hline & & CME HUPE & CME PPC & \multirow{2}{*}{$\begin{array}{l}\text { Atende } \\
\text { ao } \\
\text { modelo } \\
?\end{array}$} & \multirow{2}{*}{$\begin{array}{l}\text { Se sim, } \\
\text { mínimo } \\
\text { ? }\end{array}$} & \multirow{2}{*}{$\begin{array}{l}\text { Se sim } \\
\text { acima? }\end{array}$} \\
\hline & & \multicolumn{2}{|c|}{ Decisões táticas } & & & \\
\hline \multirow{2}{*}{$\begin{array}{l}\text { 19. Gestão } \\
\text { da } \\
\text { produção }\end{array}$} & $\begin{array}{l}\text { 19.1. Definição } \\
\text { dos horários de } \\
\text { recebimento/ } \\
\text { distribuição dos } \\
\text { materiais a serem } \\
\text { processados }\end{array}$ & $\begin{array}{l}\text { Por tipo de } \\
\text { demanda } \\
\text { (unidades de } \\
\text { internação e } \\
\text { CC). }\end{array}$ & $\begin{array}{l}\text { Por tipo de } \\
\text { demanda } \\
\text { (unidades de } \\
\text { internação e } \\
\text { CC). }\end{array}$ & Sim & $\begin{array}{c}\text { Não se } \\
\text { aplica }\end{array}$ & $\begin{array}{l}\text { Não se } \\
\text { aplica }\end{array}$ \\
\hline & \begin{tabular}{|l} 
19.2. Definição das \\
metas de \\
atravessamen \\
to dos \\
materiais
\end{tabular} & $\begin{array}{l}\text { Não há } \\
\text { definição de } \\
\text { metas de } \\
\text { atravessament } \\
\text { o. }\end{array}$ & $\begin{array}{l}\text { Não há } \\
\text { definição de } \\
\text { metas de } \\
\text { atravessament } \\
\text { o. }\end{array}$ & Não & - & - \\
\hline \multirow[t]{2}{*}{$\begin{array}{l}\text { 20. Gestão do } \\
\text { estoque }\end{array}$} & $\begin{array}{l}\text { 20.1. Definição das } \\
\text { formas de } \\
\text { monitoramen } \\
\text { to do estoque }\end{array}$ & \begin{tabular}{|l} 
Monitorament \\
o manual.
\end{tabular} & $\begin{array}{l}\text { Monitorament } \\
\text { o manual. }\end{array}$ & Sim & $\begin{array}{l}\text { Não se } \\
\text { aplica }\end{array}$ & $\begin{array}{l}\text { Não se } \\
\text { aplica }\end{array}$ \\
\hline & $\begin{array}{c}\text { 20.2. Organização } \\
\text { do estoque }\end{array}$ & $\begin{array}{l}\text { Por } \\
\text { especialidade. }\end{array}$ & $\begin{array}{l}\text { Por } \\
\text { especialidade. }\end{array}$ & Sim & $\begin{array}{c}\text { Não se } \\
\text { aplica }\end{array}$ & $\begin{array}{l}\text { Não se } \\
\text { aplica }\end{array}$ \\
\hline \multirow{3}{*}{$\begin{array}{l}\text { 21. Gestão } \\
\text { do RH }\end{array}$} & $\begin{array}{l}\text { 21.1. Definição do } \\
\text { regime de } \\
\text { escalas }\end{array}$ & $\begin{array}{l}\text { Escalas 12/60 } \\
\text { e 12/36. }\end{array}$ & $12 \times 36$ & Sim & $\begin{array}{l}\text { Não se } \\
\text { aplica }\end{array}$ & $\begin{array}{l}\text { Não se } \\
\text { aplica }\end{array}$ \\
\hline & $\begin{array}{l}\text { 21.2. Segurança do } \\
\text { profissional }\end{array}$ & $\begin{array}{l}\text { Segue RDC } \\
15 .\end{array}$ & $\begin{array}{l}\text { Segue RDC } \\
15 .\end{array}$ & Sim & $\mathrm{x}$ & \\
\hline & $\begin{array}{l}\text { 21.3. Reconhecime } \\
\text { nto } \\
\text { profissional }\end{array}$ & $\begin{array}{l}\text { Não há } \\
\text { promoções ou } \\
\text { recompensa } \\
\text { por } \\
\text { produtividade. }\end{array}$ & $\begin{array}{l}\text { Não há } \\
\text { promoções ou } \\
\text { recompensa } \\
\text { por } \\
\text { produtividade. }\end{array}$ & Não & - & - \\
\hline \multirow{3}{*}{$\begin{array}{l}22 . \\
\text { Manutenção }\end{array}$} & 22.1. Manutenção & $\begin{array}{l}\text { Manutenção } \\
\text { periódica dos } \\
\text { equipamentos. }\end{array}$ & $\begin{array}{l}\text { Manutenção } \\
\text { periódica dos } \\
\text { equipamentos. }\end{array}$ & Sim & $\mathrm{x}$ & \\
\hline & $\begin{array}{l}\text { 22.2. Manutenção } \\
\text { das } \\
\text { instalações }\end{array}$ & $\begin{array}{l}\text { Feita pelo } \\
\text { hospital. }\end{array}$ & $\begin{array}{l}\text { Feita pelo } \\
\text { hospital. }\end{array}$ & Sim & $\begin{array}{c}\text { Não se } \\
\text { aplica }\end{array}$ & $\begin{array}{l}\text { Não se } \\
\text { aplica }\end{array}$ \\
\hline & $\begin{array}{l}\text { 22.3. Manutenção } \\
\text { do sistema de } \\
\text { informação }\end{array}$ & - & - & Não & - & - \\
\hline
\end{tabular}




\begin{tabular}{|c|c|c|c|c|c|c|}
\hline & & \multicolumn{2}{|c|}{ Complexo UERJ } & \multirow{3}{*}{$\begin{array}{l}\text { Atende } \\
\text { ao } \\
\text { modelo } \\
?\end{array}$} & \multirow{3}{*}{$\begin{array}{l}\text { Se sim, } \\
\text { mínimo } \\
?\end{array}$} & \multirow{3}{*}{$\begin{array}{l}\text { Se sim, } \\
\text { acima? }\end{array}$} \\
\hline & & CME HUPE & CME PPC & & & \\
\hline & & \multicolumn{2}{|c|}{ Decisões operacionais } & & & \\
\hline \multirow[b]{2}{*}{$\begin{array}{l}\text { 23. Previsão } \\
\text { da demanda } \\
\text { de curto prazo }\end{array}$} & $\begin{array}{l}\text { 23.1. Recebimento } \\
\text { do mapa } \\
\text { cirúrgico }\end{array}$ & $\begin{array}{l}1 \text { dia de } \\
\text { antecedência. }\end{array}$ & $\begin{array}{l}1 \text { dia de } \\
\text { antecedência }\end{array}$ & Sim & $\begin{array}{l}\text { Não se } \\
\text { aplica }\end{array}$ & $\begin{array}{l}\text { Não se } \\
\text { aplica }\end{array}$ \\
\hline & $\begin{array}{l}\text { 23.2. Informação de } \\
\text { demandas } \\
\text { históricas das } \\
\text { demandas das } \\
\text { unidades de } \\
\text { internação }\end{array}$ & - & - & Não & - & - \\
\hline \multirow[t]{2}{*}{$\begin{array}{l}24 . \\
\text { Programação } \\
\text { da produção }\end{array}$} & $\begin{array}{l}\text { 24.1. Estabeleciment } \\
\text { o dos roteiros } \\
\text { de produção } \\
\text { (sequenciamen } \\
\text { to) }\end{array}$ & - & - & Não & - & - \\
\hline & $\begin{array}{l}\text { 24.2. Programação } \\
\text { da produção }\end{array}$ & $\begin{array}{l}\text { Não há } \\
\text { priorização. } \\
\text { Há alocação. }\end{array}$ & $\begin{array}{l}\text { Não há } \\
\text { priorização. } \\
\text { Há alocação. }\end{array}$ & Parcial & $\begin{array}{l}\text { Não se } \\
\text { aplica }\end{array}$ & $\begin{array}{l}\text { Não se } \\
\text { aplica }\end{array}$ \\
\hline \multirow{3}{*}{$\begin{array}{l}\text { 25. Controle } \\
\text { de qualidade }\end{array}$} & $\begin{array}{r}\text { 25.1. Monitorament } \\
\text { o da qualidade }\end{array}$ & $\begin{array}{l}\text { Segue RDC } \\
15 .\end{array}$ & $\begin{array}{l}\text { Segue RDC } \\
15 .\end{array}$ & Sim & $\mathrm{x}$ & \\
\hline & $\begin{array}{l}\text { 25.2. } \text { Rastreamento } \\
\text { dos produtos } \\
\text { processados }\end{array}$ & $\begin{array}{l}\text { Registro de } \\
\text { informações } \\
\text { no lote e } \\
\text { anexação das } \\
\text { informações } \\
\text { no prontuário } \\
\text { do paciente. }\end{array}$ & $\begin{array}{l}\text { Registro de } \\
\text { informações } \\
\text { no lote e } \\
\text { anexação } \\
\text { das } \\
\text { informações } \\
\text { no } \\
\text { prontuário } \\
\text { do paciente. }\end{array}$ & Sim & $\mathrm{x}$ & \\
\hline & $\begin{array}{l}\text { 25.3. Medição dos } \\
\text { indicadores de } \\
\text { operação }\end{array}$ & - & - & Não & - & - \\
\hline \multirow{3}{*}{$\begin{array}{l}\text { 26. Controle } \\
\text { de estoque }\end{array}$} & \begin{tabular}{|l} 
26.1. Formas de \\
controle do \\
estoque
\end{tabular} & Manual & Manual & Sim & $\begin{array}{l}\text { Não se } \\
\text { aplica }\end{array}$ & $\begin{array}{l}\text { Não se } \\
\text { aplica }\end{array}$ \\
\hline & $\begin{array}{c}\text { 26.2. Monitorament } \\
\text { o do estoque }\end{array}$ & - & - & Não & - & - \\
\hline & $\begin{array}{l}\text { 26.3. Elaboração de } \\
\text { relatórios de } \\
\text { controle }\end{array}$ & - & - & Não & - & - \\
\hline
\end{tabular}




\begin{tabular}{|c|c|c|c|c|c|c|}
\hline & & \multicolumn{2}{|c|}{ Complexo UERJ } & \multirow{3}{*}{$\begin{array}{l}\text { Atende } \\
\text { ao } \\
\text { modelo } \\
?\end{array}$} & \multirow{3}{*}{$\begin{array}{l}\text { Se sim, } \\
\text { mínimo } \\
\text { ? }\end{array}$} & \multirow{3}{*}{$\begin{array}{l}\text { Se sim, } \\
\text { acima? }\end{array}$} \\
\hline & & CME HUPE & CME PPC & & & \\
\hline & & \multicolumn{2}{|c|}{ Decisões operacionais } & & & \\
\hline \multirow{2}{*}{$\begin{array}{l}\text { 27. Controle } \\
\text { dos insumos }\end{array}$} & \begin{tabular}{|} 
27.1. Mix dos \\
insumos \\
utilizados
\end{tabular} & $\begin{array}{l}\text { Especificações } \\
\text { definidas pelo } \\
\text { CME. }\end{array}$ & $\begin{array}{l}\text { Especificaçõ } \\
\text { es definidas } \\
\text { pelo CME. }\end{array}$ & Sim & $\begin{array}{c}\text { Não se } \\
\text { aplica }\end{array}$ & $\begin{array}{l}\text { Não se } \\
\text { aplica }\end{array}$ \\
\hline & $\begin{array}{l}\text { 27.2. Monitoramen } \\
\text { to dos } \\
\text { insumos }\end{array}$ & $\begin{array}{l}\text { Monitoramento } \\
\text { da data de } \\
\text { validade. }\end{array}$ & $\begin{array}{l}\text { Monitorame } \\
\text { nto da data } \\
\text { de validade. }\end{array}$ & Sim & $\begin{array}{c}\text { Não se } \\
\text { aplica }\end{array}$ & $\begin{array}{l}\text { Não se } \\
\text { aplica }\end{array}$ \\
\hline \multirow{2}{*}{$\begin{array}{l}\text { 28. Gestão dos } \\
\text { recursos } \\
\text { humanos }\end{array}$} & $\begin{array}{l}28.1 . \\
\text { Treinamentos e } \\
\text { capacitações } \\
\text { periódicos }\end{array}$ & $\begin{array}{l}\text { Treinamentos } \\
\text { periódicos. }\end{array}$ & $\begin{array}{l}\text { Treinamento } \\
\text { s periódicos. }\end{array}$ & Sim & $\begin{array}{l}\text { Não se } \\
\text { aplica }\end{array}$ & $\begin{array}{l}\text { Não se } \\
\text { aplica }\end{array}$ \\
\hline & $\begin{array}{l}\text { 28.2. Medição dos } \\
\text { indicadores de } \\
\text { desempenho }\end{array}$ & - & - & Não & - & - \\
\hline \multirow{2}{*}{$\begin{array}{l}29 . \\
\text { Monitorament } \\
\text { o da } \\
\text { capacidade }\end{array}$} & $\begin{array}{l}\text { 29.1. Monitoramen } \\
\text { to }\end{array}$ & - & - & Não & - & - \\
\hline & $\begin{array}{l}\text { 29.2. Suprimento } \\
\text { de } \\
\text { capacidade }\end{array}$ & $\begin{array}{l}\text { Realocação do } \\
\text { número de } \\
\text { profissionais as } \\
\text { áreas de } \\
\text { operação. }\end{array}$ & $\begin{array}{l}\text { Realocação } \\
\text { do número } \\
\text { de } \\
\text { profissionais } \\
\text { as áreas de } \\
\text { operação. }\end{array}$ & Parcial & $\begin{array}{c}\text { Não se } \\
\text { aplica }\end{array}$ & $\begin{array}{l}\text { Não se } \\
\text { aplica }\end{array}$ \\
\hline
\end{tabular}




\begin{tabular}{|c|c|c|c|c|c|c|}
\hline & & \multicolumn{2}{|c|}{ Complexo UERJ } & \multirow{3}{*}{$\begin{array}{l}\text { Atende } \\
\text { ao } \\
\text { modelo } \\
?\end{array}$} & \multirow{3}{*}{$\begin{array}{l}\text { Se sim, } \\
\text { mínimo } \\
\quad ?\end{array}$} & \multirow{3}{*}{$\begin{array}{l}\text { Se sim, } \\
\text { acima? }\end{array}$} \\
\hline & & CME HUPE & CME PPC & & & \\
\hline & & \multicolumn{2}{|c|}{ Decisões operacionais } & & & \\
\hline \multirow{4}{*}{$\begin{array}{l}\text { 30. Controle } \\
\text { da informação }\end{array}$} & $\begin{array}{l}\text { 30.1. Fluxos de } \\
\text { informação }\end{array}$ & \begin{tabular}{|l|} 
Fluxo não \\
estruturado. \\
Recebimento \\
do mapa \\
cirúrgico (fluxo \\
de informação \\
entre CME e \\
CC).
\end{tabular} & $\begin{array}{l}\text { Fluxo não } \\
\text { estruturado. } \\
\text { Recebiment } \\
\text { o do mapa } \\
\text { cirúrgico } \\
\text { (fluxo de } \\
\text { informação } \\
\text { entre CME e } \\
\text { CC). }\end{array}$ & Parcial & $\begin{array}{l}\text { Não se } \\
\text { aplica }\end{array}$ & $\begin{array}{l}\text { Não se } \\
\text { aplica }\end{array}$ \\
\hline & $\begin{array}{l}\text { 30.2. Controle do } \\
\text { registro de } \\
\text { informações }\end{array}$ & \begin{tabular}{|l} 
Registro \\
manual do \\
recebimento de \\
material, \\
inspeção visual \\
dos materiais, \\
registro de \\
informações no \\
lote de \\
esterilização e \\
registro dos \\
resultados dos \\
testes de \\
controle.
\end{tabular} & \begin{tabular}{|l|} 
Registro \\
manual do \\
recebimento \\
de material, \\
inspeção \\
visual dos \\
materiais, \\
registro de \\
informações \\
no lote de \\
esterilização \\
e registro \\
dos \\
resultados \\
dos testes de \\
controle.
\end{tabular} & Sim & $\mathrm{x}$ & \\
\hline & $\begin{array}{l}30.3 . \\
\text { Arquivamento da } \\
\text { informação }\end{array}$ & $\begin{array}{l}\text { Arquivamento } \\
\text { dos registros } \\
\text { manuais. }\end{array}$ & $\begin{array}{l}\text { Arquivamen } \\
\text { to dos } \\
\text { registros } \\
\text { manuais. } \\
\end{array}$ & Sim & $\mathrm{x}$ & \\
\hline & & \multicolumn{2}{|c|}{ Decisão Objetivo } & & & \\
\hline \multirow{2}{*}{ 31. Custos } & $\begin{array}{l}\text { 31.1. Tipo de } \\
\text { custeio }\end{array}$ & - & - & Não & - & - \\
\hline & $\begin{array}{l}\begin{array}{l}\text { 31.2. Tipo de } \\
\text { custos }\end{array} \\
\end{array}$ & - & - & Não & - & - \\
\hline
\end{tabular}


A seguir será apresentada a análise de onde emergirá o posicionamento dos CMEs no modelo de referência proposto. Os CMEs aplicados são aderentes ao modelo à medida que tomem as decisões propostas e atendam de forma completa, e pelo menos, minimamente aos parâmetros estabelecidos para cada decisão. Cabe ressaltar que, na aplicação, não foi analisado se os CMEs tomaram a sequência de decisões proposta pelo modelo, visto se tratar de CMEs com operações já estabelecidas.

A Figura 40 apresenta as decisões tomadas pelos CMEs. Dentre as treze decisões e subdecisões estratégicas formuladas no modelo proposto, os CMEs não tomam decisões pertinentes às subdeciosões 1.2 e 1.3, decisão 3, subdecisões 5.1, 6.2, decisão 9, subdecisões 10.1 e 10.3 subdecisão 12.1 e decisão 13 . Nota-se que a não tomada de decisões no nível estratégico impacta na não tomada de decisões desdobradas nos níveis tático e operacional, conforme apresentado na Tabela 38.

A Tabela 38 também apresenta as ações adotadas pelos CMEs para responderem às decisões tomadas no modelo de referência proposto.

Dentre as decisões tomadas pelos CMEs, a decisão 8 (Tipos de insumos) é tomada com especificações acima do exigido pelos instrumentais normativos. As demais decisões atendem minimamente as legislações.

Conclui-se que as decisões de projeto referentes aos processos assistenciais são atendidas e sua execução baseada nos instrumentais normativos. Já as decisões de articulação e operacionalização dos processos, com avaliação da capacidade, previsão de demanda, priorização das demandas, estudo de tempos para estudar e traçar as metas de atravessamento, programação e sequenciamento das operações, etc. não são consideradas pelos gestores para tomada de decisão, visto que a natureza orientadora regulatória não contempla tais tópicos, de onde emerge a pergunta a ser discutida na subseção 5.3 sobre a suficiência dos instrumentos normativos para orientarem as decisões de projeto de CME. Dessa forma, os CMEs são aderentes ao modelo nas decisões de natureza regulatória. Nas decisões de natureza de planejamento e gestão da produção, os CMEs não tomam decisão. 


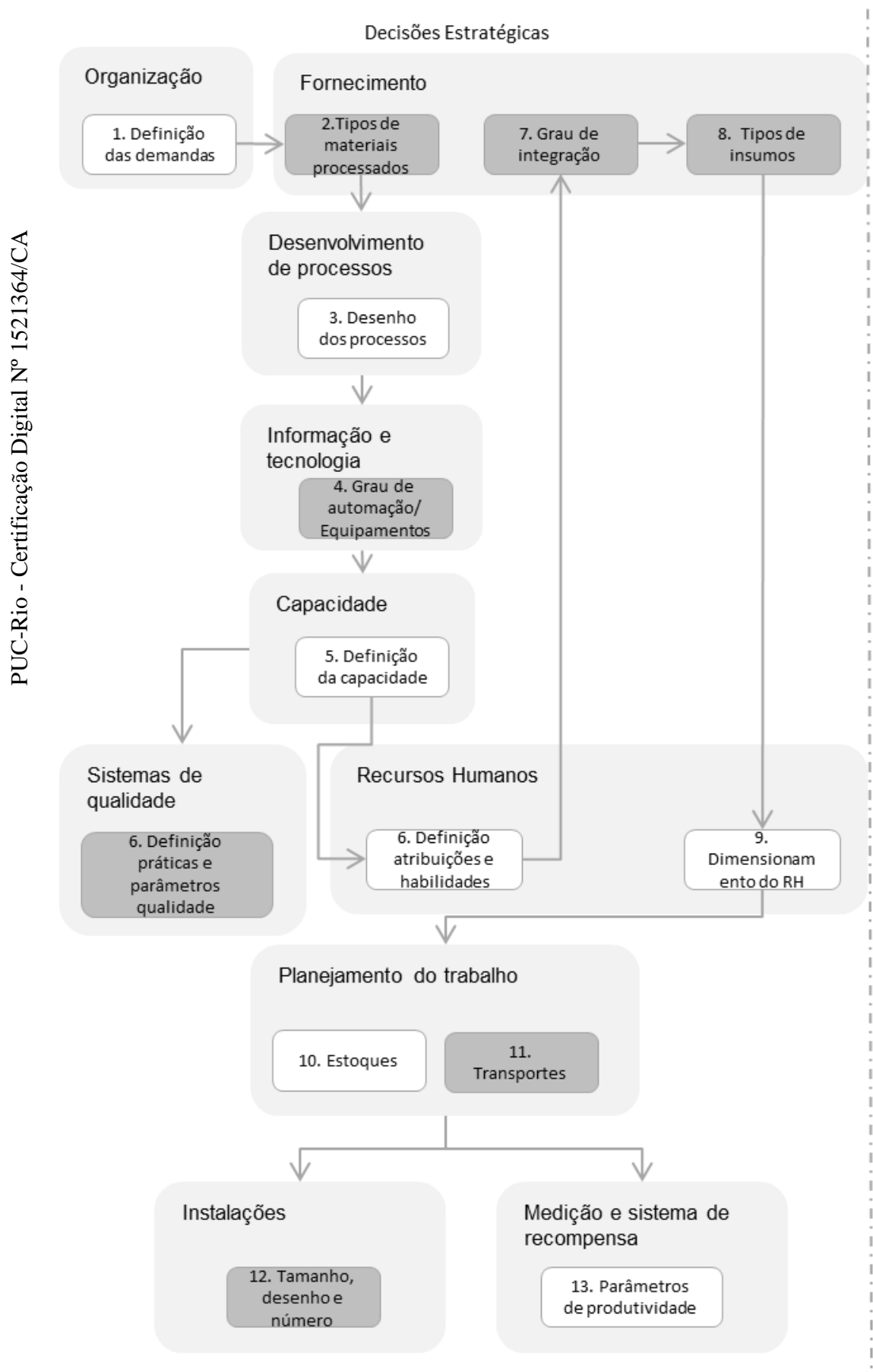

Decisões Táticas

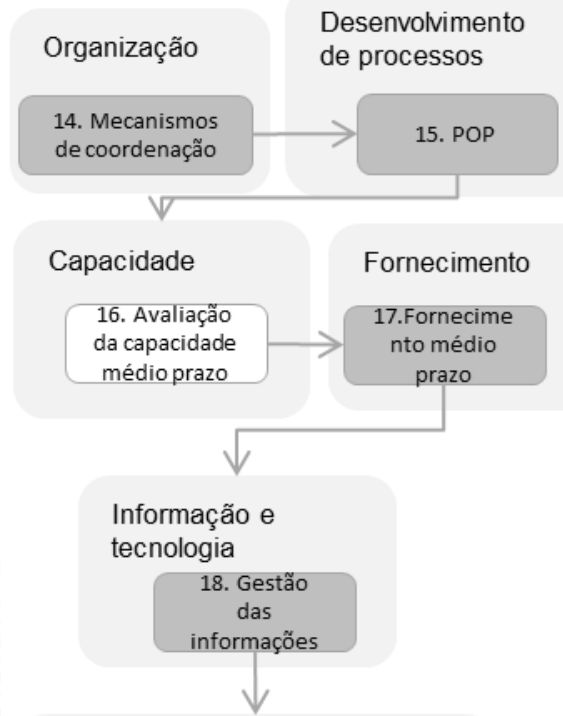

Planejamento do trabalho

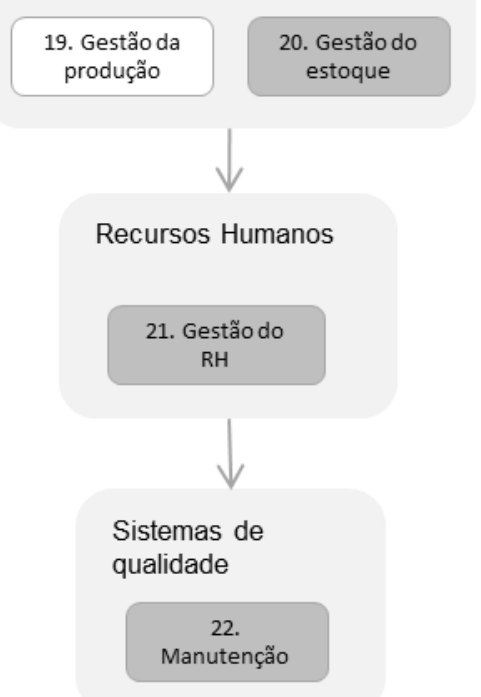

Decisões Operacionais

Planejamento do trabalho

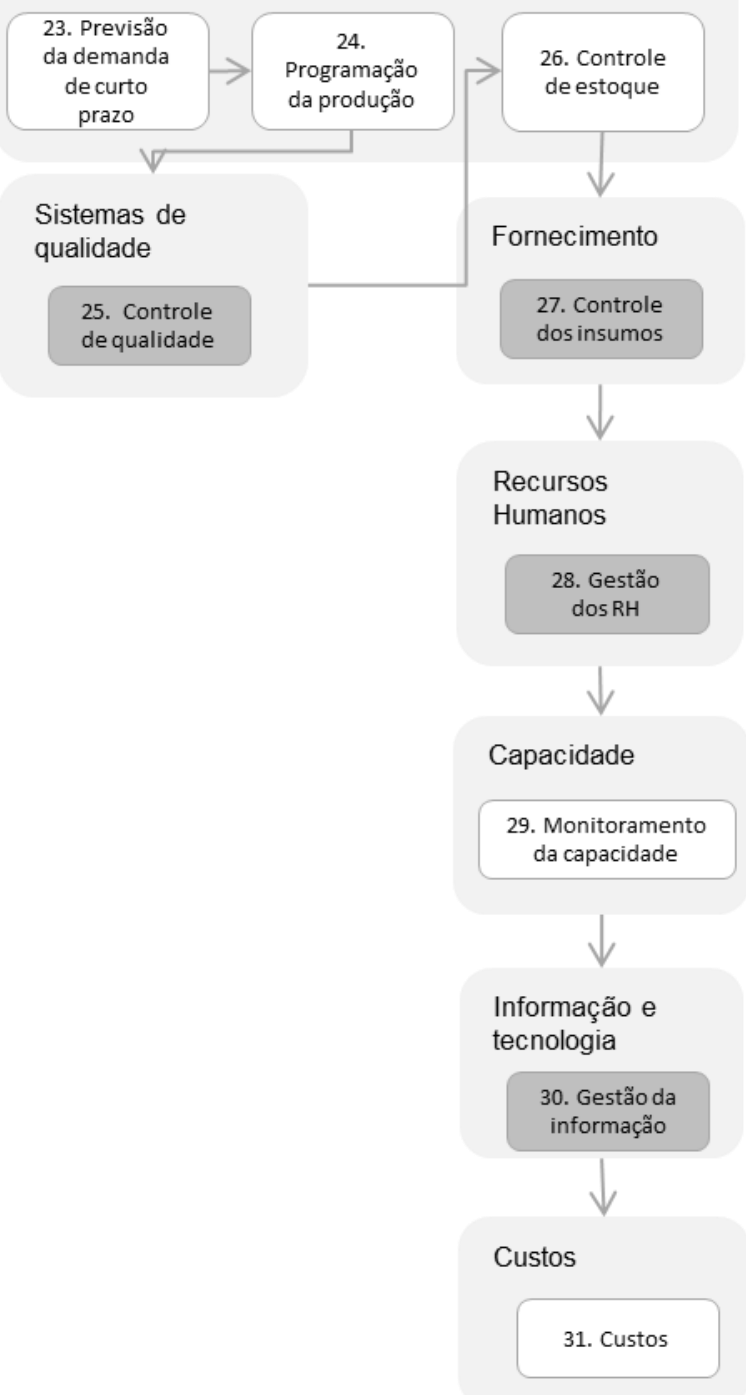

Figura 40 - Decisões do modelo de referência tomadas pelos CMEs do complexo UERJ. Elaboração própria. 


\section{3 \\ Discussões}

A partir da exposição do grau de aderência dos CMEs ao modelo proposto, através da demonstração da aplicação, geram-se discussões sobre a suficiência de cumprir os parâmetros estabelecidos pelos instrumentais normativos para obter um modelo de operações eficiente e eficaz, atendendo aos objetivos de desempenho (qualidade, segurança e minimização de custo).

As discussões expostas nesta seção desdobram-se da seguinte questão: atender os parâmetros dos instrumentais normativos é suficiente para viabilizar operações que minimizem os custos e atendam conforme os parâmetros de qualidade e segurança, mantendo a confiabilidade de entrega do produto esterilizado?

Com o posicionamento dos CMEs no modelo de referência proposto podese dizer que ambos CMEs respondem as mesmas decisões e de forma semelhante, apresentando uniformidade no atendimento aos parâmetros de qualidade e segurança contemplados nos instrumentos normativos assistenciais. Contudo, quando passam-se para as decisões referentes a capacidade, operacionalização do processo produtivo (programação e sequenciamento, alocação de recursos, estudos de tempos para traçar as metas de atravessamento por tipo de material, priorização das demandas), a aplicação do modelo demonstra que os CMEs não tomam tais decisões. Portanto, os instrumentais normativos nacionais, principais orientadores na tomada de decisão de projeto dos CMEs, não fornecem orientações sobre o projeto do sistema de operação de um CME, restrigindo-se aos aspectos da técnica da assistência à saúde. Conclui-se que projetar as operações do CME atendendo somente aos parâmetros estabelecidos pela legislação assegura a segurança da operação para os profissionais e pacientes, mas não assegura que o produto requerido por uma unidade consumidora seja entregue, de acordo com o grau de priorização, na hora certa, com previsibilidade sobre quantidades a serem produzidas, previsão das demandas, rastreabilidades dos produtos pelas etapas de operação.

Dessa forma, projetar as operações sem considerar, por exemplo, a demanda a ser atendida e a quantificação da capacidade instalada para atender tal demanda, e gerir operações sem considerar, por exemplo, aspectos de programação e 
sequenciamento da produção, estabelecimento de roteiros de produção, etc., não apresentados na legislação, resultam em projeto de operações com altos custos e retrabalhos. Portanto, os instrumentais normativos não fornecem instrumentos para operacionalizar o projeto de operações. Gerir operações de CME somente com base nos instrumentos normativos não é suficiente para uma gestão eficiente.

Outra constatação da aplicação é o atendimento majoritariamente mínimo nas decisões tomadas, com exceção da decisão 8 (tipos de insumos), as demais decisões seguem os parâmetros mínimos estabelecidos pelas legislações. Por exemplo, não são observadas tecnologias para rastreamento dos materiais, ou uso de bases de dados para arquivar as informações sobre testes de controle, visto que a legislação não exige. Os CMEs aderem aos insumos mais caros do mercado, contudo não rastreiam a conformidade do material até a última etapa de operação, resultando, por exemplo, em materiais com embalagens de alta qualidade danificadas (rasgadas) em decorrência de alguma ineficiência durante o processo de operação. Sem conformidade das práticas, programação, alocação e sequenciamento dos recursos, por exemplo, a utilização dos insumos mais caros do mercado, não será ação suficiente para resultar em produtos conformes, com atendimento às demandas requerentes. Desta constatação, cabe ressaltar um potencial avanço do modelo proposto nesta dissertação, em direção a estratificação de níveis de maturidade e consequentemente análises de fit (ajuste) entre os mesmos. 


\section{6 \\ Conclusão}

Nesta seção será apresentada a síntese da pesquisa (seção 6.1), onde são expostos o objetivo principal do trabalho, as respostas das perguntas de pesquisa e o cumprimento dos objetivos secundários para alcance do objetivo principal da pesquisa.

A seção 6.2 apresenta as contribuições da pesquisa, destacando-se a proposição dos roteiros de produção para os produtos críticos, semicríticos e não críticos e a proposição da estrutura de um modelo de referência articulado para tomada de decisão de projeto de CMEs. As limitações da pesquisa também são descritas na seção 6.2.

As propostas de trabalhos futuros são assinaladas na seção 6.3.

\section{1}

\section{Síntese da Pesquisa}

A pesquisa teve como objetivo principal a construção de um modelo de referência para auxiliar os gestores na tomada de decisão quanto ao projeto de CMEs, considerando os parâmetros de qualidade, de infecção hospitalar e dos instrumentos normativos.

A pergunta de pesquisa que originou a presente dissertação é a seguinte:

a) Como projetar um CME de forma a obter alto desempenho com atendimento dos parâmetros de qualidade, de infecção hospitalar e dos instrumentos normativos?

A resposta proposta na presente pesquisa foi a elaboração articulada de um modelo que considerasse os principais fatores necessários para projetar um CME, com base nos parâmetros estabelecidos de qualidade, infecção hospitalar e nas legislações vigentes.

A pergunta de pesquisa derivada da resposta de pesquisa originária é a seguinte:

b) Qual seria o modelo de referência voltado para o auxílio da tomada de decisão para projetar o sistema de operação de um CME? 
A resposta constitui na proposição do modelo de referência para tomada de decisão de projeto de CMEs, contemplando os requisitos a serem seguidos por qualquer $\mathrm{CME}$, tendo em vista o marco regulatório, e requisitos de planejamento e gestão de operações, que seguidos, permitem uma produção que atenda as demandas. O modelo filtra as numerosas legislações existentes para sete principais legislações com aplicação específica para o CME e estabelece uma ordem no cumprimento dos requisitos de projeto de CMEs, o que configura em uma ferramenta útil para nortear os gestores e os profissionais de saíde desse setor no cumprimento do regulatório. O modelo proposto também orienta os profissionais de saúde quanto aos requisitos de planejamento e gestão de produção, que são importantes para gerir uma operação de forma conforme e com atendimento efetivo às demandas.

Para alcançar o objetivo de construir um modelo que orientasse o projeto de CMEs, foram cumpridos os seguintes objetivos secundários:

a) Levantamento de referências através da revisão da literatura, onde foi feita uma revisão focada nos conceitos e tipos de modelos de referência voltados para área da saúde existentes, abordagem de gestão de operações para projeto e contexto das operações em CMEs, conforme descrito na seção 3.2;

b) Levantamento e identificação dos instrumentais normativos, onde foram listadas as legislações nacionais direcionadoras das operações de CMEs, sendo os conteúdos regulatórios utilizados para construir as decisões de projeto que conformam o modelo de referência proposto;

c) Condução de pesquisa de campo em CMEs representativos dos níveis de complexidade das operações, onde foram realizados o estudo através do mapeamento de processos das operações existentes em dois CMEs pertencentes ao complexo da UERJ e entrevistas aos gestores desses CMEs.

d) Análise e síntese da lógica de funcionamento à luz das categorias de operações, onde foram utilizados os conteúdos de modelo de referência, gestão de operações em saúde e especificações das operações de CMEs advindos dos instrumentos normativos e revisão da literatura, para começar a estabelecer as decisões conformadoras do modelo de tomada de decisão. 
e) Definição da estrutura do modelo de referência, onde foram definidas as decisões finais construtoras do modelo, no qual foram descritas alternativas de ações para a decisão. Nesta etapa as decisões foram articuladas através do estabelecimento da ordem de precedência para a tomada das decisões.

f) Validação do modelo com especialistas, no qual a proposta do modelo de referência foi analisada e validada pelos chefes dos CMEs onde foi realizada a pesquisa de campo.

g) Refinamento do modelo, onde as propostas de modificações sugeridas pelos chefes dos CMEs foram incorpordas ao modelo.

h) Aplicação do modelo de referência nos CMEs estudados a fim de verificar a aderência do modelo à realidade dos CMEs e desdobrar análises e discussões do modelo frente ao contexto prático dos CMEs.

\section{Contribuições e Limitações}

A pesquisa evidencia o gap na literatura quanto à existência de modelos de tomada de decisão voltados para o projeto de CMEs, visto se tratar de um setor no hospital que mais se assemelha a uma "operação fabril", com operações padronizadas no fluxo de entrada, processo e saída do material, sendo, portanto, um ambiente propício à aplicação dos conhecimentos de gestão de operações.

A proposição dos roteiros de produção para os produtos críticos, semicríticos e não críticos, apresentados nas Figura 9, Figura 8 e Figura 9, são uma contribuição para o contexto de operações em CMEs, visto a não existência compilada dos dados de tratamento de cada tipo de produto pelo fluxo de etapas das operações de esterilização.

A principal contribuição é a proposição da estrutura de um modelo de referência contendo as principais decisões de projeto a serem consideradas e a articulação das mesmas através da apresentação da ordem de precedência para aplicar a tomada de decisão.

Um desdobramento da pesquisa seria a transformação do modelo de referência proposto em um produto/software e a extensão do modelo para aplicações em outros setores produtivos.

O modelo de referência de requisitos a serem seguidos para projetar CMEs ajuda os responsáveis/gestores a tomarem decisão quanto aos aspectos de projeto 
de operações no $\mathrm{CME}$, tendo em vista que há uma miscelânea de instrumentos regulatórios, além das divergências e ausência de fronteiras entre as legislações, que dificulta a orientação de como agir quanto a tomada de decisão. Nesse sentido, o modelo proposto, filtra o número de instrumentos normativos, e organiza os requisitos a serem seguidos quanto a projeto, desdobrando-os em decisões articuladas. Além disso, o modelo prescreve alternativas de tomada de decisão para o cumprimento de cada requisito, o que facilita a tomada de decisão.

Portanto, o modelo proposto contribui para a área da saúde, visto que, dentre as numerosas legislações, o modelo traz uma proposição genérica para o cumprimento dos requisitos assisntenciais, e traz o adicional de abarcar os aspectos de planejamento e gestão da produção, não contemplados pelas legislações.

Dentre as limitações da pesquisa, destacam-se a não construção do modelo contemplando diferentes níveis de maturidade nas práticas de gestão vigentes para tomar as decisões estabelecidas pelo modelo de referência proposto e a não existência de ciclos de saturação de aplicações "testes" para refinamento do modelo em CMEs diversas (CMEs do setor privado, por exemplo).

As limitações da presente pesquisa alimentam as propostas de trabalhos futuros, apresentados na seção 6.3.

\section{3}

\section{Propostas de trabalhos futuros}

Dentre as propostas de trabalhos futuros, destacam-se: o recorte do modelo para um subconjunto de decisões a fim de aprofundar o estudo e enriquecer as propostas de alternativas de ação para tomar tais decisões e aperfeiçoar o modelo de referência proposto a partir de revisões sistemáticas da literatura.

A partir das limitações de aplicação do modelo, evidenciam-se as seguintes propostas de trabalhos futuros: aplicação de métodos de apoio a decisão (simulação, por exemplo) no modelo de referência proposto e aplicação do modelo proposto a CMEs diversas, com abrangência do setor privado, utilizando ciclos de saturação de aplicações "testes" para refinamento do modelo nestes CMEs.

Quanto a atualização do modelo, destaca-se a proposta futura de monitoramento das atualizações no regulatório vigente e a decorrente incorporação ao modelo. 
Por fim, destaca-se a proposta de construção do modelo contemplando diferentes níveis de maturidade nas práticas de gestão vigentes para tomar as decisões estabelecidas pelo modelo de referência proposto. 


\section{7 \\ Referências bibliográficas}

ANVISA. AGENCIA NACIONAL DE VIGILÂNCIA SANITÁRIA. Consulta pública no 34 de 03 de junho de 2009. Disponível em:<www4.anvisa.gov.br/base/visadoc/CP/CP\%5B26720-1$0 \% 5 \mathrm{D} . \mathrm{PDF}>$

AGENCIA NACIONAL DE VIGILÂNCIA SANITÁRIA. Resolução da diretoria colegiada- RDC $\mathrm{n}^{\circ} \quad 8, \quad$ de 27 de fevereiro $\quad$ de $2009 . \quad$ Disponível em:<www.abebrasil.org.br/imagem/pdf/RDC_08.pdf >

AGENCIA NACIONAL DE VIGILÂNCIA SANITÁRIA. Resolução da diretoria colegiada- RDC $\mathrm{n}^{\circ}$ 15, de 15 de março de 2012. Disponível em:〈www.abebrasil.org.br/imagem/pdf/RDC_15.pdf〉

AGENCIA NACIONAL DE VIGILÂNCIA SANITÁRIA. Resolução da diretoria colegiada- RDC $\mathrm{n}^{\circ} \quad 50, \quad$ de 21 de fevereiro de $2002 . \quad$ Disponível em:〈www.abebrasil.org.br/imagem/pdf/RDC\%2050.pdf>

AGENCIA NACIONAL DE VIGILÂNCIA SANITÁRIA. Resolução da diretoria colegiada- RDC $\mathrm{n}^{\circ} \quad 55, \quad$ de 14 de novembro de $2012 . \quad$ Disponível em:〈www.abebrasil.org.br/imagem/pdf/RDC55\%20Detergentes\%20Enzimaticos.pdf>

AGENCIA NACIONAL DE VIGILÂNCIA SANITÁRIA. Resolução da diretoria colegiada- RDC $\mathrm{n}^{\circ}$ 91, de 28 de novembro de 2008. em:<bvsms.saude.gov.br/bvs/saudelegis/anvisa/2008/res0091_28_11_2008.html>

AGENCIA NACIONAL DE VIGILÂNCIA SANITÁRIA. Resolução da diretoria colegiada- RDC $\mathrm{n}^{\circ} \quad 306, \quad$ de 07 de dezembro de $2004 . \quad$ Disponível em:<www.abebrasil.org.br/imagem/pdf/RDC\%20306.pdf >

AGENCIA NACIONAL DE VIGILÂNCIA SANITÁRIA. Resolução da diretoria colegiada- RDC $n^{\circ} 307$, de 14 de novembro de 2002. Disponível em:〈portal.anvisa.gov.br/legislacao>

AGENCIA NACIONAL DE VIGILÂNCIA SANITÁRIA. Resolução- RE $\mathrm{n}^{\circ} 2605$, de 11 de agosto de 2006. Disponível em:〈www.abebrasil.org.br/imagem/pdf/RE\%20N\%C2\%B02.606.pdf>

AGENCIA NACIONAL DE VIGILÂNCIA SANITÁRIA. Resolução- RE no 2606, de 11 de agosto de 2006. Disponível em:〈www.abebrasil.org.br/imagem/pdf/RE\%20N\%C2\%B02.606.pdf>

BALLOU, R. Gerenciamento da cadeia de suprimentos/ logística empresarial. Porto Alegre: Bookman, 2006

BASU, D., BHATTACHARYA, S., MAHAJAN, A., RAMANAN, V. R., CHANDY, M. Sterilization indicators in central sterile supply department: quality assurance and cost implications. Infection control \& hospital epidemiology, v. 36, n. 04, p. 484-486, 2015.

BERNARDO, P.A. Proposta de aplicação do supply-chain reference (SCOR) model no setor de varejo de e-commerce no Brasil. Dissertação de Mestrado. Universidade Federal do Rio de Janeiro, 2016.

BOLSTORFF, P.; ROSENBAUM, R. G. Supply chain excellence: a handbook for dramatic improvement using the SCOR model. New York: AMACOM Div American Mgmt Assn, 2007.

BOOTH, W.; COLOMB, G.; WILLIANS, J. The craft of research. 3. ed. USA: University of Chicago Press, 2008.

BOZARTH, C.C.; HANDFIELD, R.B. Introduction to operations and supply chain management. 2. ed. New Jersey: Pearson Prentice Hall, 2008.

BRANDEU, M.; SAINFORT, F.; PIERSKALLA, W. Operations Research and Health Care: A handbook of methods and applications. USA: Kluwer Academic Publishers, 2004 
BRASIL. Ministério de Estado da Saúde e do Trabalho e Emprego. Portaria interministerial $\mathrm{n}^{\circ}$ 482, de 16 de 16 abril $\quad$ de $1999 . \quad$ Disponível em:〈www.abebrasil.org.br/imagem/pdf/PORTARIA_INTERMINISTERIAL_N_482.pdf>

BRASIL. Ministério do Trabalho e Emprego. Norma Regulamentadora- NR no 32. Disponível em:<www.abebrasil.org.br/imagem/pdf/NR_32.pdf>

CARDOSO, Rodolfo. Construção de Modelos de Gestão Articulados por Modelos de Referência: Uma investigação sobre o uso dos modelos de referência de qualidade e excelência. 2008. Tese de Doutorado. UNIVERSIDADE FEDERAL DO RIO DE JANEIRO.

CASTILHO V, LEITE MMJ. A administração de recursos materiais na enfermagem. Administração em enfermagem. São Paulo: EPU; 2001.

CONSELHO FEDERAL DE ENFERMAGEM. Resolução no 293, de 21 de setembro de 2004. Disponível em:<www.cofen.gov.br/resoluo-cofen-2932004_4329.html>

CONSELHO FEDERAL DE ENFERMAGEM. Resolução no 424, de 19 de abril de 2012. Disponível em:<www.cofen.gov.br/resoluo-cofen-n-4242012_8990.html>

CONSELHO FEDERAL DE ENFERMAGEM. Resolução n ${ }^{\circ}$ 527, de 27 de setembro de 2016. Disponível em:<www.cofen.gov.br/resolucao-cofen-no-05272016_46348.html>

COSTA, J. A. Atividades de enfermagem no Centro de Material e Esterilização: subsídios para o dimensionamento de pessoal. Dissertação de Mestrado. Escola de Enfermagem da Universidade de São Paulo, São Paulo, 2009.

DI MASCOLO, M.; GOUIN, A. A generic simulation model to assess the performance of sterilization services in health establishments. Health care management science, v. 16, n. 1, p. 45-61, 2013.

DI MASCOLO, M.; GOUIN, A.; CONG, K. N. Organization of the production of sterile medical devices. IFAC Proceedings Volumes, v. 39, n. 3, p. 35-40, 2006.

FETTKE, P.; LOOS, P. Reference modeling for business systems analysis. USA: IGI Global, 2006.

GALLIEN, J.; GRAVES, S. C.; SCHELLER-WOLF, A. OM Forum-Practice-Based Research in Operations Management: What It Is, Why Do It, Related Challenges, and How to Overcome Them. Manufacturing \& Service Operations Management, v. 18, n. 1, p. 5-14, 2015.

GIL, A. Métodos e técnicas de pesquisa social. São Paulo: Atlas, 2007.

GOULLET, D. How the sterilization of reusable medical devices is organized in France? French Society for Sterilization (AFS), 2013

GRAZIANO, K. U.; SILVA, A.; PSALTIKIDIS, E. M. Enfermagem em centro de material e esterilização. Barueri (SP): Monole, 2011.

GREASLEY, A. Operations Management. London: Sage Publications, 2008.

HANS, E.; HOUDENHOVEN, M.; HULSHOF, H. A framework for health care planning and control. International Series in Operations Research \& Management Science. v. 168, p. 303320, 2011.

HAYES, R.; PISANO, G.; UPTON, D.; WHEELWRIGHT, S. Produção, estratégia e tecnologia: em busca da vantage competitiva. Porto Alegre: Bookman, 2008.

HEALTHCARE INFECTION CONTROL PRACTICES ADVISORY COMMITTEE. Guideline for disinfection and sterilization in healthcare facilities. Atlanta: US CDC, 2008.

HOYASHI, C. M. T.; DE ANDRADE RODRIGUES, D. C. G.; DE OLIVEIRA, M. F. A. Central de material e esterilização na formação do Enfermeiro: proposta de um Manual de Práticas. Revista Práxis, v. 7, n. 14, 2016.

IMAI, M. T. Satisfação dos clientes e funcionários da central de materiais e esterilização. Rev. adm. saúde, v. 5, n. 19, p. 5-16, 2003. 
JERICÓ, M. D. C., CASTILHO, V. Gerenciamento de custos: aplicação do método de Custeio Baseado em Atividades em Centro de Material Esterilizado. Revista da Escola de Enfermagem da USP, v. 44, n. 3, p. 745-752, 2010.

LANGEVIN, A.; RIOPEL, D. Logistics systems: Design and Optimization. USA: Springer, 2005.

LEITE, F. B. Central de material esterilizado: projeto de reestruturação e ampliação do hospital regional de Francisco Sá. Brasília (DF): Ministério da Saúde, 2008.

MCLAUGHLIN, D.B.; HAYS, J.M. Healthcare operations management. USA: Aupha, 2008.

MEROLA, E.; PADOANO, E.; ZULIANI, V. An analytic hierarchy process-based framework to support outsourcing decisions on hospital sterilization. International Journal of Business and Systems Research. v.10, n. 2,3,4, 2016.

MUSSEL, I. C. Armazenamento dos produtos para saúde estéreis no centro de esterilização e unidades assistenciais de hospitais de grande porte de Belo Horizonte. 2013. Dissertação de Mestrado. UNIVERSIDADE FEDERAL DE MINAS GERAIS.

NEIS, M. E. B., GELBCKE, F. L., SALUM, N. C., \& DE OLIVEIRA, T. T. Centro de material e esterilização: estudo do tempo efetivo de trabalho para dimensionamento de pessoal. Revista Eletrônica de Enfermagem, v. 13, n. 3, p. 422-30, 2012.

NETO, G.V.; MALIK, A.M. Gestão em saúde. Rio de Janeiro: Guanabara Koogan, 2012.

OZTURK, O.; BEGEN, M. A.; ZARIC, G. S. A branch and bound based heuristic for makespan minimization of washing operations in hospital sterilization services. European Journal of Operational Research, v. 239, n. 1, p. 214-226, 2014.

PAES, L.R.A. Gestão de operações em saúde para hospitais, clínicas, consultórios e serviços diagnóstico. São Paulo: Editora Atheneu, 2011.

PATRÍCIO, C. M., MAIA, M. M., MACHIAVELLI, J. L., NAVAES, M. D. A. O prontuário eletrônico do paciente no sistema de saúde brasileiro: uma realidade para os médicos. Scientia Medica, v. 21, n. 3, p. 121-31, 2011.

PEZZI, M. D. C. S., \& LEITE, J. L. Investigação em Central de Material e Esterelização utilizando a Teoria Fundamentada em Dados. Instituto Fernandes Figueira/FIOCRUZ, Rio de Janeiro, 2010.

REID, R.D.; SANDERS, N.R. Operations Management: An Integrated Approach. 4. ed. USA: John Wiley \& Sons, Inc, 2011.

REYMONDON, F.; PELLET, B.; MARCON, E. Optimization of hospital sterilization costs proposing new grouping choices of medical devices into packages. International Journal of Production Economics, v. 112, n. 1, p. 326-335, 2008.

RIOS, F. P.; FIGUEIREDO, K. F.; ARAUJO, C.A. Práticas de Gestão de Estoques em Hospitais: Um Estudo de Casos em Unidades do Rio de Janeiro e de São Paulo. XXXVI Encontro da ANPAD. 2012.

ROWBOTHAM, F.; GALLOWAY, L.; AZHASHEMI, M. Operations Management in Context. 2. ed. Oxford: Elsevier, 2007.

RÜTHER, S., HERMANN, T., MRACEK, M., KOPP, S., \& STEIL, J. An assistance system for guiding workers in central sterilization supply departments. International Conference on PErvasive Technologies Related to Assistive Environments (ACM). p. 3, 2013.

SANCINETTI, T. R.; GATTO, M. A. F. Parâmetros de produtividade de um centro de material e esterilização. Revista da Escola de Enfermagem da USP, v. 41, n. 2, p. 264-270, 2007.

SCHEINBERG, N.; ZHANG. B.; RASCHID, L.; MWENESI, R.; GRUM, M.; CHAN, M.; COHN, A.; DEROSIER, J.; BAGIAN, J. A Systematic Approach to Improve the Reprocessing of Surgical Instruments. Advances in Human Factors and Ergonomics in Healthcare. Advances in Intelligent Systems and Computing, v. 482. p. 275-286, 2017.

SCHMIDT, D. R. C.; YONEKURA, C. S. I.; GIL, R. F. Instrumento para avaliação de detergentes enzimáticos. Rev. Esc. Enferm USP, v. 42, n. 2, p. 282-9, 2008. 
SILVA, A. Organização do trabalho na Unidade Centro de Material. Rer. Esc. Enferm USP, v. 32, n. 2, p. 169-78, 1998.

SILVA, E.; MENEZES, E. Metodologia da Pesquisa e Elaboração de Dissertação. 3. ed. Florianópolis: Laboratório de Ensino a Distância da UFSC, 2001.

SILVEIRA, M. R. T. D. Centro de material e esterilização. Artigo apresentado ao Programa de Pós-graduação Lato Sensu em Arquitetura de Sistemas da Saúde da Universidade Católica de Brasília. UNIVERSIDADE CATÓLICA DE BRASÍLIA. 2015.

SLACK, N.; CHAMBERS, S.; JOHNSTON, R. Administração da produção. São Paulo: Atlas, 2009.

SPIEGEL, T.; CAULLIRAUX, H. M. Developing an organizational reference model by selecting and integrating multiple references. Journal of Management Research, v. 4, n. 1, p. 1, 2012.

SPIEGEL, T. O processo cognitivo e a tomada de decisão: articulações necessárias. Dissertação de Mestrado. Universidade Federal do Rio de Janeiro, 2011.

SPIEGEL, T. Contribuição das ciências cognitivas à gestão de operações: análise do impacto da experiência nas decisões do gestor de operações. Tese de Doutorado. Universidade Federal do Rio de Janeiro, 2013.

TIPPlE, A. F. V., PIRES, F. V., GUADAGNIN, S. V. T., DE SOUSA MELO, D. O monitoramento de processos físicos de esterilização em hospitais do interior do estado de Goiás. Revista da Escola de Enfermagem da USP, v.45, p.751-757. 2011.

TURRINI, R. N. T.; MORIYA, G. A. A.; BRONZATTI, J. A. G. Controle de instrumental no centro de material e esterilização. Enfermagem em Centro de Material e Esterilização, 2011.

VAN AKEN, J.; BERENDS, H.; VAN DER, H. Problem solving in organizations: a methodological handbook for business students. São Paulo: Cambrigde, 2007.

VAN DE KLUNDERT, J.; MULS, P.; SCHADD, M. Optimizing sterilization logistics in hospitals. Health care management science, v. 11, n. 1, p. 23-33, 2008.

VECINA NETO, G.; REINHARDT FILHO, W. Gestão de recursos materiais e de medicamentos. Saúde \& Cidadania FSP, 2002.

VEIGA-MALTA, I. Preventing Healthcare-Associated Infections by Monitoring the Cleanliness of Medical Devices and Other Critical Points in a Sterilization Service. Biomedical Instrumentation \& Technology, v. 50, n. 3, p. 45-52, 2016.

VISSER, J.; BEECH, R. Health operations management: paciente flow logistics in health care. New York: Routledge, 2005. 


\section{APÊNDICES}

Tabela 40 - Informações sobre validação da estrutura do modelo de referência proposto. Elaboração própria.

\begin{tabular}{|c|c|c|c|}
\hline \# & Decisão & Chefia CME HUPE & Chefia CME PPC \\
\hline 1 & Definição das demandas & $\begin{array}{l}\text { Inserção da unidade de } \\
\text { consumo "imagem". }\end{array}$ & Aprovado. \\
\hline & \multirow[t]{3}{*}{$\begin{array}{l}\text { Definição dos tipos de } \\
\text { materiais processados }\end{array}$} & $\begin{array}{l}\text { Inserção de "material } \\
\text { clínico" na demanda do } \\
\text { CC. }\end{array}$ & \multirow{3}{*}{$\begin{array}{l}\text { Inserção de "insumos } \\
\text { (próteses, pequenos artigos } \\
\text { esterilizados) na demanda } \\
\text { do CC. Inserção de } \\
\text { "instrumentais" na } \\
\text { demanda do centro } \\
\text { obstétrico. }\end{array}$} \\
\hline & & $\begin{array}{l}\text { Inserção de } \\
\text { "instrumentais" na } \\
\text { demanda do centro } \\
\text { obstétrico. }\end{array}$ & \\
\hline & & $\begin{array}{l}\text { Inserção de "materiais } \\
\text { para exame" e } \\
\text { "endoscópios" na } \\
\text { demanda do } \\
\text { ambulatório. }\end{array}$ & \\
\hline \multirow{9}{*}{ 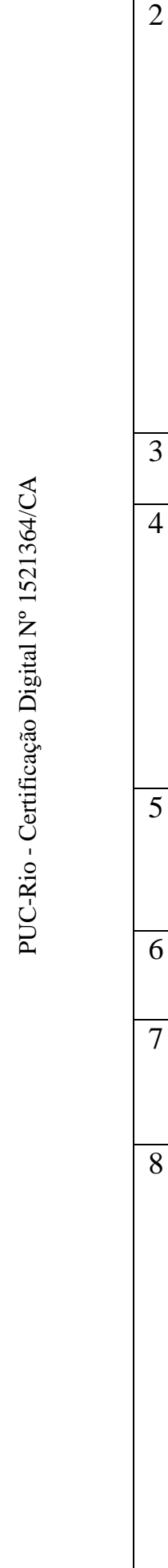 } & Desenho dos processos & Aprovado. & Aprovado. \\
\hline & $\begin{array}{l}\text { Grau de automação / } \\
\text { Equipamentos }\end{array}$ & Aprovado. & $\begin{array}{l}\text { Inserção do equipamento } \\
\text { "termodesinfectadora" na } \\
\text { área de recepção na } \\
\text { subdecisão 4.2. }\end{array}$ \\
\hline & & & $\begin{array}{l}\text { Inserção do equipamento } \\
\text { "seladora térmica" na área } \\
\text { de preparo na subdecisão } \\
4.2 \text {. }\end{array}$ \\
\hline & Definição da capacidade & Aprovado. & $\begin{array}{l}\text { Inserção de "Adequações } \\
\text { de insumos" em fator de } \\
\text { seguraça na subdecisão } \\
\text { 5.1. }\end{array}$ \\
\hline & Qualidade e RH & Aprovado. & Aprovado. \\
\hline & $\begin{array}{l}\text { Grau de integração } \\
\text { (terceirização) }\end{array}$ & Aprovado. & Aprovado. \\
\hline & \multirow[t]{3}{*}{ Tipos de insumos } & \multirow[t]{3}{*}{ Aprovado. } & $\begin{array}{l}\text { Inserção de "enzimáticos } \\
\text { ou alcalino Hipoclorito, } \\
\text { Álcool 70\%, Ácido } \\
\text { peracético/ortoftaldeído" } \\
\text { nos insumos da área de } \\
\text { recepção na subdecisão } \\
8.1 \text {. }\end{array}$ \\
\hline & & & $\begin{array}{l}\text { Inserção de "esterilizantes" } \\
\text { para completar o insumo } \\
\text { "produtos desinfectantes". }\end{array}$ \\
\hline & & & $\begin{array}{l}\text { Inserção de "roupas e } \\
\text { insumos" nos insumos da }\end{array}$ \\
\hline
\end{tabular}




\begin{tabular}{|c|c|c|c|}
\hline & & & área de armazenagem. \\
\hline 9 & Dimensionamento do RH & Aprovado. & Aprovado. \\
\hline \multirow[t]{2}{*}{10} & \multirow[t]{2}{*}{ Estoques } & \multirow[t]{2}{*}{ Aprovado. } & $\begin{array}{l}\text { Inserção de "mínimo 20\% } \\
\text { dos insumos" na } \\
\text { subdecisão } 10.1 .\end{array}$ \\
\hline & & & $\begin{array}{l}\text { Modificação de "manuseio } \\
\text { do estoque" para } \\
\text { "manuseio técnico do } \\
\text { estoque", na subdecisão } \\
\text { 10.2. }\end{array}$ \\
\hline 11 & Transporte & Aprovado. & Aprovado. \\
\hline \multirow[t]{2}{*}{12} & \multirow[t]{2}{*}{ Instalações } & \multirow[t]{2}{*}{ Aprovado. } & $\begin{array}{l}\text { Modificação de } \\
\text { "parâmetros de } \\
\text { dimensionamento } \\
\text { definidos na RDC } \\
\text { 50/2002" para "parâmetros } \\
\text { de dimensionamento } \\
\text { definidos na RDC 15/2012 } \\
\text { e RDC 50/2002", na } \\
\text { subdecisão 12.1. } \\
\end{array}$ \\
\hline & & & $\begin{array}{l}\text { Modificação de "Próximo } \\
\text { às unidades consumidoras" } \\
\text { para "Fácil acesso em } \\
\text { relação às unidades } \\
\text { consumidoras", na } \\
\text { subdecisão } 12.3 \text {. }\end{array}$ \\
\hline 13 & $\begin{array}{l}\text { Parâmetros de } \\
\text { produtividade e } \\
\text { desempenho }\end{array}$ & Aprovado. & $\begin{array}{l}\text { Retirada do objetivo de } \\
\text { verificação. }\end{array}$ \\
\hline 14 & $\begin{array}{l}\text { Mecanismos de } \\
\text { coordenação }\end{array}$ & Aprovado. & $\begin{array}{l}\text { Inserção da "farmácia" } \\
\text { como um ente na } \\
\text { subdecisão } 14.1 .\end{array}$ \\
\hline 15 & $\begin{array}{l}\text { Elaboração do } \\
\text { ProcedimentoOperacional } \\
\text { Padrão (POP) }\end{array}$ & Aprovado. & Aprovado. \\
\hline 16 & $\begin{array}{l}\text { Avaliação da capacidade } \\
\text { no médio prazo }\end{array}$ & Aprovado. & Aprovado. \\
\hline 17 & $\begin{array}{l}\text { Fornecimento médio } \\
\text { prazo }\end{array}$ & Aprovado. & $\begin{array}{l}\text { Inserção da "farmácia" } \\
\text { como um ente na } \\
\text { subdecisão } 17.3 \text {. }\end{array}$ \\
\hline 18 & Gestão das informações & Aprovado. & Aprovado. \\
\hline 19 & Gestão da produção & Aprovado. & Aprovado. \\
\hline 20 & Gestão do estoque & Aprovado. & Aprovado. \\
\hline 21 & Gestão do RH & Aprovado. & Aprovado. \\
\hline 22 & Manutenção & Aprovado. & Aprovado. \\
\hline 23 & $\begin{array}{l}\text { Previsão da demanda de } \\
\text { curto prazo }\end{array}$ & Aprovado. & Aprovado. \\
\hline 24 & Programação da produção & Aprovado. & Aprovado. \\
\hline 25 & Controle de qualidade & Aprovado. & Aprovado. \\
\hline 26 & Controle de estoque & Aprovado. & Aprovado. \\
\hline
\end{tabular}




\begin{tabular}{|l|l|l|l|}
\hline 27 & Controle dos insumos & Aprovado. & Aprovado. \\
\hline 28 & $\begin{array}{l}\text { Gestão dos recursos } \\
\text { humanos }\end{array}$ & Aprovado. & Aprovado. \\
\hline 29 & $\begin{array}{l}\text { Monitoramento da } \\
\text { capacidade }\end{array}$ & Aprovado. & Aprovado. \\
\hline 30 & Controle da informação & Aprovado. & Aprovado. \\
\hline 31 & Custos & Aprovado. & Aprovado. \\
\hline
\end{tabular}

Tabela 41 - Resultados da revisão da literatura na base Scielo

\begin{tabular}{|c|c|c|c|c|}
\hline Data & $\begin{array}{l}\text { Combinação de } \\
\text { palavras-chaves }\end{array}$ & Resultados & $\begin{array}{l}\text { Critério de } \\
\text { seleção }\end{array}$ & $\begin{array}{c}\text { Resultado } \\
\text { s }\end{array}$ \\
\hline $10 / 01 / 2017$ & sterilization & 592 & $\begin{array}{l}\text { Filtro por palavras- } \\
\text { chaves combinadas }\end{array}$ & - \\
\hline $10 / 01 / 2017$ & esterilização & 342 & $\begin{array}{l}\text { Filtro por palavras- } \\
\text { chaves combinadas }\end{array}$ & - \\
\hline $10 / 01 / 2017$ & sterilization center & 36 & $\begin{array}{l}\text { Leitura dos } \\
\text { resumos }\end{array}$ & 8 \\
\hline $10 / 01 / 2017$ & $\begin{array}{c}\text { centro de } \\
\text { esterilização }\end{array}$ & 35 & $\begin{array}{l}\text { Leitura dos } \\
\text { resumos }\end{array}$ & 8 \\
\hline $10 / 01 / 2017$ & $\begin{array}{c}\text { central sterile } \\
\text { service department }\end{array}$ & - & - & - \\
\hline $10 / 01 / 2017$ & $\begin{array}{l}\text { central de material de } \\
\text { esterilização }\end{array}$ & - & - & - \\
\hline $10 / 01 / 2017$ & reference modeling & 138 & $\begin{array}{l}\text { Filtro por palavras- } \\
\text { chaves combinadas }\end{array}$ & - \\
\hline $10 / 01 / 2017$ & modelo de referência & 1570 & $\begin{array}{l}\text { Filtro por palavras- } \\
\text { chaves combinadas }\end{array}$ & - \\
\hline $10 / 01 / 2017$ & $\begin{array}{l}\text { (sterilization) AND } \\
\text { (OR in health } \\
\text { services) }\end{array}$ & - & - & - \\
\hline $10 / 01 / 2017$ & $\begin{array}{c}\text { (esterilização) AND } \\
\text { (pesquisa } \\
\text { operacional) }\end{array}$ & - & - & - \\
\hline $10 / 01 / 2017$ & $\begin{array}{l}\text { (sterilization) AND } \\
(\text { reference model*) }\end{array}$ & - & - & - \\
\hline
\end{tabular}




\begin{tabular}{|c|c|c|c|c|}
\hline $10 / 01 / 2017$ & $\begin{array}{l}\text { (esterilização) AND } \\
\text { (modelo de } \\
\text { referência) }\end{array}$ & - & - & - \\
\hline $10 / 01 / 2017$ & $\begin{array}{l}\text { (sterilization) AND } \\
\text { (healthcare) }\end{array}$ & - & - & - \\
\hline $10 / 01 / 2017$ & $\begin{array}{c}\text { (esterilização) AND } \\
\text { (saúde) }\end{array}$ & 141 & $\begin{array}{l}\text { Leitura dos } \\
\text { resumos }\end{array}$ & 14 \\
\hline $10 / 01 / 2017$ & $\begin{array}{l}\text { (sterilization) AND } \\
\text { (decision) }\end{array}$ & 24 & $\begin{array}{l}\text { Leitura dos } \\
\text { resumos }\end{array}$ & - \\
\hline $10 / 01 / 2017$ & $\begin{array}{l}\text { (esterilização) AND } \\
\text { (decisão) }\end{array}$ & - & - & - \\
\hline $10 / 01 / 2017$ & $\begin{array}{l}\text { (sterilization) AND } \\
\text { (decision mak*) }\end{array}$ & - & - & - \\
\hline $10 / 01 / 2017$ & $\begin{array}{l}\text { (esterilização) AND } \\
\text { (tomada de decisão) }\end{array}$ & - & - & - \\
\hline $10 / 01 / 2017$ & $\begin{array}{c}\text { (reference model*) } \\
\text { AND (healthcare) }\end{array}$ & 61 & $\begin{array}{l}\text { Leitura dos } \\
\text { resumos }\end{array}$ & - \\
\hline $10 / 01 / 2017$ & $\begin{array}{l}\text { (modelo de } \\
\text { referência) AND } \\
\text { (saúde) }\end{array}$ & 371 & $\begin{array}{c}\text { Filtro por outras } \\
\text { palavras-chaves } \\
\text { combinadas }\end{array}$ & - \\
\hline $10 / 01 / 2017$ & $\begin{array}{l}\text { (reference model*) } \\
\text { AND (decision) }\end{array}$ & 18 & $\begin{array}{l}\text { Leitura dos } \\
\text { resumos }\end{array}$ & - \\
\hline $10 / 01 / 2017$ & $\begin{array}{l}\text { (modelo de } \\
\text { referência) AND } \\
\text { (decisão) }\end{array}$ & - & - & - \\
\hline $10 / 01 / 2017$ & $\begin{array}{c}\text { (reference model*) } \\
\text { AND (decision } \\
\text { mak*) }^{*}\end{array}$ & - & - & - \\
\hline $10 / 01 / 2017$ & $\begin{array}{l}\text { (modelo de } \\
\text { referência) AND } \\
\text { (tomada de decisão) }\end{array}$ & - & - & - \\
\hline
\end{tabular}


Tabela 42 - Resultados da revisão da literatura na base Scopus

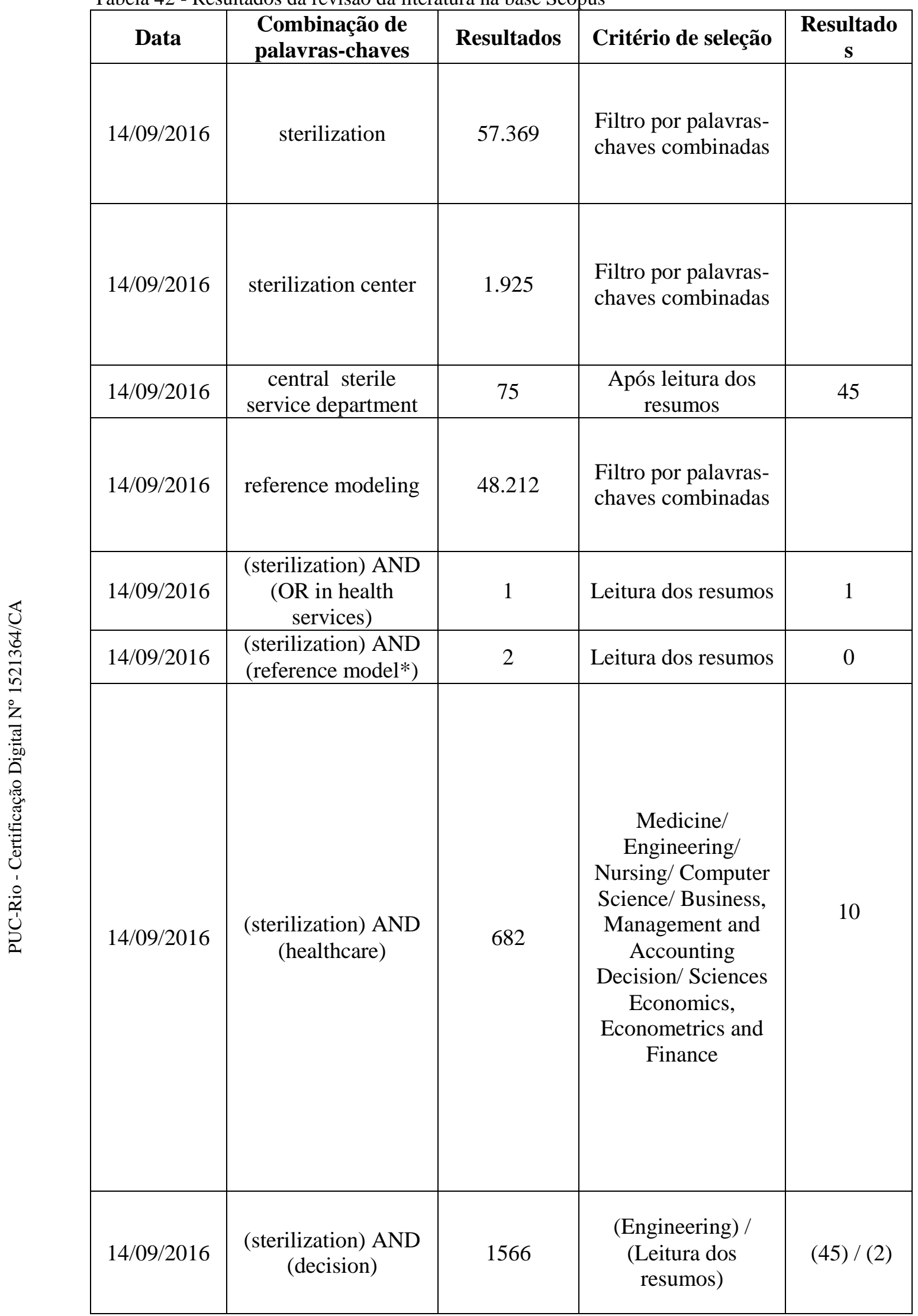




\begin{tabular}{|c|c|c|c|c|}
\hline $14 / 09 / 2016$ & $\begin{array}{c}\text { (sterilization) AND } \\
\text { (decision mak*) }\end{array}$ & - & - & - \\
\hline $14 / 09 / 2016$ & $\begin{array}{c}\text { (reference model*) } \\
\text { AND (healthcare) }\end{array}$ & 122 & Leitura dos resumos & 15 \\
\hline $14 / 09 / 2016$ & $\begin{array}{c}\text { (reference model*) } \\
\text { AND (decision) }\end{array}$ & 687 & $\begin{array}{c}\text { Decisions Science/ } \\
\text { Engineering/ } \\
\text { Business, } \\
\text { Management and } \\
\text { Accounting }\end{array}$ & 10 \\
\hline $14 / 09 / 2016$ & $\begin{array}{c}\text { AND (decision } \\
\text { mak*) }\end{array}$ & 292 & $\begin{array}{c}\text { Decision Sciences) } \\
\text { / (Leitura dos } \\
\text { títulos) }\end{array}$ & (233) / (7) \\
& (reference model*) & & \\
\hline
\end{tabular}

Tabela 43 - Resultados da revisão da literatura na base Web of Science

\begin{tabular}{|c|c|c|c|c|}
\hline Data & $\begin{array}{l}\text { Combinação de } \\
\text { palavras-chaves }\end{array}$ & Resultados & Critério de seleção & $\begin{array}{c}\text { Resultado } \\
\text { s }\end{array}$ \\
\hline $14 / 09 / 2016$ & sterilization & 21.711 & $\begin{array}{l}\text { (health care sciences } \\
\text { service, engineering } \\
\text { multidisciplinary)/ } \\
\text { (leitura dos títulos) }\end{array}$ & $(164) /(1)$ \\
\hline $14 / 09 / 2016$ & sterilization center & 652 & $\begin{array}{l}\text { (public environmental } \\
\text { occupational health, } \\
\text { engineering } \\
\text { biomedical, health } \\
\text { care sciences services) } \\
\text { / (leitura dos resumos) }\end{array}$ & $(73) /(3)$ \\
\hline $14 / 09 / 2016$ & $\begin{array}{c}\text { central sterile } \\
\text { service department }\end{array}$ & 4 & - & - \\
\hline $14 / 09 / 2016$ & $\begin{array}{l}\text { reference } \\
\text { modeling }\end{array}$ & 155.763 & $\begin{array}{l}\text { Filtro por palavras- } \\
\text { chaves combinadas }\end{array}$ & - \\
\hline $14 / 09 / 2016$ & $\begin{array}{l}\text { (sterilization) } \\
\text { AND (OR in } \\
\text { health services) }\end{array}$ & - & - & - \\
\hline $14 / 09 / 2016$ & $\begin{array}{c}\text { (sterilization) } \\
\text { AND (reference } \\
\text { model*) }^{*} \text { ) }\end{array}$ & 58 & Leitura dos resumos & - \\
\hline $14 / 09 / 2016$ & $\begin{array}{c}\text { (reference } \\
\text { model*) AND } \\
\text { (healthcare)AND } \\
\left(\text { decision } \text { mak }^{*} \text { ) }\right.\end{array}$ & 70 & Leitura dos resumos & 8 \\
\hline
\end{tabular}




\begin{tabular}{|c|c|c|c|c|}
\hline $14 / 09 / 2016$ & $\begin{array}{c}\text { (reference } \\
\left.\text { model*) AND }^{*} \text { ANecision }\right)\end{array}$ & 6.684 & $\begin{array}{l}\text { Filtro por palavras- } \\
\text { chaves combinadas }\end{array}$ & - \\
\hline $14 / 09 / 2016$ & 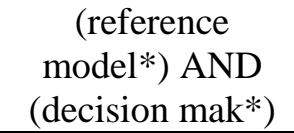 & 3.724 & $\begin{array}{l}\text { Filtro por palavras- } \\
\text { chaves combinadas }\end{array}$ & - \\
\hline $14 / 09 / 2016$ & $\begin{array}{c}\text { (sterilization) } \\
\text { AND (healthcare) }\end{array}$ & 176 & $\begin{array}{c}\text { (multidisciplinary } \\
\text { sciences, health care } \\
\text { sciences services, } \\
\text { engineering } \\
\text { multidisciplinary, } \\
\text { engineering } \\
\text { manufacturing, } \\
\text { engineering industrial, } \\
\text { computer science } \\
\text { theory methods, } \\
\text { computer science } \\
\text { interdisciplinary } \\
\text { applications, computer } \\
\text { science } \\
\text { interdisciplinary } \\
\text { applications, computer } \\
\text { science cybernetics) / } \\
\text { (leitura dos resumos) }\end{array}$ & $(10) /(3)$ \\
\hline $14 / 09 / 2016$ & $\begin{array}{c}\text { (sterilization) } \\
\text { AND (decision) }\end{array}$ & 312 & $\begin{array}{l}\text { (health care sciences } \\
\text { services, operations } \\
\text { research management } \\
\text { science, } \\
\text { multidisciplinary } \\
\text { sciences, public } \\
\text { administration) / } \\
\text { (leitura dos resumos) }\end{array}$ & $(16) /(1)$ \\
\hline $14 / 09 / 2016$ & $\begin{array}{c}\text { (sterilization) } \\
\text { AND (decision } \\
\left.\text { mak }^{*}\right)\end{array}$ & 142 & $\begin{array}{c}\text { (medicine general } \\
\text { internal, computer } \\
\text { science } \\
\text { interdisciplinary } \\
\text { applications, } \\
\text { operations research } \\
\text { management science, } \\
\text { health care sciences } \\
\text { services, } \\
\text { multidisciplinary } \\
\text { sciences, health policy } \\
\text { services, engineering } \\
\text { biomedical, } \\
\text { engineering industrial) } \\
\text { / (leitura dos resumos) }\end{array}$ & $(25) /(2)$ \\
\hline
\end{tabular}

